\title{
LOW-SEVERITY CATALYTIC TWO-STAGE LIQUEFACTION PROCESS: ILLINOIS COAL CONCEPTUAL COMMERCIAL PLANT DESIGN AND ECONOMICS
}
By
L. M. Abrams
A. G. Comolli
G. A. Popper
C. Wang
G. Wilson

September 1988

Work Performed Under Contract No. AC22-85PC80002

Hydrocarbon Research, Inc.

Lawrenceville, New Jersey 


\section{DISCLAIMER}

This report was prepared as an account of work sponsored by an agency of the United States Government. Neither the United States Government nor any agency Thereof, nor any of their employees, makes any warranty, express or implied, or assumes any legal liability or responsibility for the accuracy, completeness, or usefulness of any information, apparatus, product, or process disclosed, or represents that its use would not infringe privately owned rights. Reference herein to any specific commercial product, process, or service by trade name, trademark, manufacturer, or otherwise does not necessarily constitute or imply its endorsement, recommendation, or favoring by the United States Government or any agency thereof. The views and opinions of authors expressed herein do not necessarily state or reflect those of the United States Government or any agency thereof. 


\section{DISCLAIMER}

Portions of this document may be illegible in electronic image products. Images are produced from the best available original document. 


\section{DISCLAIMER}

This report was prepared as an account of work sponsored by an agency of the United States Government. Neither the United States Government nor any agency thereof, nor any of their employees, makes any warranty, express or implied, or assumes any legal liability or responsibility for the accuracy, completeness. or usefulness of any information, apparatus, product, or process disclosed, or represents that its use would not infringe privately owned rights. Reference herein to any specific commercial product, process, or service by trade name, trademark. manufacturer, or otherwise does not necessarily constitute or imply its endorsement, recommendation, or favoring by the United States Government or any agency thereof. The views and opinions of authors ex. pressed herein do not necessarily state or reflect those of the United States Government or any agency thereof.

This report has been reproduced directly from the best available copy.

Available to DOE and DOE contractors from the Office of Scientific and Technical Information, P.O. Box 62, Oak Ridge, TN 37831; prices available from $(615) 576-8401$, FTS 626-8401.

Available to the public from the National Technical Information Service, U. S. Department of Commerce, 5285 Port Royal Rd., Springfield, VA 22161.

\section{Price: Printed Copy A07 Microfiche A01}


DOE/PC/80002-T4

(DE89005259)

Distribution Category UC-108

\title{
LON-SEVERITY \\ CATALYTIC THO-STAGE LIQUEFACTION PROCESS \\ ILLIMOIS COAL CONCEPTUAL COMERCIAL \\ PLANT DESIGM AND ECOMOMICS
}

\author{
L. M. ABRAMS \\ A. G. COMOLLI \\ G. A. POPPER \\ C. WANG \\ G. WILSON \\ WORK PERFORMED UNDER CONTRACT \\ DE-AC22-85PC-80002 \\ HYDROCARBON RESEARCH, INC. \\ P.0. BOX 6047 \\ LAWRENCEVILLE, NEW JERSEY 08648
}

SEPTEMBER 1988

Patent. C.leared by Chicago OPC on December 29, 1988 


\section{TABLE OF CONTENTS}

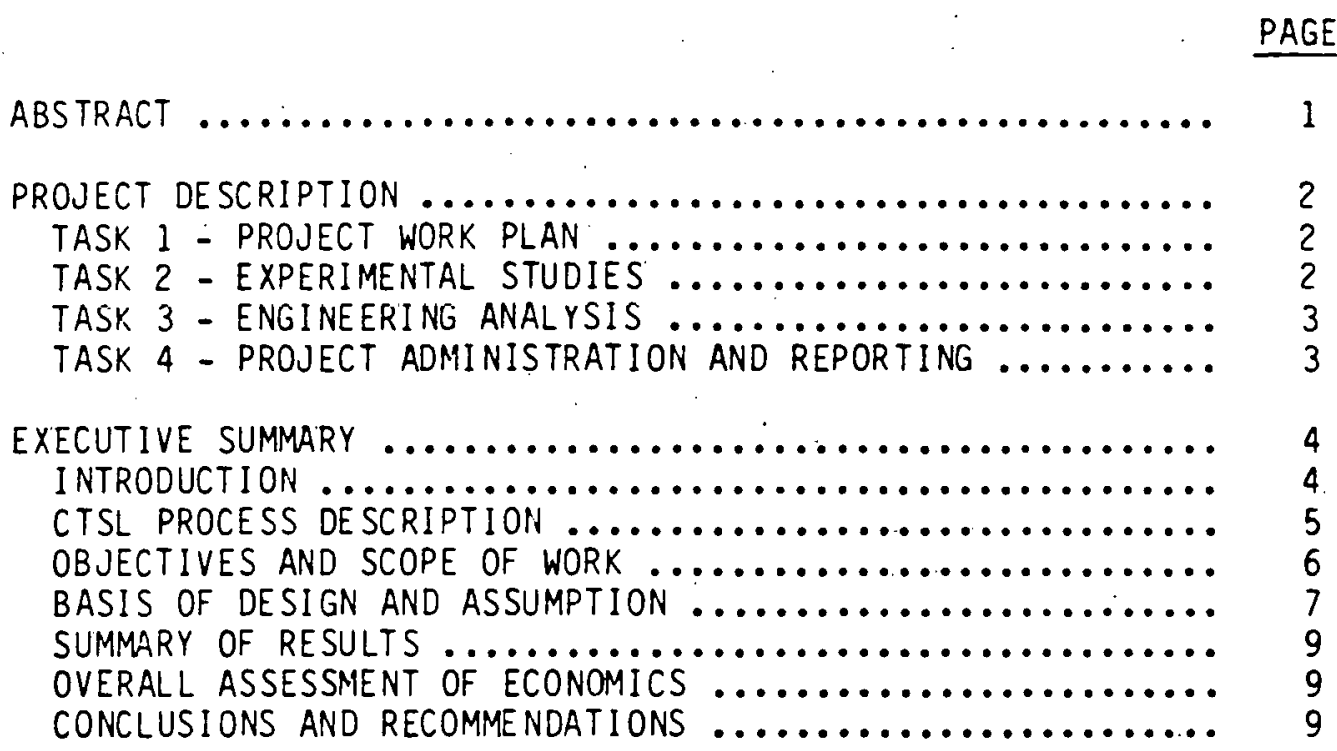

SECTION 1 - OBUECTIVES AND SCOPE OF WORK

OBJECTIVES AND SCOPE OF WORK

SECTION 2 - BASIS OF DESIGN AND ASSUMPTIONS

BASIS OF DESIGN AND ASSUMPTIONS

SECTION 3 - PLANT CONFIGURATIONS AND OVERALL DESIGNS

PLANT CONFIGURATIONS AND OVERALL DESIGNS .............. 22

OVERALL MATERIAL BALANCE ....................... 23

HYDROGEN BALANCE ............................ 23

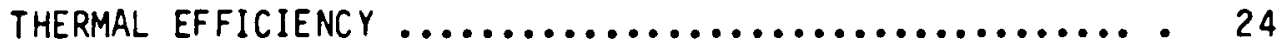

UTILITIES SUMMARY $\ldots \ldots \ldots \ldots \ldots \ldots \ldots \ldots \ldots \ldots \ldots \ldots \ldots . \ldots \ldots . \ldots \ldots . \ldots \ldots$

CAPACITY OF ONSITE PROCESS UNITS AND OFFSITE UNITS ..... 24 


\title{
TABLE OF CONTENTS
}

\author{
(cont inued)
}

PAGE

SECTION 4 - PROCESS AND SYSTEMS DESCRIPTIONS

PROCESS AND SYSTEMS DESCRIPTIONS ................. 31

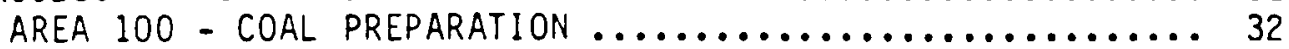

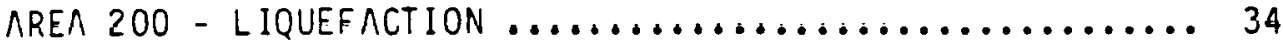

PROCESS DESCRIPTION ......................... 34

SECTIONS $100,200,300,400=$ REACTION $\ldots \ldots \ldots \ldots \ldots \ldots . \ldots . \ldots 35$

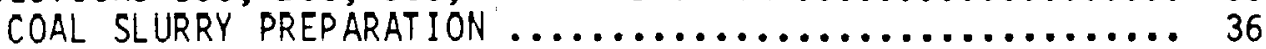

Slurry Mix Tank ........................... 36

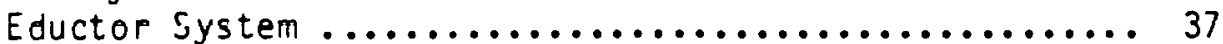

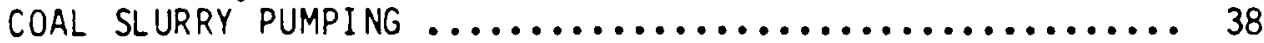

HYDROGEN COMPRESSION $\ldots \ldots \ldots \ldots \ldots \ldots \ldots \ldots \ldots \ldots \ldots \ldots \ldots . \ldots \ldots$

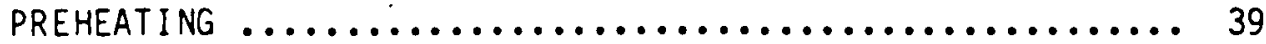

REACTION ...................................... 40

SEPARATION ..................................41

High Pressure Level Flash Section ................ 42

Intermediate Pressure Level Flash Section ............4 43

Low Pressure Level Flash Section ................ 44

SECTIONS 150, 250, 350, 450, 550 -

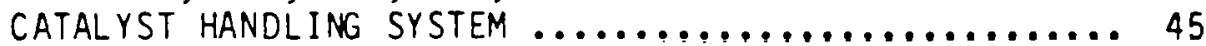

SECTION 600 - DISTILLATE SEPARATION ............... 45

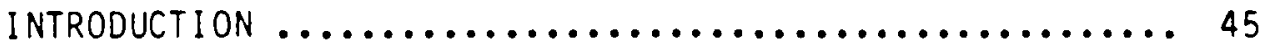

PROCESS FLOW ................................ 46

SECTION 700 - RECYCLE OIL FREPARATION .............. 48

AREA 300 - PARTIAL OXIDATION ................... 73

AREA 400 - OXYGEN PLANT .......................... 75

AREA 500 - PRODUCT TREATING .................. 77

AREA 600 - PRODUCT UPGRADING .................... 79

AREA $700-$ UTILITIES .......................... 81

AREA 800 - TANKAGE ....................... 83

AREA 900 - GENERAL OFFSITES ...................... 84 
TABLE OF CONTENTS

(cont inued)

PAGE

SECTION 5 - CAPITAL COST ESTIMATES AND ECONOMIC EVALUATION

CAPITAL COST ESTIMATES AND ECONOMIC EVALUATION ......... 87

CAPITAL INVESTMENT BASIS .......................... 87

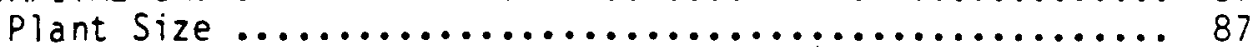

Capital Cost Basis ............................. 87

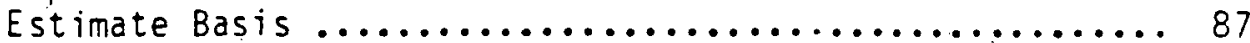

Total Erected Cost ............................ 88

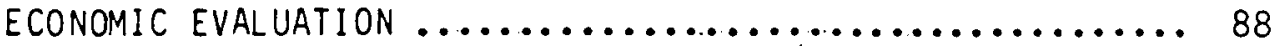

SECTION 6 - OVERALL ASSESSMENT OF ECONOMICS

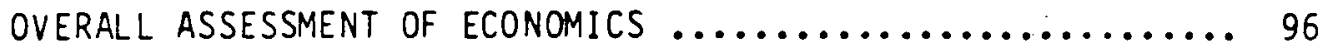

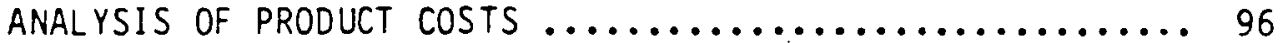

Comparison With Previous Illinois Coal Studies ........ 97

Impact of Coal Cleaning Efficiency .................. 98

Impact of Purchasing Deep-Cleaned Coal ................ 98

Hydrogen Production Alternatives ................. 100

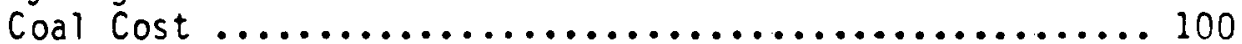

Comparison With Wyoming Coal $\ldots \ldots \ldots \ldots \ldots \ldots \ldots . . . . . .100$

SECTION 7 - CONCLUSIONS AND RECOMMENDATIONS

CONCLUSIONS AND RECOMMENDATIONS $\ldots \ldots \ldots \ldots \ldots \ldots \ldots \ldots \ldots$

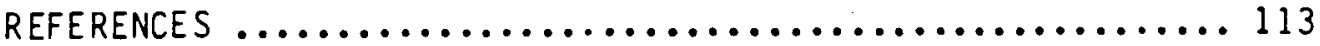

ADDENDUM - Catalyst Requirements For CTSL Demonstration

Operation With Illinois No. 6 Coal 


\section{LIST OF TABLES}

Summary of Result .......................... 10

Design Coal Feed Analys is ...................... 19

Overall Yields And Process Perfomance ............. 20

Overall Material Balance ...................... 26

Product Qualities ............................ 27

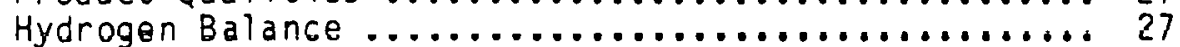

Thermal Efficiency ......................... 28

Utilities Summary .......................... 28

Lapacity of Unsite Process Units ............... 29

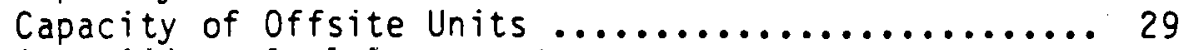

Area 100 - Coal Preparation -

Material Balance Summary ............ 33

Area 100 - Coal Preparation -

Utilities Summary ................. 33

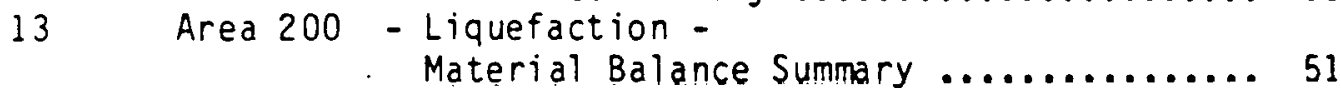

Area 200 - Liquefaction -

Utilities Summary ................ 51

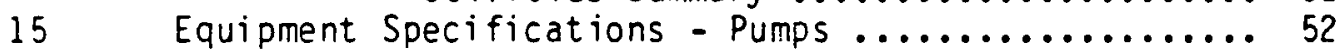

Equipment Specifications - Reactors ................ 54

Equipment Specifications - Fired Heaters ........... 55

Equipment Specifications - Heat Exchangers ......... 56

Equipment Specifications - Towers ............... 58

Fquipment Specifications - Vossols .................. 59

Equipment Specifications - Compressors ...........6 61

Slurry Mix Tank Fduct,or ....................... 62

S-102 Specification for Hydrogen Purification Unit .. 63

Catalyst Handling Ejector .........................64 64

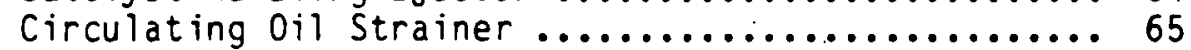

Make-Up $0 i 1$ Strainer ......................... 66

Electrical Desalter Duty Specification ...............6 67

S-602 - Neutralizing Amine Injection Unit ......... 68

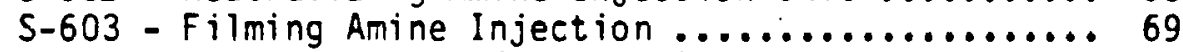


Area 300 - Partial Oxidation -

Material Balance Summary .............. 75

Area 300 - Partial Oxidation -

Utilities Summary .................. 75

Area 400 - Oxygen -

Material Balance Summary ............ 77

Area 400 - Oxygen -

Utilities Summary ................. 77

Area 500 - Product Treating Material Balance Summary ............. 79 utilities Sumary

Area 600 - Product Upgrading -

Area 700 - Steam Balance

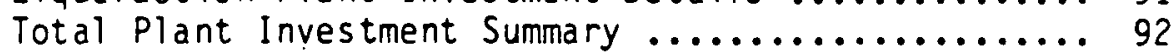

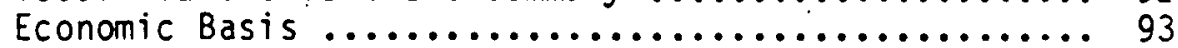

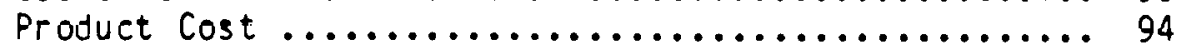

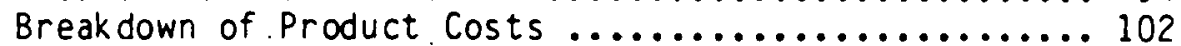

Revised Breakdown of Product Costs ................... 103

48

Summary of Results of Economic Evaluations ......... 104 Effect of Coal Cleaning Efficiency

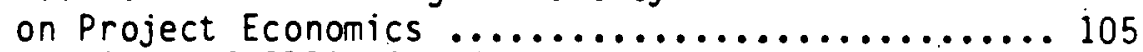




\section{LIST OF FIGURES}

FIGURE

$1 \quad$ HRI Ebullating-Bed Catalytic Two-Stage Coal Liquefaction (CTSL) Process - Simplified Flow Plan .............. 11

2 Block Flow Diagram of Major Processing Areas ........ 25

3 Block Flow Diagram of Liquefaction ................ 50

4 Effect of Coal Cleaning Efficiency on Product Cost .... 107

5 Rreakeven Feedstock Prices, Steam Refoming Versus

Partial 0xidation, at $80 \%$ Coal Cleaning Efficiency ... 107

Effect of Deep-Cleaned Coal Price on Product Cost

Using Low-Ash Coal to Liquefaction and POX .......... 108

Using Low-Ash Coal to Liquefaction and SR for

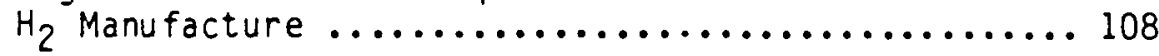

8 Effect of Natural Gas Price on Product Cost .......... 109

9 Effect of Coal Price on Product Cost ................ 109

10 Effect of Natural Gas Price on Product Cost .......... 110

11 Breakeven Coal Cost Comparison of Illinois No. 6

Versus Wyodak Coals .......................... 110

\section{LIST OF EXHIBITS}

F.XHIBIT

Process Flow Diagrams

1 Sections 100,200,300, 400 and 500 - Reaction ........71

2 Section 600 - Distillate Separation ................. 72

3 Section 700 - Recycle 0 il Preparation ............... 73 


\section{ABSTRACT}

Hydrocarbon Research, Inc. (HRI) is conducting a program for the United States Department of Energy (DOE) to evaluate a Catalytic Two-Stage Liquefaction (CTSL) Process. This program which runs through 1987, is a cont inuation of an earlier DOE sponsored program (1983-1985) at HRI to develop a new technology concept for CTSL. The earlier program included bench-scale testing of improved operating conditions for the CTSL Process on Illinois No. 6 bituminous coal and Wyoming sub-bituminous coal, and engineering screening studies to identify the economic incentive for CTSL over the single-stage $\mathrm{H}$-Coal Process for Illinois No. 6 coal. In the current program these engineering screening studies are extended to deep-cleaned Illinois coal and use of heavy recycle.

The results from this comparison will be used as a guide for future experiments with respect to selection of coal feedstocks and areas for further process optimization. A preliminary design for CTSL of lllinois deep-cleaned coal was developed based on demonstrated bench-scale performance in Run No. 227-47(I-27), and from HRI's design experience on the Breckinridge Project and $\mathrm{H}$-Coal $\$$ Process pilot plant operations at Catlettsburg. Complete conceptual commercial plant designs were developed for a grassroots facility using HRI's Process Planning Model. Product costs were calculated and economic sensitivities analyzed.

Results of this economic evaluation show a considerable price advantage achieved by incorporating the latest CTSL Process improvements. Significant further cost reduction could be affected by increasing the efficiency in the deep-cleaning operation. 
In September 1985 HRI initiated a two-year cost-shared program to study and develop a catalytic liquefaction process, based on a lowtemperature, first-stage, catalyt ic two-stage process. The Statement of Work consisted of the following:

TASK 1 - PROJECT WORK PLAN

TASK 2 - EXPERIMENTAL STUDIES

Laboratory Testing

Microautoclave tests on solvents, coals, products and catalysts, and microreactor catalyst screening.

\section{Bench-Scale Testing}

Major effort on process improvement and optimization for lilinois No. 6 coal, plus evaluation of a second, alternative coal. Some of the process improvements pvaluater include:

- Effects nf residence time, temperature, reduced recycle solvent quantity and recycle solvent composition.

- Effect of catalyst cascading in reducing catalyst requirements.

- Effect of catalyst improvements including catalyst size, shape, promoters and pore size distribution.

- Effect of coal cleaning.

- Effect of longer residence time in the first stage.

- Effect of recycling $750^{\circ} \mathrm{F}^{+}$oils to extinction.

- Effect of a thermal second stage. 
TASK 3 - ENGINEERING ANALYSIS

Data Analysis and Correlation

Economic Screening Studies

An evaluation of Wyoming coal and an updated assessment on Illinois No. 6 coal based on process improvements demonstrated in Task 2 .

Conceptual Plant Designs

Plant designs on Wyoming coal and an update on Illinois No. 6 coal $\therefore$ to provide a basis for the economic screening studies.

\section{TASK 4 - PROJECT ADMINISTRATION AND REPORTING}

$\therefore:$ In addition to normal reporting requirements four topical reports and a final report will be prepared. The topical reports are as follows:

$\frac{\text { Topical }}{1}$

Wyoming Coal Conceptual Commercial Plant Design and Economics

2 Illinois roal Program

3. Illinois Coal Conceptual Commercial Plant Design and Economics Update

$4 \quad$ Alternative Coal Studies

This report covers work performed under Task 3 on Illinois coal. 


\section{INTRODUCTION}

Hydrocarbon Research, Inc. (HRI) has extensive experience in the development of coal liquefaction process technology. The H-Coal ${ }^{\oplus}$ Process, which features a single catalytic ebullated-bed reactor, has been successfully developed and demonstrated at bench, PDU and large pilot plant scales, It is generally recognized, however, that single-stage coal liquefaction cannot achieve all of the multiple objectives of coal liquetaction, given the single ser of operating conditions. As a result, various two-stage coal liquefaction concepts have crolved, which to varying degrees have been successful in improving coal liquefaction chemistry.

In 1981-1982, HRI conducted a series of laboratory experiments using a themal first-stage reactor, followed by a closely-coupled, catalytic ebullated-bed, second-stage reactor. This themalcatalytic process concept features a sequential reaction scheme of complete liquefaction in a non-catalytic system, followed by catalytic hydrogenation in a separate second stage. During this work HRI realized that there may be considerable advantages to a t.wn-stage system that accomplishes liquefaction and hydrogenation simultaneously as opposed to sequentially. This realization fomed the bas is for the "New Technology" concept of Catalyt ic Two-Stage Liquefaction (CTSL). The roncept of CTSL is to operate two elosely-coupled catalyt ic ebullated-bed reactors in series. The first stage operates at substantially lower temperatures than the second stage.

In 1983 HRI was granted a two-year contract to investigate this process concept at laboratory and bench unit scales. The firstyear of the program. focused on 11 linois No. 6 bituminous coal. A series of process variable studies were conducted at the benchscale to deterinine the preferred operating conditions for CTSL. After the preferred operating conditions were established, a twenty-five day Demonstration Run 227-20(I-11) was carried out at constant operating conditions, to detemine catalyst deactivation rates and process performance at commercial catalyst age. The demonstration run provided the bas is for a comparative engineering and economic evaluation of CTSL relative to the $\mathrm{H}$-Coalo Process. 
The results of this study showed a $12 \%$ economic advantage for CTSL over the $\mathrm{H}$-Coalo Process.

The second year of the program focused on Wyoming sub-bituminous coal. Similar to the work on Illinois No. 6 coal, a series of bench-scale process variable runs were conducted to detemine the preferred CTSL operating conditions for Wyoming sub-bituminous coal. A demonstration run was then conducted at the preferred operating conditions to establish catalyst deactivation rates and process perfomance at a commercial catalyst age.

In 1985 HRI was granted a new two-year contract from DOE to further investigate the CTSL Process. Bench efforts have been cont inued aimed at improving process. perfomance with Illinois No. 6 coal over the level demonstrated in the above mentioned studies. These efforts recently culminated in a twenty-five day process Denonstration Run 227-47(1-27). Results of this run formulated the bas is for a revised engineering estimate. This report contains the results of the engineering estimate and presents the econamic analyses based on the results of the updated engineering evaluation. The Run 227-47(I-27) extinction recycle process is designated as heavy recycle operation $\left(>750^{\circ} \mathrm{F}\right)$ and the previous process run, $227-20(1-11)$, as light recycle operation $\left(>550^{\circ} \mathrm{F}\right)$.

\section{CTSL PROCESS DESCRIPTION}

Based on data developed under this program, as well as earlier work by HRI and others, product in of high yields of distillate liquid fuels of high quality from direct coal liquefaction is favored by catalytic processing in the presence of hydrogen. HRI's approach is to ut ilize the commercially-proven catalytic ebullated-bed reactor system in two elosely=coupled stages.

A simplied flow scheme for the Catalyt ic Two-Stage Liquefaction Process (CTSL) is shown in Figure 1. Coal is slurried with a process-derived recycle slurry oil, mixed with hydrogen and fed to the first-stage catalyt ic ebullated-bed reactor. The key feature that differs from. most processes is the lower first-stage temperature $\left(<800^{\circ} \mathrm{F}\right)$ and conditions favoring early hydrogenation, directly and through the promotion of hydrogen transfer reactions in the solvent. products, characteristically are better quality 
than other competing direct liquefaction processes, i.e., high hydrogen/carbon ratio, higher API gravities and lower heteroatom content.

The CTSL Process conducts the conversion and hydrogenation simultaneously rather than sequentially thus capping the free radicals and reducing the formation of unstable products likely to recombine and polymerize. By operating the first stage at lower temperatures with catalyst, and high hydrogen pressure, conditions exist that favor in situ regeneration of the solvent and transfer of hydrogen to the coal and coal products as fomled, reducing the chance for condensation reactions.

First stage products pass directly to the higher temperature second stage for further cudl dild lieavy oil cunversion in the presencc of a high relative concentration of regenerated solvent. The opt imum second stage conditions occur when coal and residuum convers ion and heteroatom removal peak, wi thout approaching a themal severity where product dehydrogenation becomes significant.

Both reactor stages use conventional ebullated-bed hydrogenation/hydroconversion catalysts. The second-stage reactor effluent is separated into vapor and liquid-slurry streams. The vapor is cooled and further separated to recover hydrogen which is recycled back to the reactor. The reactor slurry product is depressurized and fractionated to produce high quality distillate products and the slurry is feed to solids-separation to produce a heavy $750^{\circ} \mathrm{F}^{+}$recycle slurry orl (sollds-free) and a sulid pruducl (ash and unconverted coal). With the CTSL Process conditions selected for this conceptual design, near extinction of the heavy liquids rerycle is achieved.

\section{QBJECTIVES AND SCOPE OF WORK}

The objective of this study is to detemine the economic impact of several process improvements demonstrated in the research program since the earlier Illinois conceptual design, based on Run 227-20(I-11). These process improvements include the following:

- Reduced Coal Feed Ash Level 
- Reduced Recycle To Coal Feed Ratio

- Use of Heavy Recycile:Stream

- Increased Reactor Volume

- Increased distillate Liquid Yield

The Scope of Work includes:

- Development of a preliminary engineering design on the liquefaction section (Area 200) for CTSL of Illinois coal.

- Preparation of a conceptual design of a complete grassroots coal liquefaction plant using HRI's Process Planning Model.

- Calculation of products costs for CTSL of Illinois coal and overall assessment of economics including comparison with prior results on 1 llinois coal using light recycle.

\section{BASIS OF DESIGN AND ASSUMPTION}

Yields from liquefaction are elementally balanced based on demonstrated perfomance in Run 227-47(I-27) on Illinois No. 6 coal. This coal had been cleaned by heavy media washing to reduce the ash content to $5.77 \mathrm{~W} \%$. The CTSL distillable liquid product yield is $77.5 \mathrm{~W} \%$ on moisture and ash-free (M.A.F.) coal, compared to $50.9 \mathrm{~W} \%$ on M.A.F. coal for the single-stage $H$-Coal Proces with lllinois coal and with $64.5 \mathrm{~W} \%$ previously demonstrated in light recycle CTSL operations.

In addition, the distillate product from the heavy-recycle CTSL operation contains a much lower proportion of heavy gas oil, with only $6.3 \%$ of the distillable product boiling above $750^{\circ} \mathrm{F}$, compared to a value of $13.6 \%$ of the distillable product for the light recycle CTSL operation.

The preliminary liquefaction section design is based on HRI's experience from the Breckinridge project. Five parallel reactor trains are provided for Illinois coal. Total coal rate to 
liquefaction is $8,400 \mathrm{~T} / 0$ on a dry basis. This is lower than the $9,428 \mathrm{~T} / 0$ used for light recycle and in the Breckinridge Project design due to the higher hydrogen consumption and maximum reactor diameter considerations. However, the greater efficiency of the heavy recycle CTSL operation results in a higher yield of plant products 41,948 BPSD, compared to 34,934 BPSD for the light recycle CTSL operation.

Other design basis information is as follows:

- 0il-to-Solids Ratio in the coal feed slurry is 1.5:1. Deashing is used to provide a solids-free recycle thereby reducing total recycle liquid requirements compared to the solids containing recycle slurry used in the light recycle lllinois coal design.

- Reactor Effluent from the second stage is quenched with recycle hydrogen to redure the potential for ronking in the reactor eftluent separator and in downstream equipment.

- The Slurry Mix Tank is operated at $450^{\circ} \mathrm{F}$.

- Coal Feed Space Velocity is lower, $44.4 \mathrm{Lbs} / \mathrm{Hr} / \mathrm{Ft}^{3}$ catalyst (stage) compared to the prior design with Illinois coal, $67 \mathrm{Lbs} / \mathrm{Hr} / \mathrm{Ft}^{3}$ catalyst (stage).

- Catalyst Replacement Rate has been increased to 3 Lbs/Ton coal from the 1 Lb/Ton coal used in the previous light recycle study. This reviser ratalyst intilization is based on the apparent catalyst deactivation in the kinetic modelling of the key reactions involved applied to distribution in the reactor of catalyst of various ages in an operating system with rontinuous catalyst replacement.

The designs of the other areas of the conceptual commercial plant are specified consistently using HRI's Process Planning Model. The ash concentrate from deashing is gasified via partial oxidation for hydrogen production. The balance of the hydrogen required by the plant is produced via partial oxidation of the ash concentrate reject stream from deep-cleaning the coal. The whole liquid product from liquefaction is hydrotreated, and the hydrotreated heavy naphtha is catalytically reformed. The principal products from the plant are gasnline and diesel fuel. 
Results of the conceptual commercial plant design are summarized in Table 1.' Dry coal feed to the plant is 12,805 TPSD. Electric power (106 MW) is purchased. The total product rate is 41,948 BPSD. The total plant investment is \$2109MM (1984\$) and the product cost is $\$ 38.35 / B b 1$.

\section{OVERALL ASSESSMENT OF ECONOMICS}

The economics calculated are non-site specific and based on U. S. Gulf coast investment costs and mine-mouth coal costs. This was performed to afford the consistent basis for comparison with previous studies.

With the evaluation bas is selected the heavy recycle CTSL Process shows. a 5\% price advantage over the previous light recycle mode $(\$ 38.35 / B b 1$ versus $\$ 40.25 / B b 1)$. Both CTSL processes are significantly lower than the one-stage $\mathrm{H}$-Coal@ Process $(\$ 45.94 / \mathrm{Bb}$ l).

Significant further cost reduction could be achieved by increasing the efficiency of the coal cleaning operation. Thus for an efficiency increase from 70 to $80 \%$ the product cost would decrease fram $\$ 38.35$ to $\$ 36.69 / \mathrm{Bb} .1$, using steam reforming of purchased natural gas.

\section{CONCLUSIONS AND RECOMMENDATIONS}

The main conclusion from this study is that heavy recycle CTSL operation with deep-cleaned Illinois No. 6 coal presents a significant reduction in cost over light recycle operation.with Illinois No. 6 coal. The product cost for the heavy recycle CTSL operation with deep-cleaned Illinois. No. 6 coal is estimated to be $\$ 36.69 / \mathrm{Bb}$, compared to $\$ 40.25 / \mathrm{Bb} 1$ for light recycle mode without coal cleaning. 


\section{SUMPARY OF RESULTS}

CASE

Heavy Recycle Light Recycle

COAL FEED, TPSD

To Liquefaction

To Partial Oxidation

TOTAL

8,400

$\frac{4,405}{12,805}$

106

13,170

28,778

$\frac{28,778}{41,948}$

TOTAL

BY-PRODUCTS

LPG, BPSD

Sulfur, TPSD

Ammonia, TPSD

Ash to Disposal, TPSD

Total Plant Investment, MMs (1)

PRODUCT COST (2)

Operating Cost, MMS/Yr

By-Product Revenue, MMS/Yr

Product Cost, MMS/Yr

$\$ / B b 1$
289

329

143

1,498

2,109

546

15

531

38.35
1,918

$\begin{array}{r}9,428 \\ 1,552 \\ \hline 10,980\end{array}$

90

10,967

23,967

34,934

376

112

1,254

479

12

467

40.52

Notes:

(1) 1984 total erected cost at a U. S. Gulf Coast location. Includes $25 \%$ project contingency.

(2) First year product cost based on $25 \%$ equity, $15 \%$ DCF return, $10 \%$ interest on debt and $5.0 \%$ annual inflation (see Section 5). 


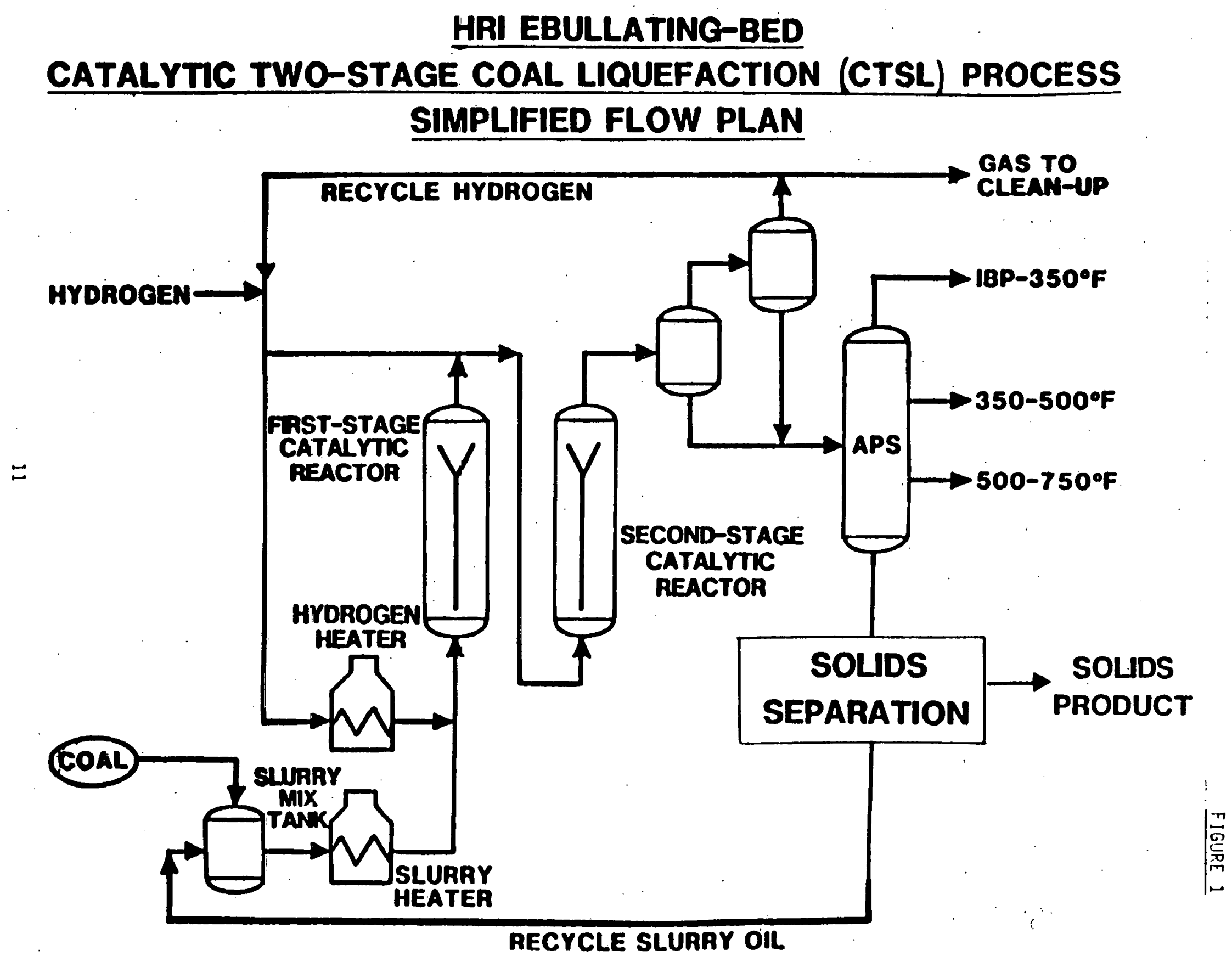


SECTION 1

OBJECTIVES AND SCOPE OF WORK 


\section{OBJECTIVES AND SCOPE OF WORK}

The objective of this conceptual commercial plant design and economics study is to calculate the economics for CTSL using Illinois No. 6 bituminous coal with heavy severity. Consistent with this overall objective are the following specific objectives:

- Provide a preliminary engineering design of the CTSL plant with Illinois No. 6 coal on a comparable basis with the prior designs executed for $\mathrm{H}$-Coal ${ }^{\otimes}$, CTSL on 11 linois No. 6 coal with light recycle and Wyoming sub-bituminous coal.

- Use HRI's Process Planning Model to develop an opt imized conceptual commercial plant design and econonics for complete a grassroots plant, including all necessary onsite and of fsite facilities.

- Compare CTSL economics with prior results using Illinois No. 6 coal with light recycle.

- Identify areas for improvement in CTSL design and evaluation in the contract extension.

To meet the objectives of this study, the scope of work includes the development of a complete conceptual commercial plant design for CTSL on Illinois No. 6 coal. A preliminary engineering design of the liquefaction section (Area 200) is included in sufficient detail to support a meaningful budget-type cost estimate. A summary of work included in the preliminary engineering design is as follows:

- Design Basis

- Battery limits include coal slurry preparation, preheat, reaction, primary separation, hydrogen recycle, recycle slurry preparation and product fractionation.

- Process Description

- Overall Material Balance 
- Utilities and Catalyst Consumption

- Major Equipment Specifications

- Battery limits estimates of major equipment costs.

HRI's Process Planning Model is used to optimize the remaining areas of the plant including: coal preparation, hydrogen manufacture, emission and effluent control systens, product upgrading, utilities and general offsites. Optimized economics are detemined by the computer model simulations and the overall product costs are calculated. 
SECTION 2

BASIS OF DESIGN AND ASSUMPTIONS 
The CTSL conceptual commercial plant design is based on performance demonstrated in bench-scale Run No. 227-47(I-27)(1) on Illinois No. 6 coal (Burning Star Mine). This twenty-five-day demonstration run was conducted at constant operating conditions, progressive with temperature adjustment to maintain minimum heavy oil yields, determined to be an improved set of operating conditions from prior bench scale screening. The design coal feed analysis is shown in Table 2. Yields for CTSL are based on Period 21 from Run 227-47(1-27). CTSL Process yields are also shown based on performance previuusly demonstrated in Run $227-20(1-11)(2)$. CTSL Process yields and process perfomance are compared in Table 3.

CTSL distlllable liquid product yield $\left(C_{4}=975^{\circ} \mathrm{F}\right)$ is $77.5 \mathrm{~W} \%$ on M.A.F. coal compared to $64.5 \mathrm{~W} \%$ on M.A.F coal previously demonstrated. This represents an increase in liquid product yield in excess of 20\%. In addition, the distillate product from the heavy recycle CTSL operation contains a much lower proportion of heavy gas oil, with only $6.3 \%$ of the distillable product boiling above $750^{\circ} \mathrm{F}$, compared to a value of $13.6 \%$ of the distillable product for the light recycle CTSL operation. The distillate sulfur and nitrogen levels are reduced. Those changes are reflected in lower downstream treating costs for the coal liquefaction products. nverall hydrogen consumption is higher than previously demonstrated and the hydrogen efficiency (weight ratio of $C_{4}-975^{\circ} \mathrm{F}$ liquid yield to hydrogen consumption) is slightly less (9.9 versus 10.7 ) than proviously demonstrated.

The preliminary design of the liquefaction sections is hased on HRI's experience from the Breckinridge Project $(3)$. The Breckinridge Project design, completed in 1982, was a site-specific design of a pioneer (first) commercial-scale coal liquefaction plant using the $\mathrm{H}$-Coal Process on Illinois No. 6 coal. HRI was responsible for the design of the liquefaction section of the plant. The design included eight parallel reaction trains. Subsequent studies by Bechtel showed a plant with four parallel reaction trains to be preferred as a minimum economic plant size. This study is based on providing a slightly lower coal feedrate to liquefaction than in the four train light recycle lllinois No. 6 coal design. The capacity of the reactor trains is set by providing maximum-sized (diameter) reactors that can be shop-fabricated using conventional 
techniques for heavy-walled vessels. Other design basis information is as follows:

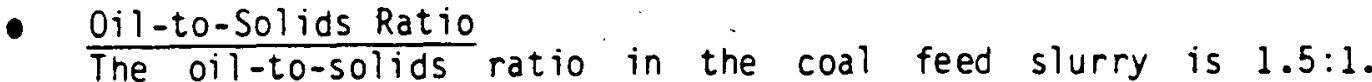
Deashing is included in the liquefaction section so that a solids-free recycle slurry oil is provided.

- Catalyst Replacement Rate

The catalyst replacement rates were rigorously calculated for both the first and second stages based on process kinetic models derived from bench-scale data. (See Addendum)

- Quench of Reactor Effluent

The reactor effluent from CTSL (second-stage) is quenched with recycle hydrogen. This quench was not included in the original Breckinridge Project design. However, it was thought to be necessary to prevent coking in the reactor effluent separator at the Catlettsburg $\mathrm{H}$-Coalo Pilot Plant $(4)$.

Design of the other areas of the conceptual commercial coal liquefaction plant are specified using HRI's Process Planning Model(5). HRI's Process Planning Model is based on the latest process and economic information available for all onsite and of $f-$ site areas required in a complete grassroots coal liquefaction facility. Those areas include:

$\begin{array}{ll}\frac{\text { Area }}{100} & \text { Description } \\ 200 & \text { Codl Prifadion } \\ 300 & \text { Liquefaction } \\ 400 & \text { Partial Oxidation } \\ 500 & \text { Oxygen Plant } \\ 600 & \text { Product Treating } \\ 700 & \text { Product Upgrading } \\ 800 & \text { Utilities } \\ 900 & \text { Tankage } \\ & \text { General Offsites }\end{array}$

These areas are described in detail in later sections of this report. Pertinent design basis information for the major onsite process areas is summarized as follows: 
- Hyorogen Production - The ash concentrate stream fram deashing in the liquefaction section is fed to partial oxidation as a water slurry for hydrogen production. Also supplied to partial oxidation is the ash concentrate reject stream from deep cleaning the coal. The balance of the hydrogen is produced via steam reforming a portion of the product gas.

- Product Upgrading - The whole liquid product from liquefaction is hydrotreated and the hydrotreated heavy naphtha $\left(180-350^{\circ} \mathrm{F}\right)$ is catalytically reformed. The prime products fram the plant include unleaded gasoline and No. 2 diesel fuel. 


\section{DESIGN COAL FEED AMALYSIS(1)}

\section{Coal Type: Illinois No. 6 (Burning Star Mine) \\ Deep Cleaned By Heavy Media Washing}

PROXIMATE ANALYSIS, $W \%$ ORY COAL

Volatile Matter
Fixed Carbon
Ash
TOTAL

ULTIMATE ANALYSIS, $W \%$ DRY COAL

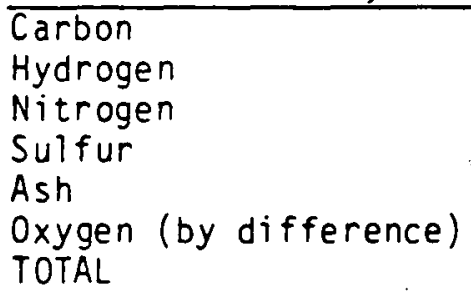

HEATING VALUE (HHV), BTU/LB DRY

MOISTURE, $W \%$ ON COAL FEED TO LIQUEFACTION

SULFUR FORMS, W\% DRY COAL

Organic

Pyritic

Sulfate

TOTAL

$$
\begin{array}{r}
40.30 \\
53.93 \\
5.77 \\
\hline .100 .00
\end{array}
$$

73.92

4.93

1.51

2.75

5.77

$\therefore \quad 11.12$

100.00

13,181

3.08

2.02

0.72

$\frac{0.01}{2.75}$

(1)From Run $227-47(1-27)$ 


\section{OVERALL YIELDS AND PROCESS PERFORMANCE}

W\% ORY COAL

$\mathrm{H}_{2} \mathrm{~S}$

$\mathrm{NR}_{3}$

$\mathrm{COx}$

$c_{1}-c_{3}$

$\mathrm{C}_{4}-40^{\circ} 0^{\circ} \mathrm{F}$

$400-650^{\circ} \mathrm{F}$

$650-750^{\circ} \mathrm{F}$

$750-975^{\circ} \mathrm{F}$

$975^{\circ} \mathrm{F}^{+}$

Toluene Soluble

Toluene Insoluble

Unconverted Coal

Ash

TOTAL
HEAVY RECYCLE (1) LIGHT RECYCLE (2)

\subsection{0}

1.38

10.57

0.10

8.44

21.23

30.14

17.02

4.59

2.89

1.87

1.07

2.77

5.77

$\frac{5.77}{107.40}$

77.5

5.0

72.6

97.1

94.0

9.9

2.43

0.98

10.52

0.42

5.87

17.72

24.26

7.57

7.80

11.86

8. 88

2.98

4.88

11.05

64.5

4.1

55.7

94.5

81.2

10.7

\section{PROCESS PERFORMANCE}

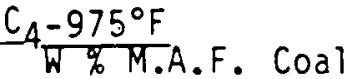

B/T M.A.F. Cual

$C_{4}-750^{\circ} \mathrm{F}, W \%$ M.A.F. Coal

Coal Conversion, $W \% M . A . F$.

$975^{\circ} \mathrm{F}$ Conversion, W\%.M.A.F.

Hydrogen Efficiency

PRINCIPAL OPERATING CONDITIONS

\section{Coal Feed,}

Lbs $/ \mathrm{Hr} / \mathrm{Ft}^{3}$ Catalyst (Stage)

Solvent Recycle, Lbs/Lb Coal

Residual 0 il In Solvent, $W \%$

Temperature, ${ }^{\circ} \mathrm{F}$

First Stage

Second seage

Hydrogen Partial Pressure, Psi

44.4

1.15

47.1

767

823

1900

66.7

2.82

30.4

750

827

1900

(1)Run $227-47(I-27)$

(2) Run 227-20(I-11) 
SECTION 3

PLANT CONFIGURATIONS AND OVERALL DESIGNS 
Complete, grassroots conceptual commercial plant designs are developed using HRI's Process Planning Model. Plant facilities which are specified include:

$\begin{array}{ll}\frac{\text { Area }}{100} & \text { Description } \\ 200 & \text { Coal Preparation } \\ 300 & \text { Liquefaction } \\ 400 & \text { Partial Oxidation } \\ 500 & \text { Oxygen Plant } \\ 600 & \text { Pruducl Tredlimy } \\ 700 & \text { Product Upgrading } \\ 800 & \text { Utilities } \\ 900 & \text { Tankage } \\ & \text { General Offsites }\end{array}$

A detailed description of each of these plant sections is provided in Section 4 - Process and System Descriptions of this report.

Figure 2 presents a block flow diagram of the major processing areas. Coal is received and prepared in Area 100 - Coal Preparation. The deep-cleaned coal is sent to Area 200 - Liquefaction. Ash concentrate from deashing is fed to Area 300 = Partial oxidation for production of hydrogen. The ash concentrate reject stream from deep cleaning the coal in Area 100 is likewise sent to - Partial 0xidation - Area 300. Oxygen required for partial oxidation is produced in Area 400 - Oxygen Plant. The hydrogen produced goes to liquefaction and Area 600 - Product Upgrading. The liquid product from liquefaction is further processed in Area 600 Product Upgrading. In product upgrading the total distillate liquid product is hydrotreated and the hydrotreated heavy naphtha is catalytically reformed. Purge gases and sour water from liquefaction and product upgrading are treated in Area 500 - Product Treating, where $C_{45}$ are recovered for blending to gasoline, as well as sulfur and ammonla by-products. The prime products from the plant are a high octane unleaded gasoline and a No. 2 diesel fuel. 


\section{OVERALL MATERIAL BALANCE}

The overall plant material balance is summarized in Table 4 . The dry coal feed to liquefaction is 8,400 TPSD. 13,170 BPSD of gasoline and 28,778 BPSD of No. 2 diesel fuel are produced, for a total liquid product rate of $41,948 \mathrm{BPSD}$ or $4.99 \mathrm{Bbl} / \mathrm{Ton}$ of dry coal to liquefaction.

The by-products recovered include LPG, sulfur, ammonia and ash. Sulfur, LPG and ammonia provide revenue credits, while a cost is incurred for ash disposal.

Liquid product qualities are presented for the gasoline and diesel products in Table 5. The gasoline produced is high octane $(90(R+M) / 2)$ unleaded. Lower octane ratings could be obtained by reducing the catalytic reformer severity (set at 103 RON). Coal derived naphthas, however, possess excellent, reformability, consequently little savings are realized by reducing reforming severity. This gasoline would probably be sold to a refiner, for blending with lower octane petroleum derived gasoline. The diesel fuel has a cetane number greater than 40 with essentially no sulfur or nitrogen.

\section{HYDROGEN BALANCE}

The overall plant hydrogen balance is shown in Table 6 . Presented are hydrogen consumiptiun in liquefaction and upgrading, as well as purge and solution losses, and hydrogen production in partial oxidation of ash concentrate and steam reforming of light gases. Hydrogen consumption per barrel of liquid product is $6,580 \mathrm{SCF} / \mathrm{Bb}$. Overall $83 \%$ of the hydrogen is consumed in liquefaction, $14 \%$ in upgrading and $3 \%$ represent physical losses to fuel gas.

Eighl percent of hydrogen is produced via partial oxidation of the ash concentrate from liquefaction, $90 \%$ via partial oxidation of the ash-concentrate reject stream from deep-cleaning coal and the balance by steam reforming of light gases. 
THERMAL EFFICIENCY

Thermal efficiency is defined as the percentage of the plant energy inputs (coal and electric power) which leave the plant as products and by-products. The themal efficiency is calculated in Table 7. The inputs to the plant are the coal feed to liquefaction and to partial oxidation, as well as purchased electric power (362 GBtu/SD).

Outputs from the plant include gasoline, diesel, LPG, sulfur and ammonia. The outputs total $246 \mathrm{GBtu} / \mathrm{SD}$. As a result, the themal efficiency is $68.0 \%$.

\section{UTILITIFS SUMMAARY}

A summary of the ut ility usages is provided in Table 8. All utilities are internally supplied with the exception of purchased electric power.

CAPACITY OF ONSITE PROCESS UNITS AND OFFSITE UNITS

The capacities of the onsite process units and of fsite units are summarized in Tables 9 and 10 . 


\section{BLOCK FLON DIAGRAM OF MANOR PROCESSING AREAS}

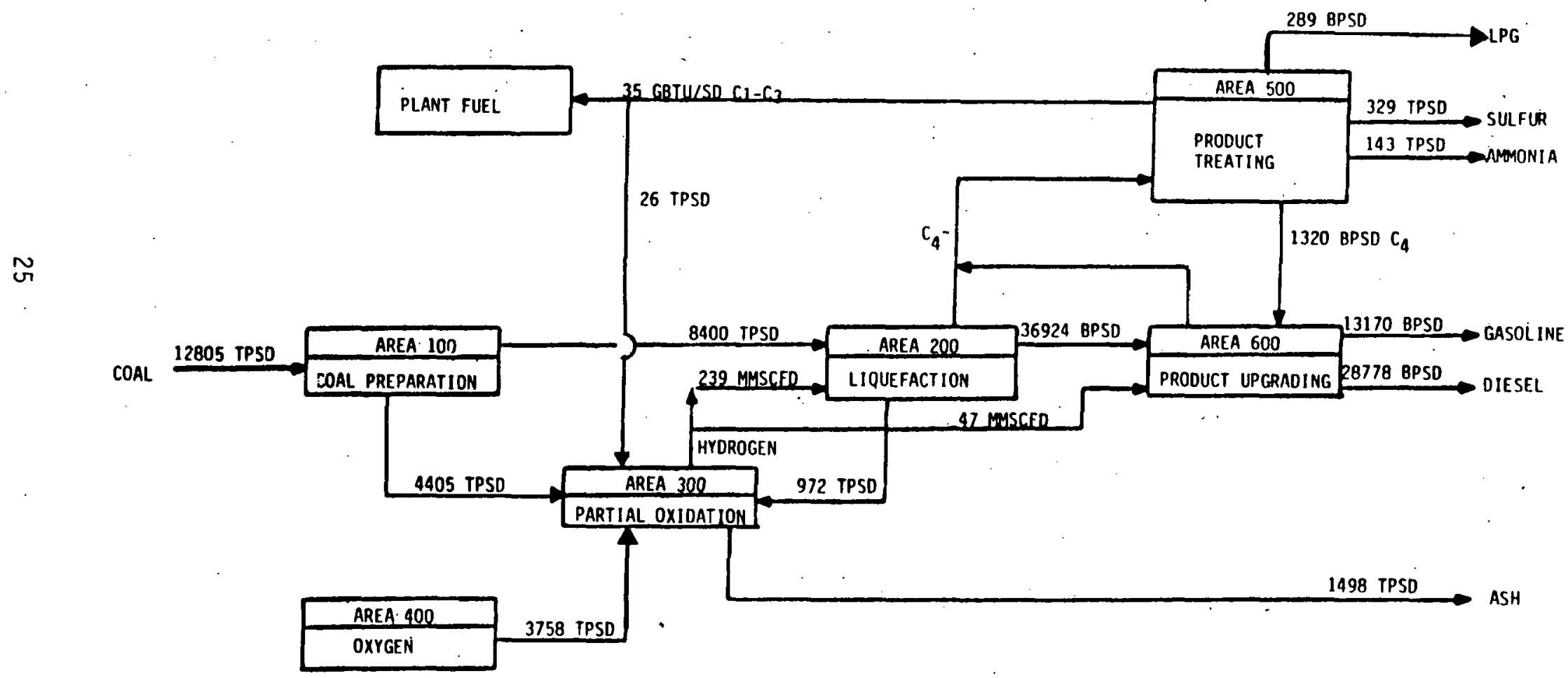


HEAVY RECYCLE LIGHT RECYCLE

COAL FEED, TPSD

To Liquefaction

$\begin{array}{r}8,400 \\ 4,405 \\ \hline 12,805\end{array}$

9,428

To Partial Oxidation

TOTAL

Purchased Electric Power, MW

106

$\frac{1,552}{10,980}$

LIQUID PRODUCTS, BPSD

Gasoline

Diesel

TOTAL

$B / T$ Dry Coal to Liquefaction

$B / T$ Dry Coal Total

BY-PRODUCTS

LPG, BPSD

Sulfur, TPSD

Ammonia, TPSD

Ash to Disposal, TPSD
13,170

$\frac{28,778}{41,948}$

$\frac{28,778}{41,948}$

4.99

3.28

289

329

14.3

1,498
90

10,967

23,967

$\frac{23,967}{34,934}$

3.71

3.18

376

112

1,254 


\section{PRODUCT QUALITIES}

GASOL INE

${ }^{\circ} A P I$

RON (Clear)

48.7

RVP, psia

$R+M / 2$, (Estimated)

11.5

90

DIESEL

OAPI

34.7

Cetane Number

$>40$

TABLE 6

HYDROGEN BALANCE

HYDROGEN CONSUMPTION, MMSCFD

Liquefaction

Upgrading (Net)*

40

Purge and Solubility Losses

10

TOTAL

Hydrogen Consumption, SCF/B of Liquid Products

HYDROGEN PRODUCTION, MMSCFD

Partial Oxidation

Bot toms

Coal

Light Gases $\left(C_{1}-C_{3}\right)$

4

TOTAL

* Net hydrogen consumption. Hydrogen consumed in hydrotreating less hydrogen produced in catalytic reforming. 


\section{THERMAL EFFICIENCY}

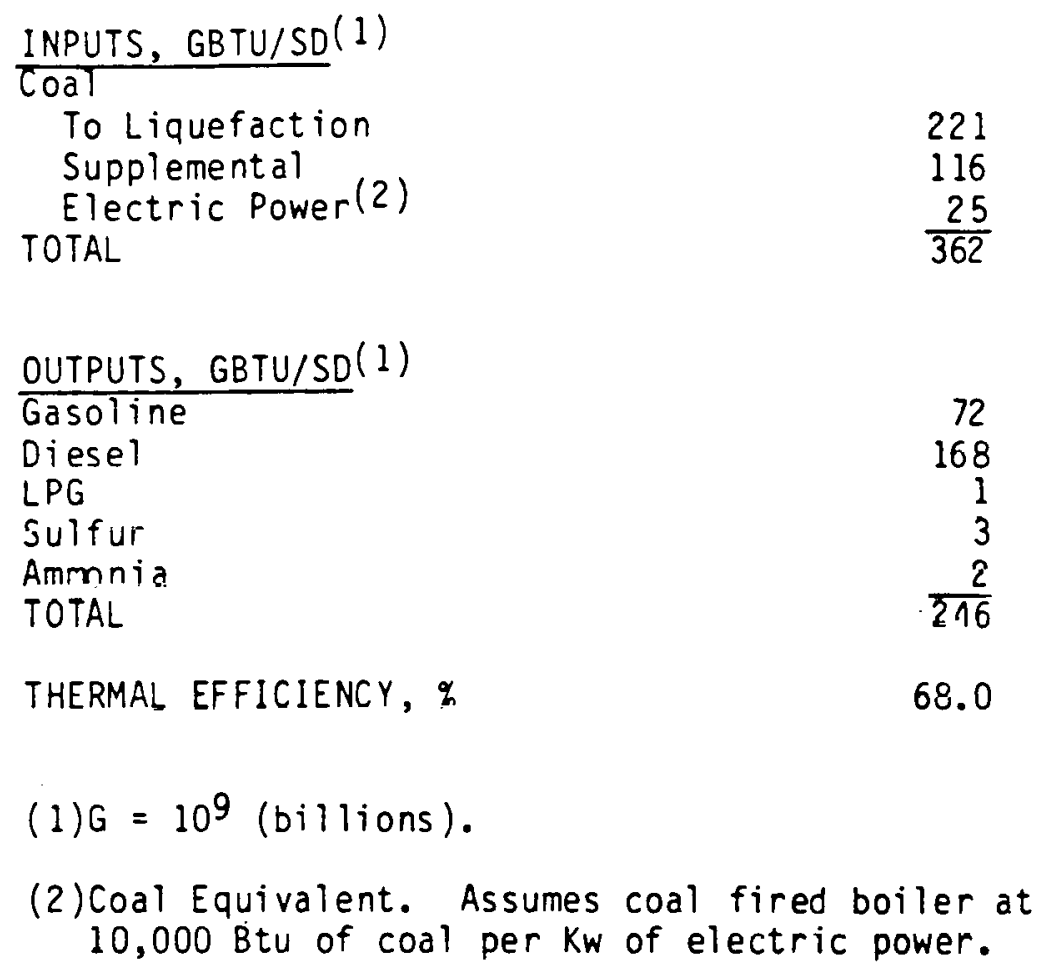

OUTPUTS, GBTU/SD (1)

THERMAL EFFICIENCY, \%

(1) $G=10^{9}$ (billions).

(2) Coal Equivalent. Assumes coal fired boiler at $10,000 \mathrm{Btu}$ of coal per $\mathrm{Kw}$ of electric power.

\section{UTILITIES SURMARY}

ELECTRIC POWER, MW

Purchased

106

Via Steam Turbine Drivers

66

TOTAL

$\frac{66}{172}$

600 Psig Steam, MLb/Hr

Cooling Water, MGPM

Process Fuel, GBtu/SD 35

Raw Water, MGPM 


\section{CAPACITY OF ONSITE PROCESS UNITS}

AREA

200 - Liquefaction.

300 - Partial Oxidation

400 - Oxygen Plant

500 - Product Treating

Acid Gas Remova?

Sour $\mathrm{H}_{2} \mathrm{O}$ Stripping

Sulfur

Light Ends

600 - Product Upgrading

Hydrotreating

Catalytic Reforming
CAPACITY UNITS

TPSD Dry Coal $\quad 8,400$

MMSCFD Hydrogen 286

$\begin{array}{ll}\text { TPSD Oxygen } & 3 ; 758\end{array}$

TPSD $\mathrm{H}_{2} \mathrm{~S}$ plus $\mathrm{CO}_{2}$

TPSD Sour $\mathrm{H}_{2} \mathrm{O} \quad 4,805$

TPSD Sulfur 329

$\begin{array}{ll}\text { TPSD } \mathrm{C}_{4} & 26\end{array}$

BPSD Raw Coal Liquid 37,623

BPSD $180-350^{\circ} \mathrm{F} \quad 8,817$

TABLE 10

\section{CAPACITY OF OFFSITE UNITS}

AREA

$$
\begin{gathered}
100 \text { - Coal Preparation } \\
800 \text { - Utilities } \\
\text { Power Distribution } \\
\text { Steam Generation } \\
\text { Cooling Water }
\end{gathered}
$$

900 - Tankage

Liquid Products

Waste Solids Handling

LPG

1000 - General Offsites
CAPACITY UNITS

TPSD Dry Coal 12,805

$M w$

$\mathrm{MLb} / \mathrm{hr}$

MGPM

106

93

73

BPSD

TPSD

BPSD

41,948

1,498

289

TPSD Dry Coal

12,805 
SECTION 4

PROCESS AND SYSTEMS DESCRIPTIONS 


\section{PROCESS AND SYSTEMS DESCRIPTIONS}

This section provides a description of the processes and systems contained in each of the functional areas. The functional areas in the conceptual commercial plant designs are as follows:

$$
\begin{aligned}
& \frac{\text { AREA }}{100} \text { - } \text { Coal Preparation } \\
& 200 \text { - Liquefaction } \\
& 300 \text { - Partial Oxidation } \\
& 400 \text { - Oxygen Plant } \\
& 500 \text { - Product Treating } \\
& 600 \text { - Product Upgrading } \\
& 700 \text { - Utilities } \\
& 800 \text { - Tankage } \\
& 900 \text { - General Offsites }
\end{aligned}
$$

Area 200 is described in considerable detail, including major equipment specifications, based on the preliminary design developed for this study. Other sections of the plant are duty specified and overall designs are developed based on HRI's Process Planning Model. HRI's Process Planning Model uses state-of-the-art computer modeliing techniques to develop optimized conceptual commercial plant designs and economics for a complete, grass-roots coal liquefaction facility. The process infomation contained in the model is based on the most recent commercial liquefaction plant designs and also reflects the learnings from the large pilot plant projects completed. 
Coal (Illinois No. 6) is received at the plant via rail car. Coal is conveyed to live storage piles for three days nomal use. A thirty-day emergency coal storage pile (dead storage) is maintained. Mobile equipment is used to reclaim coal from dead storage to the active storage pile.

Coal is reclaimed from live storage and conveyed to coal sluraye surge bins ahead of the mills. Cual is simultancously crushed and dried in rollei wills. The hot combustion gasps are filtered iil a bag house and discharged to the atmosphere. Dry coal is delivered to coal storage hins at a nominal minus 30 mesh particle size.

Facilities in coal preparation included equipment required for deep cleaning the coal by heavy media washing. The ash content of coal fed to liquefaction is the reby reduced from 11.7 to $5.77 \mathrm{~W} \%$. At the same time an ash concentrate reject stream, containing $23 \mathrm{~W} \%$ ash, is sent to Partial Oxidation - Area 300.

Material balance and utility summaries are provided in Tables 11 and 12 , respectively. 


\section{AREA $100-$ COAL PREPARATION}

\section{Material Balance Summary}

POUNDS PER HOUR

\begin{tabular}{|c|c|c|}
\hline \multicolumn{3}{|c|}{ POUNDS PER HOUR } \\
\hline & $P F$ & IDUCTS \\
\hline Feed (1) & To Liquefactiont 2 & To Partial oxidation \\
\hline 942,300 & 659,610 & 282,690 \\
\hline 124,810 & 40,390 & 84,420 \\
\hline$, 067,110$ & 700,000 & 367,110 \\
\hline
\end{tabular}

(1) Dry Coal Basis. As received coal contains approximately $10 \mathrm{~W} \%$ moisture.

(2) Dry Coal Basis. Crushed and dried coal contains approximately $3 \mathrm{~W} \%$ moisture.

TABLE 12

\section{AREA 100 - COAL PREPARATION}

\section{Utilities Summary}

$\begin{array}{lr}\text { Electric Power, Kw } & 7,980 \\ \text { Cooling Water, Gpm } & 132 \\ \text { Process Fuel, MMBtu/Hr } & 266\end{array}$




\section{PROCESS DESCRIPTION}

CTSL converts coal into liquid hydrocarbon products by utilizing two catalytic ebullated-bed reaction stages in series. Both reaction stages operate at lower temperatures than the conventional single stage $\mathrm{H}$-Coal ${ }^{\circledR}$ process, with the first of the two stages at a lower temperature than the second.

Figure 3 presents a simplified block flow diagram of the liquefaction area. Coal is mixed with recycled oil and the combined slurry is pumped to reaction pressure, preheated and then combined with make-up and recycled hydrogen. Reaction is carried out in the twostage catalytic ebullated-bed reactors. Reactor effluent is separated into a hydrogen-rich vapor stream which is returned to the reactor, a hydrocarbon liquid stream which is sent to fractionation and a slurry stream which is sent to solids separation. The raw products leaving liquefaction, namely naphtha, light and heavy distillates, are prepared in the fractionator which also forms the fractionator bottoms recycle oil for mixing the coal. Finally, the reactor slurry is separated into a solids-free recycle oil and a reject solids-rich stream which is sent to partial oxidation.

This CTSL plant is designed to convert 8,400 Tons/Day of Illinois Nn. 6 coal. The reaction area consists of five identical trains each handiing 1,680 Tons/Day. The reactor train capacity is set to correspond to the maximum diameter vessel, Breckinridge and the original Illinois coal CTSL designs.

The reactor trains are identified by series 100, 200, 300, 400 and 500 equipment numbers. Reactor effluent is first processed in the separation equipment and then fed to downstream units.

A. catalyst handling system is provided for each reactor train. Thus, there are five catalyst handling trains: Section 150, 250, 350,450 , and 550 . 
Slurry streams from the separation equipment of the five reactor trains are combined and processed in a single Recycle 0il Preparation train, Section 700. This section prepares a solids-free recycle stream containing a sufficient quantity of residuum to effect the desired level of conversion. The net yield of residuum and solids is separated in this section and fed to the gasifiers in Area 300.

One Distillate Separation train, Section 600, is provided to process the distillate streams from the five reactor trains and stripper overhead vapor from Section 700 . This Distillate Separation train recovers valuable distillate products and prepares an oil stream to be recycled for slurrying fresh coal.

Material balance and utility summaries are shown in Tables 13 and 14. Major equipment specifications are shown in Tables 15 through 30.

SECTIONS $100,200,300,400,500-$ REACTION

Sections $100,200,300,400$, and 500 are comprised of five identical trains of reaction equipment. Each section processes 1,680 Tons/Day of Illinois No. 6 coal for a combined plant capacity of 8,400 Tons/Day. Each of the five identical trains employs the same processing schemes which consist of the following steps:

1. Coal Slurry Preparation.

2. Coal Slurry Pumping

3. Hydrogen Compression

4. Preheating

5. Reaction

6 . Separation

These steps are described below for a typical train of the five parallel reaction trains. Reference is made to PFD No. E-12-1-01A for these sections (Exhibit 1). 


\section{COAL SLURRY PREPARATION}

The coal slurry preparation step prepares the slurry feed to the reactors. The equipment required in this step include a slurry mix tank, an eductor system and its auxiliaries, and several heat exchangers.

Slurry Mix Tank

The slurry mix tank provides a means of mixing finely divided coal with oil to obtain a pumpable slurry mixture. The drum also provides surge capacity for the reactor feed.

Fresh, ground, and dried coal is delivered to the slurry mix tank (Q-101 to Q-501) through the fresh coal feed chutes. The fresh coal, available af. approximately $170^{\circ} \mathrm{F}$, is slurried with two process derived streams. The first stream originates from the solidliquid separation unit, $S-701$ in Section 700. This solids-free stream contains the residuum recycle material required to obtain the desired level of conversion. The second slurrying stream, the fractionator bottoms obtained in the Fractionation section, is recycled in order to meet the required recycle oil composition and the oil to solids ratio necessary to form a pumpable slurry mixture. Part of the fractionation bot toms stream is used as a makeup oil to the eductor motive liquid. The remainder is delivered to the slurry mix tank.

The slurry mix tank is designed to operate at a temperature of approximately $450^{\circ} \mathrm{F}$. From a themal efficiency point of view, it is advantagenus to operate at temperatures higher than $450^{\circ} \mathrm{F}$. However, lahoratory data indicate that above approximately $450^{\circ} \mathrm{F}$, the recycle residuum material tends to increase in viscosity and precipitate heavy components. In order to maintain the mix tank at this temperature the liquid purge stream from the bottom of the eductor separator (Q-102) is heated by heat exchange with eductor make-up liquid in M-110 before being recycled back to slurry mix tank.

It is expected that some residual moisture in the fresh coal will be vaporized. These vapors are vented and condensed in the eductor system. The condensed hydrocarbon vapors are returned to the siurry mix tank and the condensed slean is used as wash water fur the desalter in Section 600 . 


\section{Eductor System}

Contacting the relatively cold coal which contains residual moisture with hot recycle slurry and oil material results in the formation of steam and hydrocarbon vapors. These vapors, if not properly vented and condensed, would result in a build-up of backpressure in the slurry mix tank. Vapors would be forced through the coal feed chutes and would then condense in the coal feed areas where the condensate. would cause coal to agglomerate and plug up the feed lines.

To alleviate these conditions, the CTSL Process utilizes an eductor-scrubber system that has proven effective at the $\mathrm{H}$-Coale Pilot Plant at Catlettsburg. The system includes the eductor (S-101 to S-501) an eductor separator (Q-102 to Q-502) and an eductor circulating pump (J-102 to J-502).

The eductor, using a recirculating stream of hydrocarbon liquid similar in composition to the recycle oil, serves the following functions simultaneously:

- Entrains and compresses the slurry mix tank vapor vent

- Cools the slurry mix tank stream thereby condensing a significant portion of the vaporized hydrocarbons.

- Washes out any coal dust particles entrained in the vent stream.

The eductor motive liquid is supplied under flow control, from the eductor circulating pump. The motive liquid entrains Q-101 vent stream and the mixture discharges to the eductor separator (Q-102). In Q-102, condensed hydrocarbons and entrained coal dust are separated from the vapor stream. The vapor stream, which is essentially steam, is condensed in the upper packed zone of Q-102.

In order to prevent accumulation of condensed hydrocarbons and coal dust particles in the motive liquid, a slipstream of the eductor separator liquid is purged back to the slurry mix tank. Correspondingly, a fresh make-up stream of recycle oil is bled into the eductor motive liquid to maintain inventory balance. This eductor make-up oil stream is cooled by generating 200 psig steam in $M-109$ and heat exchange with eductor bottom purge stream in M-110. Before being bled into the eductor motive liquid, this eductor make-up oil stream is further air-cooled. The temperature 
of the eductor make-up oil is set such that no additional cooling is required to achieve a reasonable eductor separator bot toms temperature. Low temperature at the bot tom of the eductor separator, while reducing vent losses, would increase the risk of water condensing in this section. Since the density of water is almost identical to that of the motive liquid, separation by density difference would not be feasible.

The upper section of the eductor separator consists of a packed pumparound zone designed to condense steam and light hydrocarbon vapors. The net material is withdrawn, under level control, to Q-103, where condensed sour water is separated from hydrocarbons, then used as wash water for Section 600 - Desalter.

\section{COAL SLURRY PUMPING}

The reactor slurry feed from the slurry mix tank is pumped to reactor pressure by a booster and high pressure pump system. Booster (centrifugal) pumps $(J-101 \mathrm{~A} / \mathrm{B} / \mathrm{C})$ provide positive suction pressure to the high pressure (reciprocating) slurry feed pumps $(J-105 A / B / C)$. Two booster and two high pressure pumps, each handling $50 \%$ of the flow, are used to pump the slurry to the reactor pressure via slurry preheaters. A third booster and a third high pressure pump are used as spares.

Using two independent pumps at all times insures slurry flow to the reactor, even if one pump fails. Availability of slurry flow to the reactors is of major importance in the operation of the CTSL process. This is because the slurry feed absorbs the heat of reaction released in the reactors, and thus controls the reactor temperature. Loss of reactor feed would lead to vaporization of reactor liquid, eventually causing the ebullating pumps to lose suction. Loss of the ebullating pumps will cause the catalyst bed to slump and reactor operation then resembles that of a fixed-bed reactor.

Each of the slurry booster pumps $(J-101)$ is sized to provide about $50 \%$ of the net forward stream as recycle to the slurry mix tank. This recycie stream ensures constant movement in the slurry transfer lines, thus avoiding the possibility of solids settling and lines plugging. 
HYDROGEN COMPRESSION

Make-up hydrogen from the Gasification section and recovered hydrogen from the Hydrogen Purification section are combined in the make-up hydrogen suction knockout drums $(Q-116)$. This combined hyorogen stream is compressed to reactor pressure by six two-stage reciprocating compressors (R-101-1 A/B to R-101-6 A/B) operating in parallel. Four of these compressors are used during nomal operation and two are provided as spares. Each operating compressor is capable of handing $25 \%$ of the combined hydrogen feed flow to the five reactor trains. Thus, one make-up hydrogen compression system, consisting of four operating and two spare twostage compressors, services the five parallel reactor trains. Each compressor discharges to a common manifold from which hydrogen feeds each train under flow control.

The high pressure hydrogen stream to each reactor train is combined with a recycle hydrogen stream from the recycle hydrogen compressor (R-102 to R-502) servicing that train. The total hydrogen stream then feeds the reactors via a heat exchange and preheating circuit as described below.

\section{PREHEATING}

In the CTSL Process, with two reaction stages, two separate heaters are provided to heat the reactor feed streams. One is a vapor phase heater to preheat most of the feed hydrogen to the first stage. The other is a slurry heater designed to preheat a mixture of the coal slurry feed and a portion of the feed hydrogen.

Hydrogen feed gas is first preheated by exchange against the reactor effluent vapor in M-105A/B. A portion of this hydrogen feed is injected into the coal slurry feed to the slurry heater in order to prevent coking. The slurry mixture is then heated in the slurry heater $(L-101$ to $L-501)$. The first-stage reactor temperature is controlled by adjusting the slurry heater outlet temperature. The outlet temperature of the slurry heater is controlled by adjusting the rate of fuel fired to the heater.

The remaining hydrogen stream is heated to reactor temperature in the hydrogen heater $(L-102$ to $L-502)$. As in the slurry heater, the outlet temperature of this heater is controlled by adjusting the 
rate of fuel fired. Enough extra capacity is designed into these two feed heaters to assure flexibility in controlling the operating temperatures.

\section{REACTION}

In the CTSL Process, coal conversion is achieved in two catalyt ic ebullated-bed reaction stages in series. The first-stage reactor operating temperature is lower than the second-stage reactor tempcrature. However, buth reaction stages operatie at a lower temnerature than the conventional $\|$-Cuale sinyle stage reaction temperature. Using two stages rather than a single stage to achieve conversion increases the overall yields of distillate material. The first stage promotes hydrogenation, while the second stage enhances the kinetics of hydroconversion. The net result is an increase in the overall yields and an improvement in hydrogen selectivity to liquid distillate products.

The CTSL reactors $(K-101$ to $K-501$ and $K-102$ to $K-502)$ incorporate the principle of ebullating bed operation as successfully demonstrated in the Catlettsburg $\mathrm{H}$-Coal ${ }^{\circledR}$ pilot plant and in several commercial $\mathrm{H}-0 \mathrm{il}{ }^{\otimes}$ units currently operating throughout the world.

Coal slurry-hydrogen mixture from the sluiry feed heater along with preheated recycle hydrogen are introduced at the bottom of the first-stage CTSL reactor. The entire mass inside of the reactor is held in a flutalized ebullated state by recirculating liquid from the top of the reactor through the recirculating ehullating pump (J-106) and back into the bottom of the reactor. By keeping the reactor contents in an ebullated state, there is very little temperature difference across the reactor, and the exothemic heat liberated by the hydrogenation reactions is removed as sensible heat rise of the net coal-slurry feed stream. Slurry feed inlet. temperature is controlled at a temperature sufficiently below reactor temperature to maintain the reactor in heat balance. In addition to the coal particles, nickel-molybdenum catalyst pel lets are also held in suspension in the first-stage. CTSL reactor. Since the coal particles are much finer than the catalyst pellets, a separation can be made between these solids such that the coal and ash particles are removed with the liquid-gaseous reactor effluent products, while the catalyst remains behind in suspension in the 
reactor. Control of the expansion of the ebullated catalyst bed is obtained by varying the circulation rate through the ebullating pump with the gas velocity held constant.

Effluent from the first-stage CTSL reactor is quenched with cold hydrogen from the recycle hydrogen compressor, and introduced into the botton of the second-stage CTSL reactor. The interstage quench hydrogen flowrate is controlled to maintain the reactor in heat balance. Second-stage reactor operation and bed ebullation is essentially the same as that of the first-stage reactor.

The CTSL reactors are lined internally with 6" castable refractory as protection from temperature excursions which could possibly occur under abnomal upset conditions.

\section{SEPARATION}

The reactor effluent is separated into its. vapor and liquid phases outside the reactor. Separation is achieved at three consecutive pressure levels.

- The high pressure level operates at essentially the reactor pressure. The hydrogen-rich stream, after the cooling, separation and water wash steps, is recycled back to the reactor.

- The intermediate pressure level operates at the same pressure level as the Hydrogen Purification Unit (HPU). Recovered hydrogen and other light gases from the intermediate pressure flashes can be fed directly to the HPU without further compression.

- A low pressure level which removes dissolved light gases plus hydrogen wich would otherwise overload the downstream fractionation system. After removal of $\mathrm{H}_{2} \mathrm{~S}$ from the flash gas, the low pressure gas is blended into the fuel gas system. 
High Pressure Level Flash Section

The effluent from each second-stage CTSL reactor is separated into its vapor and slurry phases outside the reactor in a separate reactor effluent separator vessel (Q-104). While in the vessel, the slurry is quenched by direct contact with hydrogen from the recycle gas compressor. Hydrogen fed through a sparger achieves equilibrium with the reactar effluent siurry. This quenching method has proven effective in preventing coke fomation in the reactor separator vessel at the H-Coalo Pilot Plant at Catlettsburg. The slurry is then let down in pressure and fed directly to the intemediate pressure slurry drum $(0-107)$.

Vapor from Q-104 is cooled by exchange against hydrogen in exchanger $M-105 A / B$ as previously described. M-105A/B has two shel is in sertes.

Condensate produced in $M-105$ is then separated from the hydrogen rich vapor stream in the high pressure hot condensing drum (Q-105). This intermediate flash drum operates at a relatively high temperature so as to 1) prevent chloride salts from precipitation and 2) prevent steam from condensing out in the presence of heavy hydrocarbons. Heavy hydrocarbons are removed prior to injecting wash water in a downstream exchanger as these heavy hydrocarbons could cause emulsion problems that could create difficulties in the downstream oil-water phase separation. The heavy hydrocarbons, collected in Q-105, are flashed adiabatically to the intemediate pressure level.

Vapor from Q-105 is water-washed to dissolve ammonium chloride, ammonium sulfide and bicarbonate salts wich might form as the reactor vapor is conled. The vapor-wash water mixt,ure is then aircooled in the reactor effluent conoler (M-106). The mixture leaving $M-106$ is separated into three phases (vapor, hydrocarbon liquid and water) in the high pressure cold condensing drum (Q-106).

Vapor from Q-106 is compressed to the reactor pressure via the recycle hydrogen compressor $(R-102)$. The compressed hydrogen is then split into recycle, reactor interstage quench and reactor efflucnt quench gas streams. The reactor interstage quench hydrogen is used to quench the first-stage reactor effluent as previously described. The reactor effluent quench hydrogen is used to cool the second-stage reactor effluent slurry. The recycle hydrogen is sent back to the reactor after being preheated as previously described. A portion of the vapor leaving Q-106 is taken 
as a vent to prevent build-u.p of methane, ni.trogen and other noncondensibles in the recycle hydrogen stream. This vent stream is let down in pressure and fed to a unit for hydrogen recovery. The use of a hydrogen recovery unit minimizes fresh make-up hdyrogen requirements.

The three phase mixture entering Q-106 is separated in the settling zone of the drum into a heavy water phase, a light oil phase which floats on top of the water, and a vapor phase which exists above the liquid phases. The oil phase overflows a vertical baffle and is accumulated in the oil compartment of the drum. Water is removed by means of a boot in the phase separating zone of the drum. An interface level controller controls the withdrawal rate of the water. The sour water is pressured to accumulator Q-114 where it is depressured to essentially atmospheric pressure, mixed with water wash streams from the intenmediate and low pressure flash sections, and pumped to sour water stripping.

Hydrocarbon liquid from the oil side of Q-106 is depressured to the oil side of Q-109, which is a similar phase separating drum operating at the intemediate pressure level. 0il from Q-109 is subsequentiy depressured to the oil side of the low pressure cold condensing drum $(0-112)$ and then pressured to Section 600 for separation and recovery of hydrocarbons.

\section{Intermediate Pressure Level Flash Section}

Feed to the intemediate pressure flash section consists of the depressurized reactor effluent slurry from Q-104, plus the heavy and light hydrocarbon condensate streams let down from the high pressure flash section. The primary purpose of this intemediate pressure flash section is to recover a portion of the hydrogen dissolved in the reactor effluent streams at a pressure sufficiently high to be fed directly to a hydrogen recovery unit wi thout further compression.

The reactor effluent slurry is flashed adiabatically in the intermediate pressure slurry drum (Q-107). Because of the solids' erosive characteristics, dual valves are provided for depressuring reactor effluent slurry. The valves are installed to enable one valve to be taken out of service while the other value is in service. 
Vapor from Q-107 is then combined with the heavy condensate let down from Q-105 in the high pressure section and the mixture is then separated in the intermediate pressure hot condensing drum $(Q-108)$. For reasons similar to those described in the high pressure section, a two-stage condensing system is used to first condense heavy hydrocarbons from the flashed vapor to a water washing step. Heavy condensate from Q-108 is let down to the low pressure hot condensing drum (Q-111). Vapor leaving Q-108 is water washed to dissolve sulfide and carbonate salts, partially condensed in $M-107$ and separated in Q-109 by a procedure similar to that described in the high pressure flash section. The washed hydrocarbons from Q-106 (light condensate from high pressure section) do not require reseparation of oil and water, hence, they are fed directly to the hydrocarbon section of the intemediate pressure cold condensing drum (Q-109). This has an advantage of reducing the drum volume required for phase eeparation. Sour water is pressured to the sour water accumulator (Q-114). Light condensate is let down in pressure to the low pressure cold condensing drum $(0-112)$ and non-condensable vapors are fed directly to the hydrogen recovery unit.

Low Pressure Level Flash Section

Reactor effluent slurry from the intermediate pressure level is flashed adiabatically to the low pressure slurry drum (Q-110). This. low level flash section is used to remove light gases and to recover by adiatic flashing, valuable hydrocarbon liquids from the coal ash slurry. Slurry from Q-110 is pumped to the recycle oil preparation section atmospheric flash drum (Q-701).

Flashed vapors are condensed and water-washed in a two step condensation procedure as in the high and intemediate pressure flash sections. The vapor stream fron Q-110 is combined with the heavy condensate from Q-108, and the mixture is separated in Q-111. Heavy condensate from $Q-111$ is pumped to Section 600 for recovery and separation of hydrocarbon products. Vapor fram Q-111 is water washed, cooled in air cooler M-100, and separated in the oil-water section of the low pressure cold condensing drum (Q-112). Light condensate from the intemediate pressure cold condensing drum (Q-109) is fed directly to the hydrocarbon section of Q-112. In drum Q-112, the vapor, hydrocarbon liquid, and water phases are scparated. 
Non-condensable vapors from.Q-112, after removal of $\mathrm{H}_{2} \mathrm{~S}$ and $\mathrm{CO}_{2}$ by amine absorption, are fed to the fuel gas header. Light hydrocarbon condensate from Q-112 is pumped to Section 600 for recovery and separation of hydrocarbon products while sour water is pressured to the sour water accumulator (Q-114).

Sour water from the three sections discussed above is let down to essentially atmospheric pressure and collected in the sour water accumulator $(0-114)$. Flash vapors from the sour water drum are vented to the fractionator overhead vent compressor where the vapors are mixed with of $f$-gas from the fractionator, compressed and then sent to the gas treating plant for removal of sulfur compounds. Sour water is pumped to the sour water treating plant where ammonia and $\mathrm{H}_{2} \mathrm{~S}$ are stripped from the water.

SECTION $150,250,350,450, \& 550$ - CATALYST HANDLING SYSTEM

One of the most significant advantages of the ebullated-bed reactor system is the ability to add and withdraw a portion of the catalys.t without interrupting the operation of the plant. Catalyst addition and withdrawal are made batchwise on a once-per-day basis, thereby maintaining a constant level of catalyst performance.

\section{SECTION 600 - DISTILLATE SEPARATION}

INTRODUCTION

Section 600 is the distillate separation section of the CTSL Plant. It consists of a single train, designed for 8,400 Ton/Day dry coal. Feed comes lo Sectiorl 600 from the five slurry freparation, Reaction, and Separation Trains, Sections 100 to 500, and also from Recycle 0 il Preparation, Section 700. These streams are processed in the fractionator for product recovery. Overhead naphtha is stabilized before being transferred to storage. Distillates, as well as flush oil for the instrument bleeds and seal oil for the ebullating pumps are transferred to the product tank fams. The fractionator bottoms strean is recycled back to the reactor section where the material is used as a component of the slurry oil stream. 
Drawing E-12-6-01 (Exhibit 2) is a process flow diagram for Section 600 .

\section{PROCESS FLOW}

Light condensate products from the low pressure loop of Sections 100 to 500 are combined, preheated against hot heavy distillate in M-611A/B and phase separated in Desalter Preflash Drum (Q-601). The vapor stream is fed directly to the flash zone of the rractionator. The liquid stream is pumped, under flow control, to the Desalter $(\xi-601)$. Wash water to the Desalter cons ists of the ronnensate from the Srruhber separator (0102 to 502) in Sections 100 to 500, and the sour water fram Fractionator Overhead Receiver (Q-603). The wash stream is first preheated against the water effluent from the desalter in M-613, and is then contacted with the liquid hydrocarbon from Q-601 in a mixing valve upstream of the Desalter. In the Desalter, water is coalesced, decanted in the presence of an electric field, and drawn on interface level control. The desalter feed water flow rate is maintained by a split-range flow controller. Either the stripped sour water header provides make-up requirements, or excess water is sent to sour water treating. Salt-laden desalter effluent water is sent to waste water treatment (to prevent chloride buildup in the sour water recycle loop).

Treated hydrocarbons from the desalter are preheated by exchange with the light distillate pumparound and the heavy distillate pump around. The preheated stream is then mixed with heavy condensate from the low pressure loop of Sections 100 to 500, and the resulting two-phase mixture is separated in the fractionator Preflash Drum (Q-602). Preflash drum vapors are fed directly to the fractionator flash zone. The liquid stream is pumped, under flow control, through the Fractionator Feed Heater $(L-601)$. The heater outlet temperature is controlled by adjusting the rate of the fuel fired in the heater. Furnace efficiency is increased by superheating $50 \mathrm{psig}$ and 150 psig steam in the convection section. By-passing saturated steam around the superheating coils is used to control the superheated steam outlet temperature.

The fractionator operating pressure is maintained by a pressure controller at the fractionator overhead receiver. The fractionator 
top'temperature is controlled by adjusting the reflux flow rate to the top tray of the tower. In order to lift as much distillate-cut materials as possible, the Fractionator Feed Heater operates at a high heater outlet temperature with superheated stripping stean injected upstream of the heater. Steam on flow control is used to strip the fractionator bottoms. The fractionator bot toms stream is recycled back to the slurry mix tank to meet recycle slurry oil requirement.

Each side stream from the tower is a total liquid draw with the reflux pumped back to the tray below. The net heavy distillate product is stripped with superheated steam. The overhead stripped vapor is returned to the tower. The stripped heavy distillate product is pumped and cooled in the $200 \mathrm{psig}$ and 75 psig steam generators, $M-609$ and $M-610$. The resulting stream from $M-610$ is further cooled against low pressure condensate in $M-611 \mathrm{~A} / \mathrm{B}$ and then air-cooled. The cooled product is sent as needed to flush oil storage, with the balance of the heavy distillate product being combined with cooled light distillate product and pumped to distillate storage. The pumparound exchanger circuit is designed for maximum heat recovery from the heavy. distillate pumparound. The heavy distillate pumparound is cooled by heat exchange against fractionator feed in $M-603 A / B$, and further cooled in the 200 psig steam generator $(M-604)$.

Light distillate is drawn from the tower. The light distillate product is then stripped with superheated steam. Cooled light distillate is combined with cooled heavy distillate product and pumped to distillate storage.

A neutralizing amine compound and a filming amine compound are injected through metering pumps into the fractionator overhead vapor line. The overhead vapor is condensed by air cooling in M-605 followed by a water-cooled trim condenser $(M-606)$. Condenser effluent consisting of a liquid water phase, a liquid hydrocarbon phase, and a wet hydrocarbon vapor phase flow to the fractionator Overhead Receiver (0-603) where the three phases are separated. Sour water is drawn of $f$ the vessel boot and pumped by J-603 to the desaiter. Condensed hydrocarbons are net naphtha product and tower reflux. The reflux to the tower is returned under flow control which is reset by top vapor temperature control. Naphtha product is pumped under flow control to the Naphtha Stabilizer (N-604). 
Vapor from Q-603 flows to the vent gas compressor suction drum $(Q-604)$ and is compressed by $R-601$ and sent to the naphtha stabilizer. Suction pressure is held constant in the overhead receiver by a compressor by-pass pressure controller. Flashed vapor from the sour water drums and wash water drums in Section 100 to 500 also flows to the suction of R-601 through Q-604.

The objective of the naphtha stabilizer is to remove $C_{4}$ and lighter materials from the naphtha product. Tower feed from Q-603 is preheated against the stabilizer bottoms. Overhead vapor is cooled and partially condensed in M-616. Vapor, water and hydrocarbon liquid are separated in the stabilizer overhead receiver (Q-605). Condensed liquid is used for tower reflux.

Vapor traffic in the stabllizer is maintained by sending the total liquid draw off the bottom tray through a once=through reboiler, $(M-617)$. The reboiler uses steam as a heating medium. Tower bottoms are exchanged against incoming tower feed and then further cooled in the Stahilizer Trim Cooler $(M-618)$ before being pressured on level control to stabllized naphtha storage.

SECTION 700 - RECYCLE OIL PREPARATION

PROCESS DESCRIPTION

The function of Section 700 in the CTSL Process is to provide a solids-free reactor recycle stream containing a sufficient quantity of residuum material such that the desired level of conversion is obtained in the reactor. The single-train recycle vil preparation section handles slurry from all five reactor trains, Sections 100 to 500 .

Slurry received from $Q-110$ to $Q-510$ is mixed with superheated steam and flashed in the atmospheric flash drum (Q-701) to remove light ends from the slurry stream. The stripped light ends from Q-701 are returned as part of the vapor feed to $N=601$ fractionator. The slurry from $Q=701$ is then pumped to the Solid-Liquid Separation Unit $(S-701)$. From the separation unit a solids-free recycle stream is pumped to the slurry mix tanks (Q-101 to Q-501). The net residuum and solids from the separation unit is fed to the partial oxidation gasifiers.

Drawing E12-7-01 (Exhibit 3) is a process flow diagram of Section 700 . 
The CTSL Process design for this Illinois No. 6 coal study is based on providing a solids separation unit to prepare a solids-free recycle liquid. Operation with a solids-free recycle reduces the amount of recycle required to maintain a given oil-to-solids ratio in the coal feed slurry. It al so allows higher residuum $\left(975^{\circ} \mathrm{F}\right.$ ) concentration in the recycle liquid and as a result higher overal 1 conversion of $975^{\circ} \mathrm{F}^{+}$liquid to distillable products.

The solids separation unit process performance for this design is based on the liquefaction process performance demonstrated with Wyodak coal in Run 227-27. The solid product rejected from the deashing unit (ash concentrate) contains the net yield of $975^{\circ} \mathrm{F}$ liquid plus all of the unconverted coal and ash. Samples of topped separator bottoms from Run 227-27 were sent to. Kerr-McGee and Sandwel] Technologies for evaluation in their ROSE-SR(13) and CENTRAX (14) processes. A comparison of estimated performance, in terms of liquid recovery with these processes and that used in the design is as follows:

\section{ROSE-SR \\ CENTRAX \\ Design}

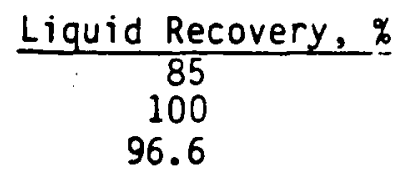

The ROSE-SR Process performance is estimated based on performance demonstrated with other feedstocks, primarily at Wilsonville. The CENTRAX Process performance is based on small-scale laboratory tests.

In actual. practice, during bench scale operations, oils were extracted from filter cake using toluene solvent. With this procedure oil recovery from the cake was from 85 to $90 \%$ complete. CENTRAX projected $100 \%$ oil recovery based on laboratory scale tests and Kerr McGee estimated $85 \%$ recovery based on properties of the atmospheric bottoms well within the range of recovery used in this study with a net yield of $2.9 \% 975^{\circ} \mathrm{F}^{+}$residuum plus coal and ash for the heavy recycle case. 


\section{BLOCK FLOW' DIAGRAM OF LIQUEFACTION}

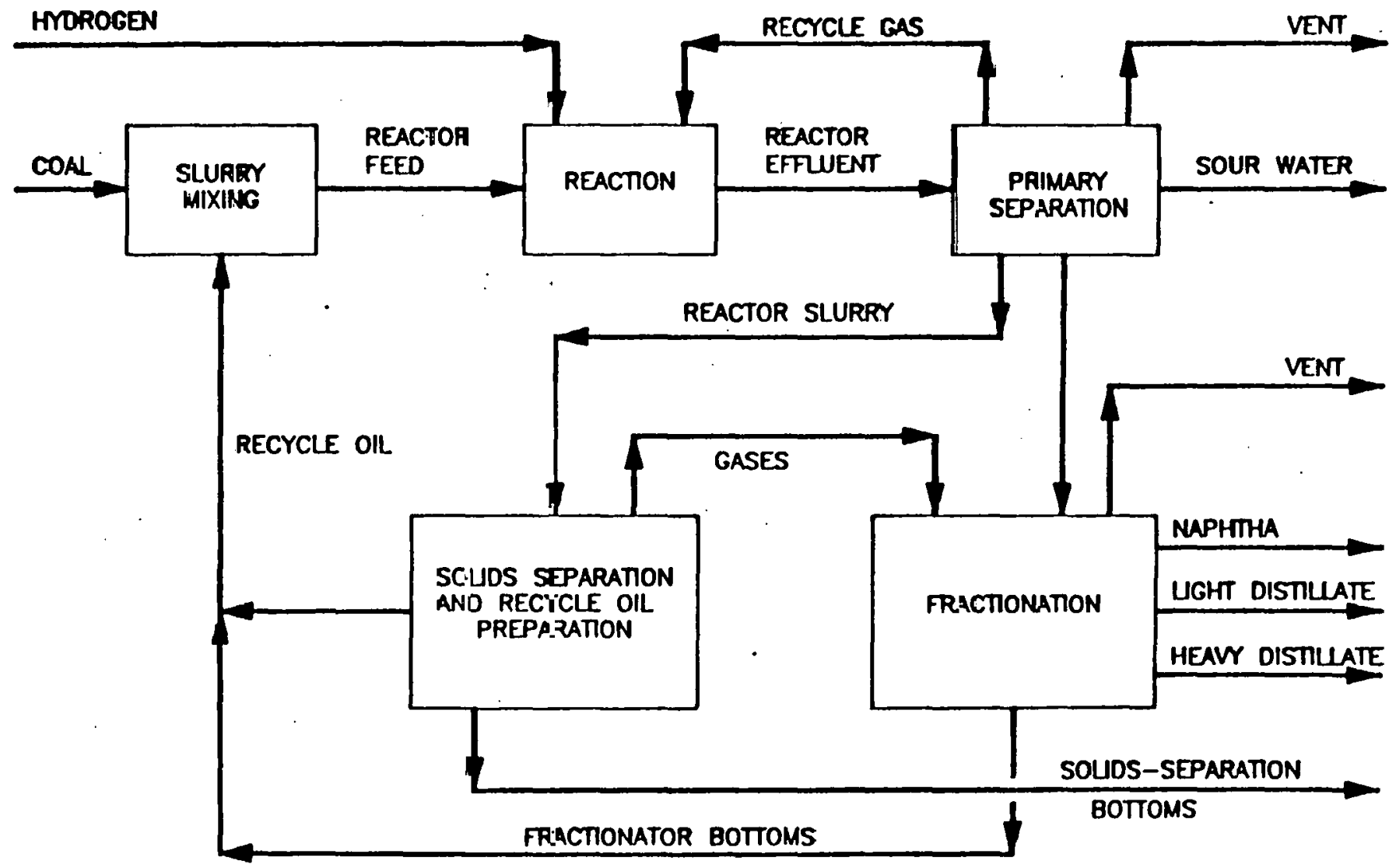


AREA 200 - LIQUEFACTION

\section{Material Balance Summary}

\begin{tabular}{lr}
\multicolumn{1}{c}{ DESCRIPTION } & LBS/HR (DRY BASIS) \\
\cline { 2 - 2 } Coal Feed & 700,000 \\
Make-Up Hydrogen & 52,408 \\
Other Gases with Hydrogen & $\frac{15,253}{767,661}$ \\
TOTAL & \\
& \\
Stabilized Naphtha & 136,326 \\
Light Distillate & 62,817 \\
Heavy Distillate & 286,377 \\
Solids Separation Bottoms & 81,000 \\
DEA Absorber Bottoms (Net Pick-Up) & 1,766 \\
HPU Total Vent & 72,385 \\
Low Pressure Vent & 15,326 \\
Stabilizer Vent & 12,261 \\
Dissolved NH3, H2S, CO & 25,413 \\
Net Water Yield & 73,990 \\
TOTAL & 767,661
\end{tabular}

\section{AREA 200 - LIQUEFACTION}

Utilities Summary

Electric Power, $\mathrm{Kw}$

Cooling Water, Gpm

63,811

4,520

Net Steam Produced

600 fsig, Lb $/ \mathrm{Hr}$

60,767

200 Psig, $\mathrm{Lb} / \mathrm{Hr}$

10,095

Process Fuel, MMBtu/Hr 


\section{EQUIPMENT SPECIFICATIONS - PUMPS}

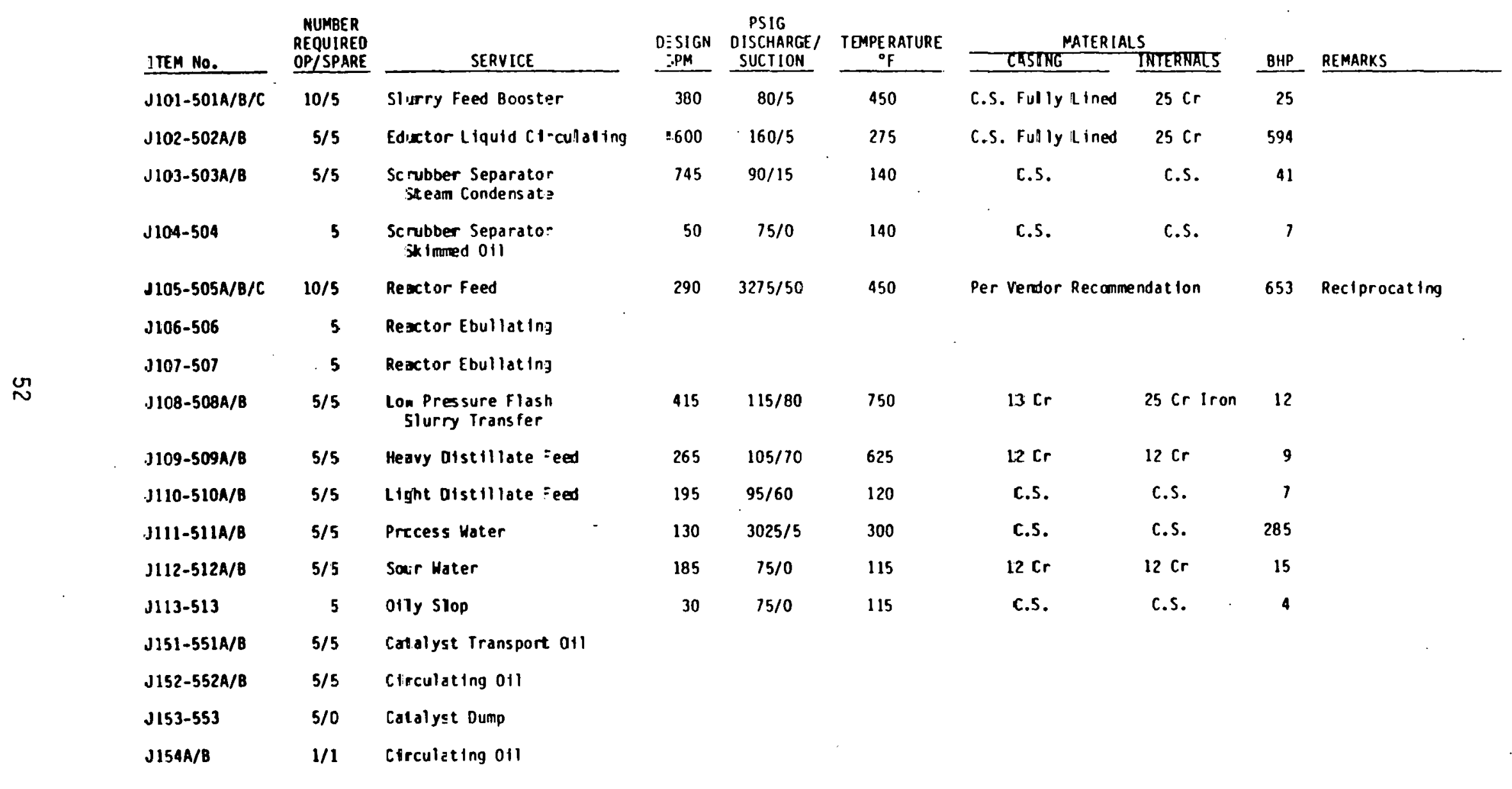




\section{EQUIPPENT SPECIFICATIONS - PUTPS}

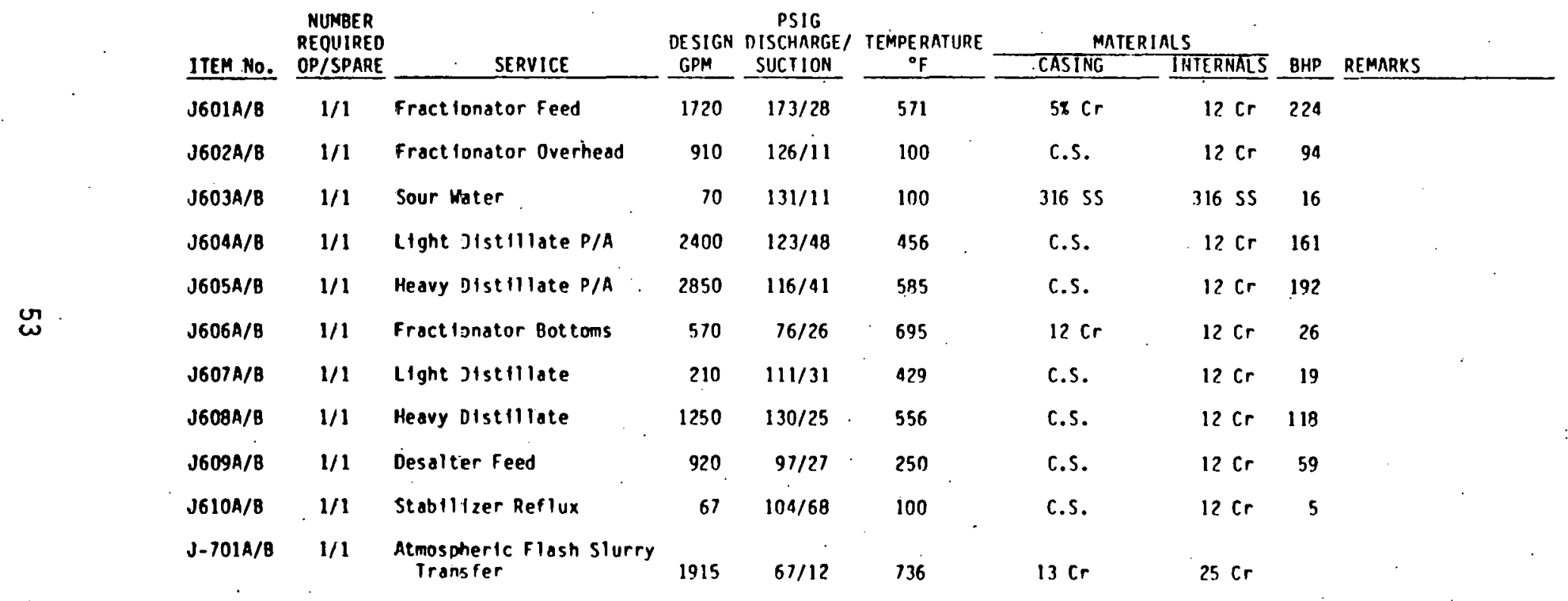




\section{EGGUTPMEHT SPECIFICATIONS - REACTORS}

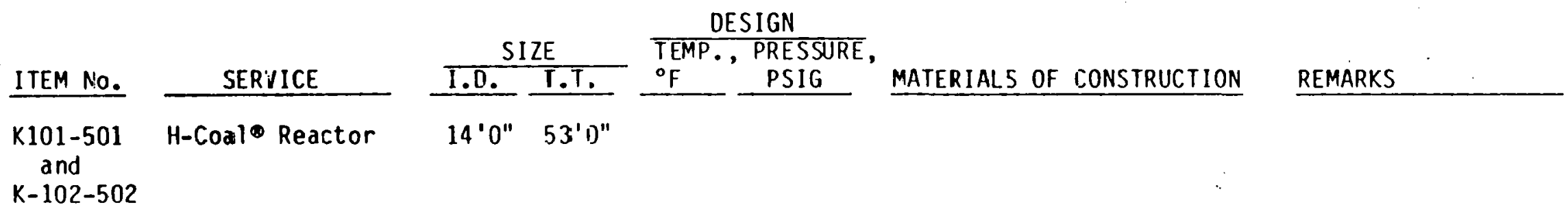

$\stackrel{\leftrightarrow}{\not}$

NOTES:

1. Ten (10) identical reactors required. 


\section{EQUIPMENT SPECIFICATIONS - FIRED HEATERS}

ITEM No. $\begin{gathered}\text { NUHBER } \\ \text { REQUIRED }\end{gathered}$

\begin{tabular}{|c|c|c|c|}
\hline $\begin{array}{c}\text { DESIGN } \\
\text { DUTY, } \\
\text { MMBtu/Ar }\end{array}$ & $\begin{array}{l}\text { OU } \\
\text { TEMP., } \\
{ }^{\circ} \mathrm{F} \\
\end{array}$ & $\begin{array}{l}\text { PEET } \\
\text { PRESSURE, } \\
\text { PSIG }\end{array}$ & MATERIALS OF CONSTRUCTION \\
\hline 20.5 & 584 & 3065 & 347 S.S. or Incoloy 801 \\
\hline 24.0 & 950 & 3065 & 347 S.S. \\
\hline 120.0 & 750 & 22. & $\begin{array}{l}9 \mathrm{Cr}-1 \text { Mo Tube Radiant; } \\
\text { C.S. Tube Convection }\end{array}$ \\
\hline
\end{tabular}

REMARKS

$\begin{array}{lll}\text { L101-501 } & 5 & \text { Slurry Feed } \\ \text { L102-502 } & 5 & \text { Hydrogen } \\ \text { L-601 } & \text { I } & \begin{array}{c}\text { Fract ionator Feed } \\ \text { Heater }\end{array}\end{array}$


EQUIPMENT SPECIFICATIONS - HEAT EXCHAMGERS

\begin{tabular}{|c|c|c|c|c|c|c|c|c|c|}
\hline ITEM No. & $\begin{array}{r}\text { NUMBCZ } \\
R \equiv Q U I R \equiv D \\
\text { OY SPAPEE } \\
\end{array}$ & SERVICE & IYPE & $\begin{array}{l}\text { DUTY, } \\
\text { MMBEU/Hr }\end{array}$ & $\begin{array}{c}\text { ARFA } \\
\mathrm{Ft}^{2}\end{array}$ & $\begin{array}{l}\text { DESIGN - } \\
\text { PRESSIIRT. } \\
\text { PSIG }\end{array}$ & $\begin{array}{l}\text { SIIELL/TURE } \\
\text { MATERIALS OF } \\
\text { SONSTRUCTION }\end{array}$ & REMARKS & \\
\hline M1:1-501 & $5 / 0$ & Eductor 011 Cosler & :ir Cooler & 2.2 & $2.250^{\circ}$ & 100 & c.s. & & \\
\hline M1 12-502 & $5 / 0$ & $\begin{array}{l}\text { Scrubber Separstar } \\
P / A \text { Exchange- }\end{array}$ & $5 \& 1$ & 5.0 & 950 & $100 / 100$ & C.S./C.S. & & \\
\hline MLIJ3 & $1 / 0$ & $\begin{array}{l}\text { Make-up Hydrogen } \\
\text { Bypass Coole- }\end{array}$ & :1r Cooler & 17.3 & $3250^{*}$ & 600 & c.s. & & \\
\hline $\begin{array}{l}\text { MLOS-1 to } \\
\text { MLO4-6 }\end{array}$ & $4 / 2$ & $\begin{array}{l}\text { Make-up Hydzogen } \\
\text { interstag? Cooler }\end{array}$ & Air Cnoler & 6.6 & $1500^{*}$ & 1800 & C.S. & & \\
\hline$M 105-505 A / B$ & $5 / 0$ & $\begin{array}{l}\text { React or Effluent } \\
\text { Vapor/liyd-ogen seed }\end{array}$ & & & & & & & \\
\hline$M 106-506$ & $5 / 0$ & Reactor Effluent Eooler & & & & & & & \\
\hline $9107-507$ & $5 / 0$ & $\begin{array}{l}\text { Intermediatz } \\
\text { Pressure iapor }\end{array}$ & Ar Cooler & 3.6 & $700^{*}$ & 875 & 3045.5. & & \\
\hline$M 108-508$ & $5 / 0$ & Low Pressur? Vapor & Mir Cooler & 3.1 & $700^{*}$ & $\begin{array}{l}1008 \\
\text { Full Vac. }\end{array}$ & 3045.S. & & : \\
\hline $4109-509$ & $5 / 0$ & $\begin{array}{l}\text { Eductor Dilisteam } \\
\text { Generator }\end{array}$ & Kettle & 2.3 & 130 & $370 / 100$ & C. $5.111-13 \mathrm{Cr}$ & & \\
\hline M1 10-510 & $5 / 0$ & $\begin{array}{l}\text { Eductor } 011 \text { iscrubijer } \\
\text { Bot tom } \mathrm{Pu} \text {-ge }\end{array}$ & $S \& 1$ & 1.6 & 230 & $\begin{array}{l}508 \text { Full } \\
\text { Vac./100 }\end{array}$ & C.S. $/ 5 \mathrm{Cr}-1 / 2 \mathrm{MO}_{0}$ & & 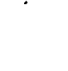 \\
\hline$M 151-551$ & $5 / 0$ & Circulating 011 & Mr Cooler & 1.2 & $1500^{\star}$ & 150 & c.s. & & \\
\hline$M 601 \mathrm{~A} / \mathrm{B}$ & $2 / 0$ & $\begin{array}{l}\text { Light Distillate/ } \\
\text { Fract iona:or Fead }\end{array}$ & $S \& T$ & 23.9 & 7100 & $-150 / 150$ & $\begin{array}{l}\text { c.s.l } \\
11-i 3 \mathrm{Cr}\end{array}$ & & \\
\hline$M 602 A / B$ & $1 / 0$ & $\begin{array}{l}\text { Light Distillate } \\
\text { P/A Trim }\end{array}$ & Atr Cooler & 6.4 & $1050^{*}$ & 150 & $11-13 \mathrm{Cr}$ & Fan BHP 15 & 5 \\
\hline$M 6103 A / B$ & $2 / 0$ & $\begin{array}{l}\text { Heavy DIsti late } J / A \\
\text { Fract Ionazor fead }\end{array}$ & $S \& T$ & 37.0 & 8600 & $15 C / 150$ & $\begin{array}{l}11 / 4 \mathrm{Cr}-1 / 2 \mathrm{Mol} \\
5 \mathrm{Cr}-1 / 2 \mathrm{M}_{0}\end{array}$ & & \\
\hline M604 & $1 / 0$ & $\begin{array}{l}\text { Heavy D1stf late } P / A \\
200 \text { Psig steam }\end{array}$ & Kettle & 35.7 & 4550 & $300 / 150$ & C. $5 . / 5 \mathrm{Cr}-1 / 2 \mathrm{MO}$ & & \\
\hline M605 & $1 / 0$ & $\begin{array}{l}\text { Fract ionator Overhead } \\
\text { Condenser }\end{array}$ & Air Cooler & 95.3 & $18420^{*}$ & $\begin{array}{l}1508 \\
\text { Full vac. }\end{array}$ & c.5. & Fan BHP 31 & 13 \\
\hline$M 605$ & $1 / 0$ & $\begin{array}{l}\text { Fract lonator Overbead } \\
\text { Irlm Cooler }\end{array}$ & $S \& T$ & 7.3 & 4200 & $\begin{array}{l}150 \text { Ful1 } \\
\text { Vác./100 }\end{array}$ & C.S./C.S. & & \\
\hline M607 & $1 / 0$ & $\begin{array}{l}\text { Light Distfllated } \\
75 \text { Psig Stear }\end{array}$ & Kettle & 3.2 & 700 & $150 / 150$ & C.5./11-13Cr & & \\
\hline
\end{tabular}




\section{EQUIPMENT SPECIFICATIONS - HEAT EXCHANGERS}

\begin{tabular}{|c|c|c|c|c|c|c|c|c|c|c|}
\hline & ITEM No. & $\begin{array}{l}\text { NUMBER } \\
\text { REQUIRED } \\
\text { OP/SPARE } \\
\end{array}$ & SE ?VICE & TYPE & $\begin{array}{l}\text { DUTY, } \\
\text { MMBtu/Hr }\end{array}$ & $\begin{array}{l}\text { AREA } \\
\mathrm{Ft}^{2}\end{array}$ & $\begin{array}{l}\text { DESIGN } \\
\text { PRESSURE, } \\
\text { PSIG }\end{array}$ & $\begin{array}{l}\text { SHELL/TUBE } \\
\text { MATERIALS OF } \\
\text { CONSTRUCTION } \\
\end{array}$ & REMARKS & \\
\hline & M608 & $1 / 0$ & $\begin{array}{l}\text { Light Distillate } \\
\text { Trim Cooler }\end{array}$ & Air Cooler & 6.8 & $4800^{\star}$ & 150 & $11-13 \mathrm{Cr}$ & Fan BHP & 71 \\
\hline & M609 & $1 / 0$ & $\begin{array}{l}\text { Heavy Distillate/ } \\
200 \text { Psig Steam }\end{array}$ & Kettle & 24.0 & 2750 & $300 / 150$ & $\mathrm{C.S} . / 5 \mathrm{Cr}-1 / 2 \mathrm{Mo}$. & & \\
\hline & M610 & $1 / 0$ & $\begin{array}{l}\text { Heavy Distillate/ } \\
75 \text { Psig Steam }\end{array}$ & Kettle & 19.4 & 3150 & $150 / 150$ & C.S./C.S. & & \\
\hline & M611 & $1 / 0$ & $\begin{array}{l}\text { Heavy Distillate/ } \\
\text { LP Condensate }\end{array}$ & $S \& T$ & 23.4 & 6110 & $150 / 150$ & C.S./C.S. & & \\
\hline$y$ & M612 & $1 / 0$ & Heavy Distillate/Trim & Air Cooler & 19.7 & $23500^{\star}$ & 150 & C.S. & Fan BHP & 352 \\
\hline & M613 & $1 / 0$ & Desalter Wash/Effluent & $S \& T$ & 1.7 & 260 & $150 / 150$ & C.S./C.S. & & \\
\hline & M615 & $1 / 0$ & Stabilizer Feed Bottoms & $S \& T$ & 10.0 & 1800 & $150 / 100$ & C.S./C.S. & & \\
\hline & M616 & $1 / 0$ & $\begin{array}{l}\text { Stabilizer Overhead } \\
\text { Condenser }\end{array}$ & $S \& T$ & 3.0 & 1850 & $100 / 75$ & C.S./C.S. & & \\
\hline & M617 & $1 / 0$ & Stabilizer Reboiler & $S \& T$ & 11.6 & 4500 & $100 / 225$ & C.S./C.S. & & \\
\hline & M618 & $1 / 0$ & $\begin{array}{l}\text { Stabilizer Naphtha } \\
\text { Trim Cooler }\end{array}$ & $S \& T$ & 9.6 & 2700 & $100 / 75$ & C.S./C.S. & & \\
\hline & *Bare Tub & Surface & rea & & & & & & & 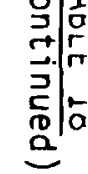 \\
\hline
\end{tabular}




\section{EQJIPMENT SPECIFICATIONS - TONERS}

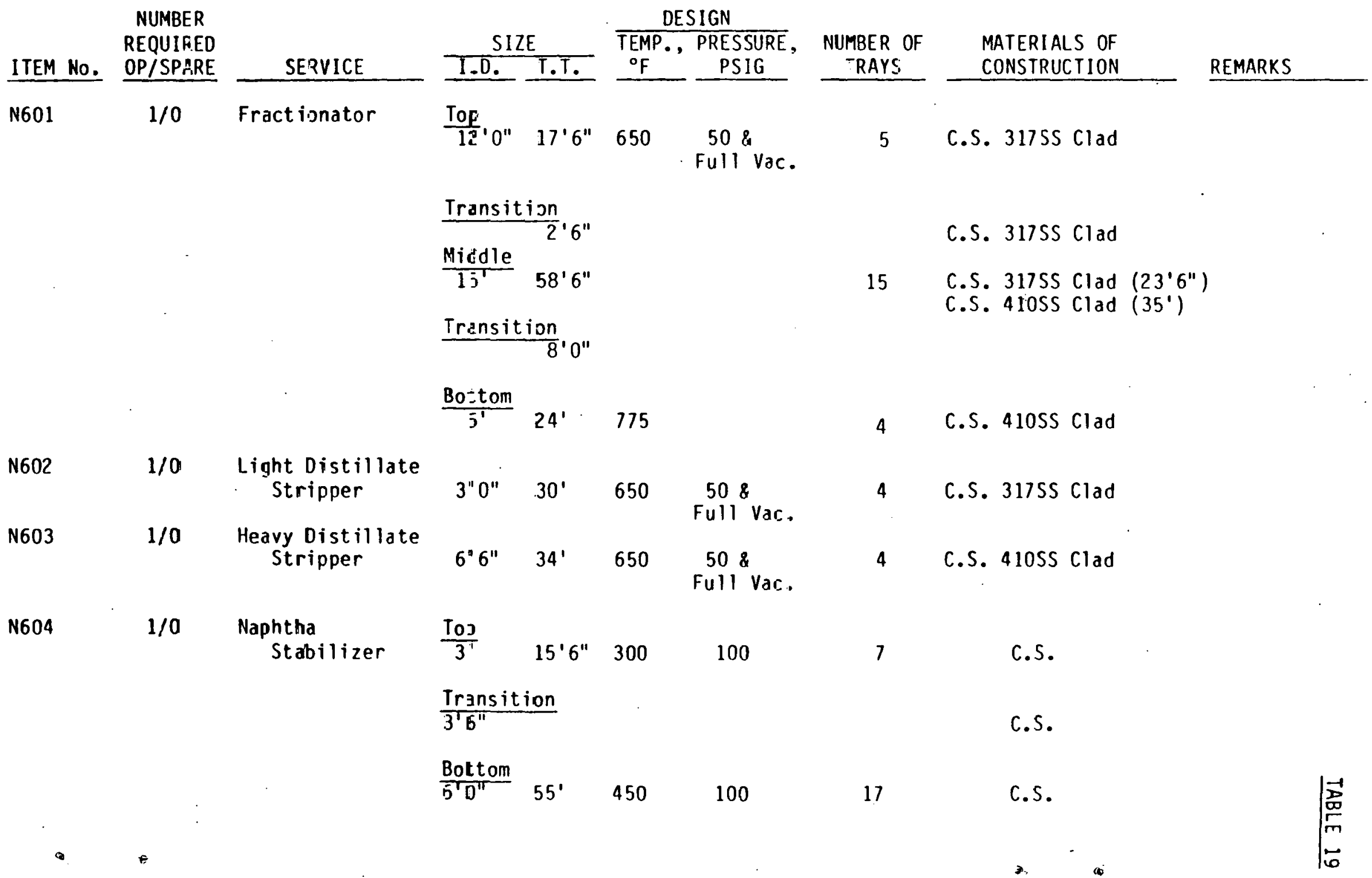




\section{EQUIPAENT SPECIFICATIONS - VESSELS}

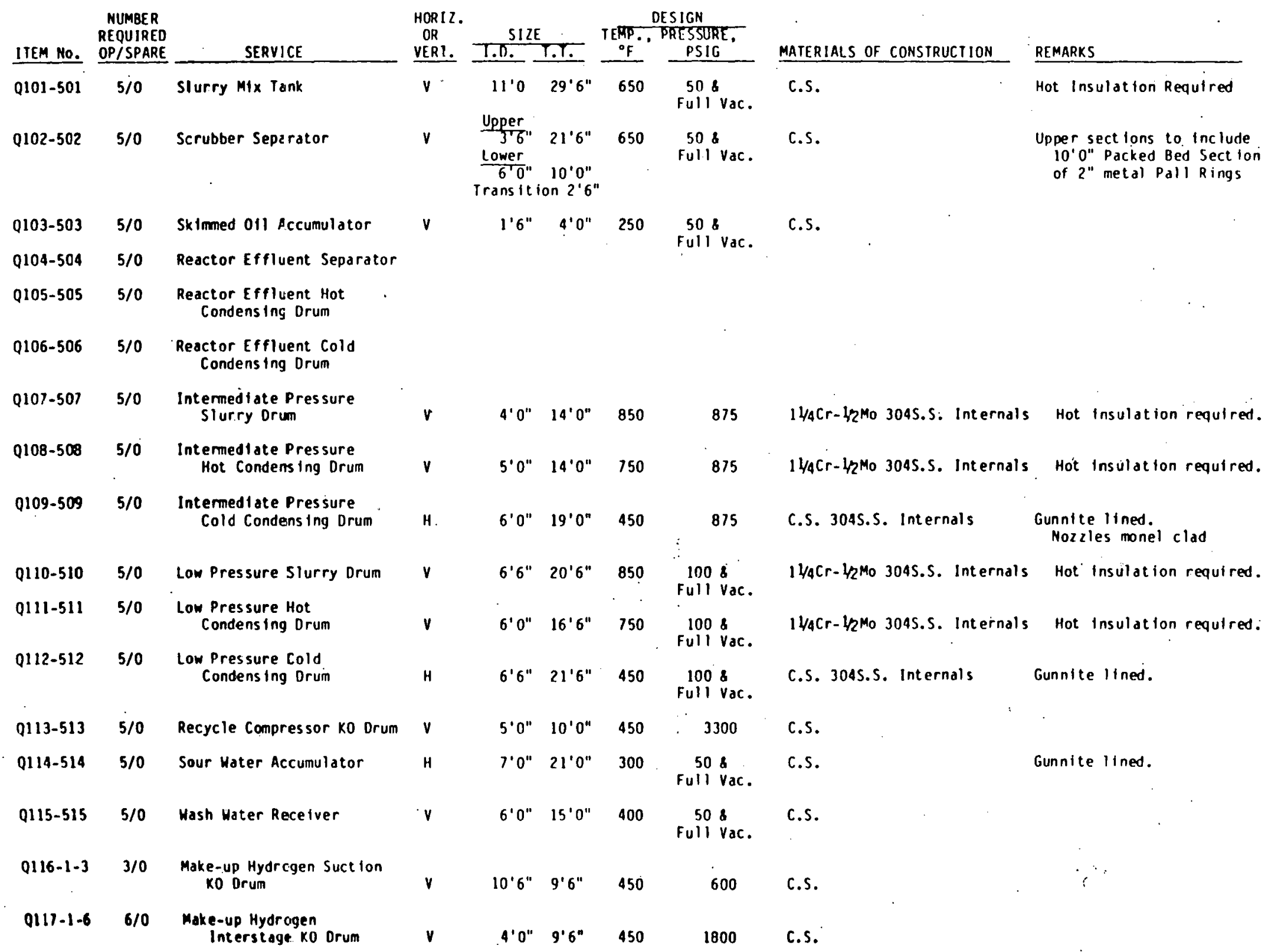


EQU:PMENT SPECIFICATIONS - VESSELS

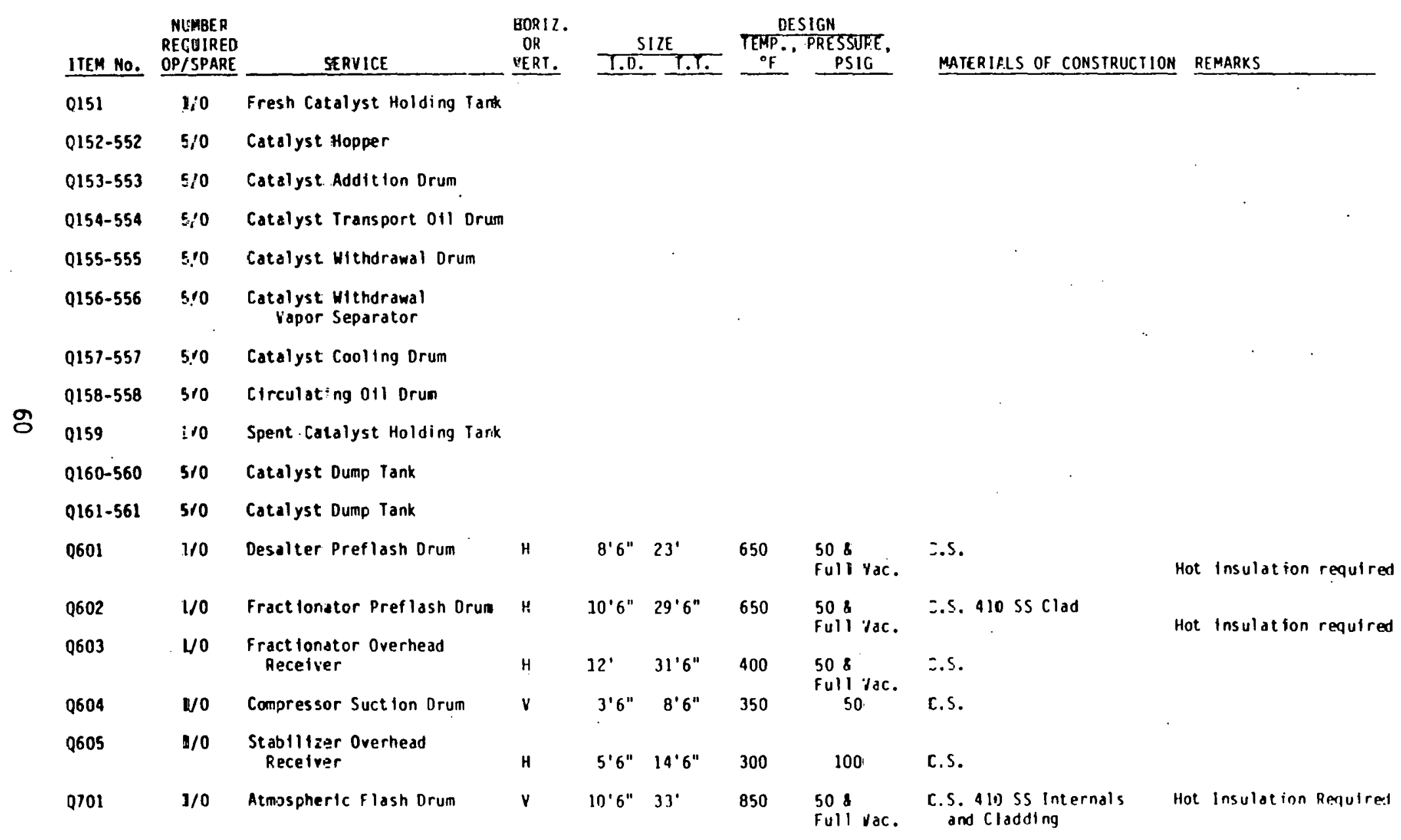




\section{EQUIPMENT SPECIFICATIONS - COMPRESSORS}

\begin{tabular}{|c|c|c|c|}
\hline ITEM No. & R101-1-6A/B & $R 102-502$ & $\mathrm{R} 601 \mathrm{~A} / \mathrm{B}$ \\
\hline $\begin{array}{l}\text { NUMBER REQUIRED } \\
\text { OPERAT I NG/SPARE }\end{array}$ & $4 / 2$ & $5 / 0$ & $1 / 1$ \\
\hline SERVICE & Make-up Hydrogen & Recycle Hydrogen & Vent Gas \\
\hline TYPE & $\begin{array}{c}\text { Reciprocating } \\
(2 \text {-Stage })\end{array}$ & Centrifugal & Reciprocating \\
\hline DESIGN, MMSCFD & 105 & 131 & 1.7 \\
\hline $\begin{array}{l}\text { TEMPERATURE, }{ }^{\circ} \mathrm{F} \\
\text { (Suction) }\end{array}$ & 30 & 130 & 100 \\
\hline $\begin{array}{l}\text { PRESSURE, PSIG } \\
\text { Suction } \\
\text { Discharge }\end{array}$ & $\begin{array}{r}535 \\
3275\end{array}$ & $\begin{array}{l}2950 \\
3225\end{array}$ & $\begin{array}{r}3 \\
85\end{array}$ \\
\hline MW of GAS & 3.30 & .8 .87 & 43.2 \\
\hline DRIVE & Electric & Electric & Electric \\
\hline BHP/MACHINE & 12,050 & 970 & 162 \\
\hline
\end{tabular}


ITEMS S-101 to S-501

SLURRY MIX TANK EDUCTOR

(Five Itèms Required)

\section{DESCRIPTION}

Liquid eductor using hydrocarbon motive liquid to remove vapors and entrained coal dust particles escaping from the slurry mix tank. Vendor shall design provisions for a continuous wash at suction area to prevent bridging and plugging due to presence of coal dust.

PROCESS DUTY.

Suction

Pressure

Temperature

0.5 psig (maximum) $450^{\circ} \mathrm{F}$

Eductor Discharge Pressure 1.0 psig (minimum) (Vendor to provide his maximum design discharge pressure for the given suction load and motive liquid.)

INLET STREAM TO EDUCTOR

$$
\begin{aligned}
& \text { Water Vapor } \\
& \text { Hydrocarbons } \\
& \text { Total }
\end{aligned}
$$$$
\begin{array}{cr}
\text { M.W. } & \frac{\text { Lbs } / H r}{4,622} \\
\hline 18 & 1,220 \\
279 & 5,851
\end{array}
$$

Inlet stream will also contain coal dust (estimated $200 \mathrm{lbs} / \mathrm{hr}$.).

MOTIVE LIQUID

$4.3^{\circ} \mathrm{API}$ coal-derived hydrocarbon

$4,100 \mathrm{GPM}$ at $100 \mathrm{psig}$ and $275^{\circ} \mathrm{F}$ at eductor nozzle

Mot ive liquid may contain up to $1.0 \mathrm{~W} \%$. coal dust particles

(About $100 \mathrm{micron}$ size)

MATERIAL OF CONSTRUCTION

Eductor Nozzle - Stainless Steel

Suction Chamber/Diffuser - Cast iron or fabricated steel. 


\section{S-102 \\ HYDROGEN PURIFICATION UNIT}

DESCRIPTION Provide a hydrogen purification unit for the recovery of a high purity hydrogen stream. Vendor to include an amine absorption unit for the removal of $\mathrm{H}_{2} \mathrm{~S}$ and $\mathrm{CO}_{2}$ compounds present in the feed stream.

FEED STREAM

Temperature Pressure

COMPONENT

$\mathrm{H}_{2}$

CO

$\mathrm{H}_{2} \mathrm{~S}$

$\mathrm{NH}_{3}$

$\mathrm{CO}_{2}$

$\mathrm{CH}_{4}$

$\mathrm{C}_{2} \mathrm{H}_{6}$

$\mathrm{C}_{3} \mathrm{H}_{8}$

$\mathrm{NC}_{4}$

TOTAL

\section{MOLS/HR}

10351.2

802.8

885.0

50.1

2.5

26.6

1.4

1397.3

501.7

308.9

106.9

70.0

14501.1 $120^{\circ} \mathrm{F}$

700 psig

LBS/HR

20868

22477

24781

1708

42

478

59

22356

15102

13622

6212

5866

133571
MOL. FRACTION

$$
0.7135
$$

0.0553

0.0610

0.0035

0.0002

0.0018

0.0001

0.0963

0.0346

0.0213

0.0074

0.0050

1.0000

\section{PRODUCT SPECIFICATION}

Hydrogen Concentration, Min.

Temperature

Pressure

Hydrogen Recovery

$88 \mathrm{~V} \% \mathrm{Min}$. $120^{\circ} \mathrm{F}$ Max. 580 psig min. $99.3 \%$ min.

MECHANICAL SPECIFICATION

A. Vessels to be designed and stamped in accordance with ASME code. Elertrical instal lation for Class I. Div. I area.

Exchangers to meet TEMA $R$ Specifications

Vessels and exchangers to be specified with $1 / 8$ " corrosion allowance.

B. Fuel gas header pressure $=50$ psig 
$S-151$ TO S-551

CATAL YST HANDLING EJECTOR

(Five Required)

TYPE: $\quad$ Single stage vacuum jet complete with surface type aftercondensor.

DUTY: $\quad$ Ejector system to be capable of evacuating a system volume of $375 \mathrm{ft}^{3}$, initially at atmospheric pressure and ambient tempemperature to a final pressure of $100 \mathrm{~mm} \mathrm{Hg}$. abs. within 15 minutes. System is initially filled with air. Discharge preseure of jet is 1 psig.

UTILITIES: Cooling water - $85^{\circ} \mathrm{F}, 30^{\circ} \mathrm{F}$ maximum rise Steam - 150 psig saturated, may contain up to $1.0 \mathrm{~W} \%$ moisture.

MATERIAL OF

CONSTRUCTION: Manufacturer's standard. 


\section{S-152 TO S-552}

\section{CIRCULATING OIL STRAINER}

(Five Required)

TYPE:

In-line basket type mesh screen strainer.

FLUID STRAINED: $\quad 4.3^{\circ} \mathrm{API}$ Vacuum Gas 0 il

$24,500 \mathrm{Lbs} / \mathrm{Hr}$

OPERATING TEMP: $\quad 250^{\circ} \mathrm{F}$

SPECIFIC GRAVITY

AT $250^{\circ} \mathrm{F}$

0.98

PARTICLES REMOVED: Catalyst fines, coal fines, coke.

PARTICLES SIZE

TO BE REMOVED: $\quad 0.032^{\prime \prime}$ and larger 


\section{S-153}

\section{MAKE-UP OIL STRAINER}

(One Unit Required)

IYPE:

In-line basket type mesh screen

FLUID STRAINED:

4. $3^{\circ} \mathrm{API} 0$ il

$10,600 \mathrm{Lb} / \mathrm{Hr}$

OPERATING TEMPERATURE:

$695^{\circ} \mathrm{F}$ Maximum

SPECIFIC GRAVITY:

0.84

AT $695^{\circ} \mathrm{F}$

PARTICLES REMOVED:

Conal and ash fines

PARTICLES SIZE REMOVED: $\quad<5$ Micron 


\section{ELECTRICAL DESALTER DUTY SPECIFICATION}

HYDROCARBON FEED

\begin{tabular}{l}
\hline Boiling Range \\
UOP "K" \\
Gravity \\
Viscosity \\
Vapor Pressure \\
Moisture \\
Solids
\end{tabular}

Salt

PERFORMANCE

Design Throughput Operating Conditions

$\therefore$ Design Conditions

Design Duty

WASH WATER

Available Rate

Source
$\mathrm{C}_{4}$ to $950^{\circ} \mathrm{F}$

11.1

$32.2^{\circ}$ API $\left(0.78\right.$ s.g. (o $\left.245^{\circ} \mathrm{F}\right)$

$0.65 \mathrm{cP}$ C $245^{\circ} \mathrm{F}$

37 PSIA $0245^{\circ} \mathrm{F}$

Negligible

$0.1 \mathrm{~W} \%(\operatorname{Max}$.

Coal Ash (10 to 100 Micron Particles)

Ammonium Chloride $\left(\mathrm{NH}_{4} \mathrm{Cl}\right)$

5 to 10 ib per $1000^{4} \mathrm{Bb}$

ALLOWABLE HYOROCARBON $\triangle P: 10$ Psi (Inlet to outlet)

EMULSION REMOVAL

Provide three (3) perforated collection headers for manual emulsion drawoff. Locate these headers horizontally at 9", 18 " and 27" above the desaller inlet feed distributor. Each collection header is to have a separate draw-off nozzle. 


\section{NEUTRALIZING AMINE INUECTION UNIT}

\section{SERVICE}

To provide a preassembled, skid mounted equipment package for the purpose of storing and metering a controlled dosage of a liquid corrosion inhibitor to the overhead vapor line of the atmospheric fractionator, N-601.

\section{COMPONENTS}

Two (2) metering pumps capable of delivering 2.0 gal/hr liquid corrosion inhibitor at 100 psig (azm. suction). Stardard screw adjustment required from zero to full stroke.

Materials: Pump Body $=$ C.S.

$$
\text { Plungers or Diaphrams - S.S. }
$$

One (1) atmospheric storage tank adequate for seven (7) days' inventory of liquid corrosion inhibitor (250 gal. min.)

Materials: C.S. or FRP

\section{DTHER FQIIIPMFNT}

Vendor to advise any requirements for dilution, dispersion, or agitation: Vondor to provide all interconnerting piping and inslruilientation (ineluding alarm connections to purchaser's system drid calibrate gauge glass).

\section{CORROSION INHIBITOR}

Vendor to recommend a specific neutralizing amine (morpholine, cyclohexylamine, etc.) for a fractionator overhead dew-point vapor which is cooled from 325 to $100^{n} \mathrm{~F}$.

\begin{tabular}{l} 
POUNDS/HOUR \\
\hline Total \\
$\mathrm{H}_{2} \mathrm{~S}$ \\
$\mathrm{CO}_{2}$ \\
$\mathrm{NH}_{3}$ \\
$\mathrm{Chlorides}$
\end{tabular}

\begin{tabular}{rr} 
VAPOR AT \\
$\frac{325^{\circ} \mathrm{F}}{315,410}$ & $100^{\circ} \mathrm{F}$ \\
\cline { 2 - 2 } 563 & 7,250 \\
5 & 306 \\
42 & 4 \\
Trace & 17 \\
Tran &
\end{tabular}

\section{CONDENSED $\left(100^{\circ} \mathrm{F}\right)$}

$\frac{\text { HYDROCARBONS }}{279,640}$ WATER




\section{FILMING AMINE INJECTION}

\section{SERYICE}

To provide a preassembled, skid mounted equipment package for the purpose of storing and metering a controlled dosage of a liquid filming-type amine to the overhead vapor line of the atmospheric fractionator, $\mathrm{N}-601$.

\section{COMPONENTS}

Two (2) metering pumps capable of delivering $0.5 \mathrm{gal} / \mathrm{hr}$ liquid filming amine at 100 psig (atm. suction). Standard screw adjustment from zero to full stroke.

Materials: Pump Body = Carbon Steel

$$
\text { Plungers or Diaphrams - Stainless Steel }
$$

One (1) atmospheric storage tank adequate for seven (7) days' inventory of liquid filming-type amine (250 gal. min.)

Materials: Carbon steel or FRP

\section{INSTRUAENTATION}

Vendor to provide alarm connections to purchaser's system. The storage tank shall be equipped with a calibrated gauge glass. Piping shall be arranged such that liquid can be pumped either from the tank or directly from the calibrated gauge glass.

\section{FILMING AMINE}

Vendor to recommend a specific filming-type amine (octadecylamine, etc.) and injection rate for a fractionator overhead dew-point vapor which is cooled and partially condensed from 325 to $100^{\circ} \mathrm{F}$. (A dosage rate of $5 \mathrm{ppm}$ (weight) corresponds to $0.22 \mathrm{gal} / \mathrm{hr}$.) 
ITEM S-701

SOLID-LIQUID SEPARATOR (DEASHING) UNIT

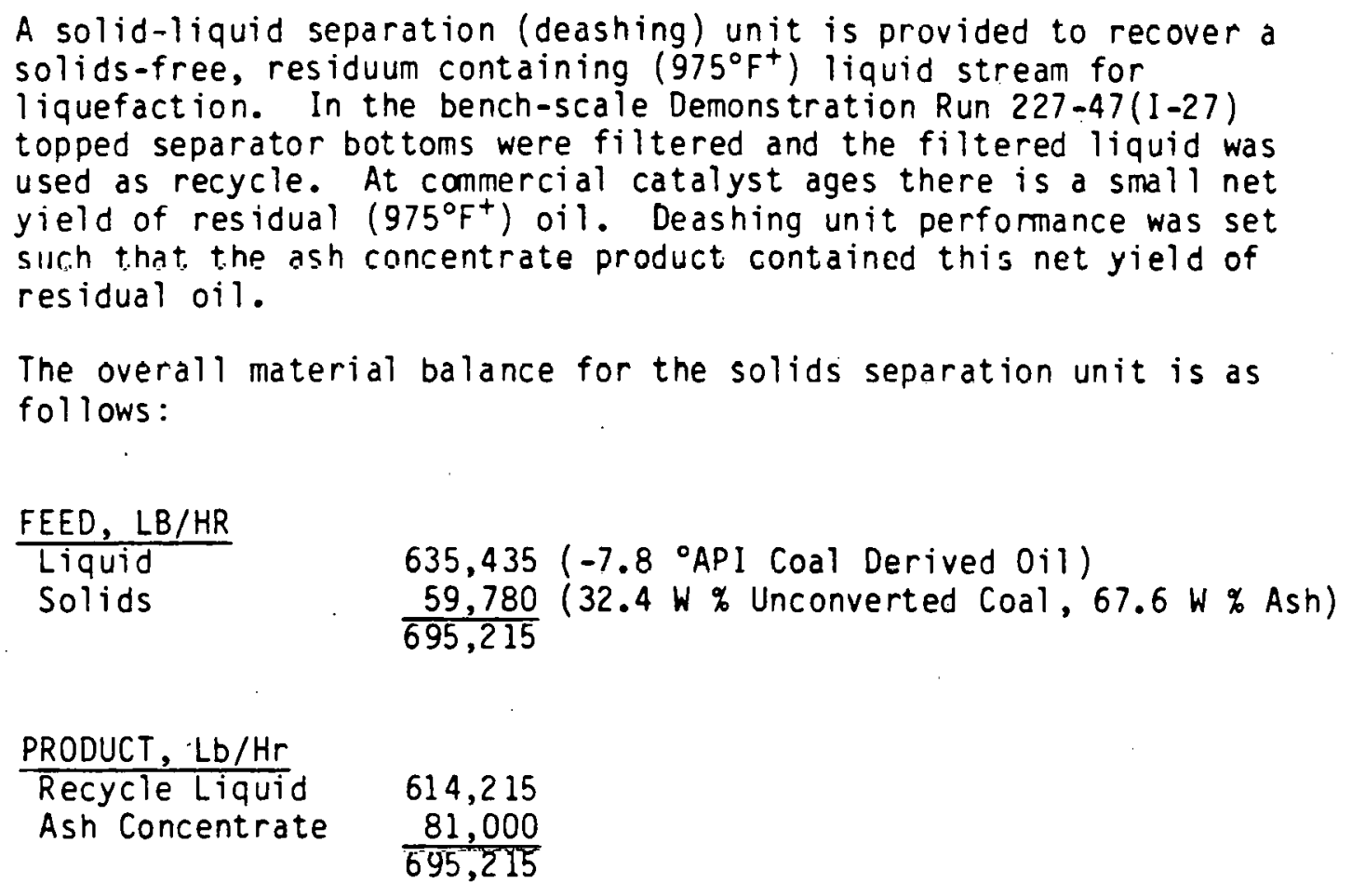




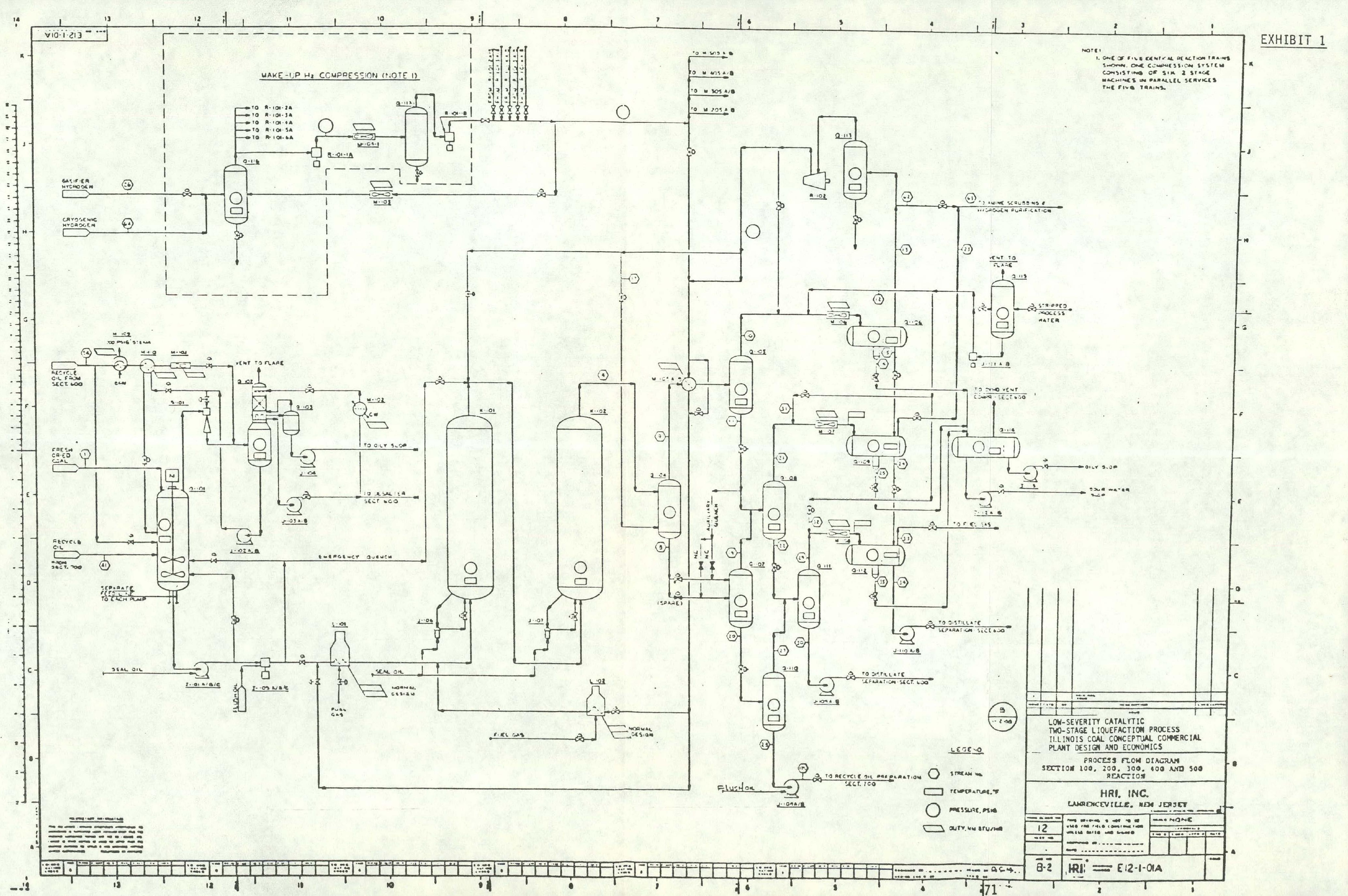




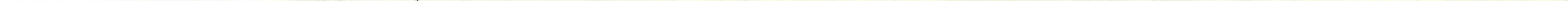


FROM $0-110$
FROM $0-210$

FROM Q-310

FROM 0-410

FROM 0-510

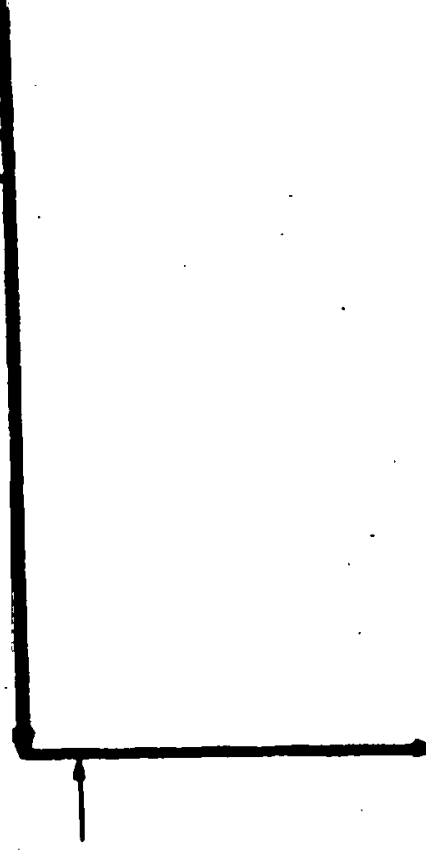

50 PSIG SUPERHEATED STEAM

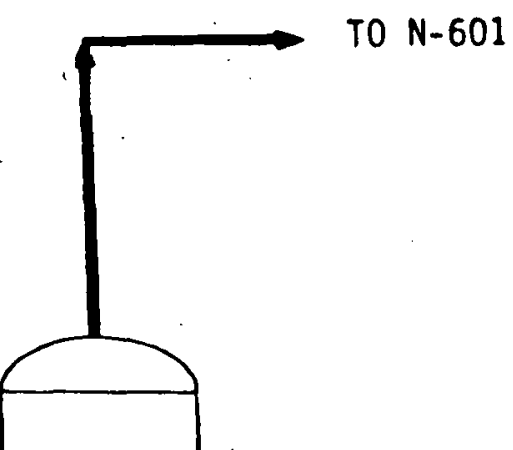

Q-701

ATMOSPHERIC FLASH DRUM
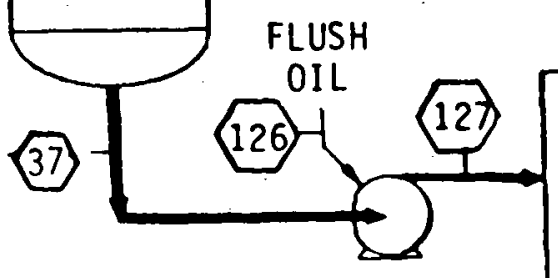

OIL

$J-701 A / B$

ATMOSPHERIC FLASH

SLURRY TRANSFER PLMP

SOLIUS TO GASIFIER

$S-701$

SOLID-LIQUIID

SEPARATION INIT

PROCESS FLOW DIAGRAM

SECTION 700 - RECYCLE OIL PREPARATION

HRI. INC.

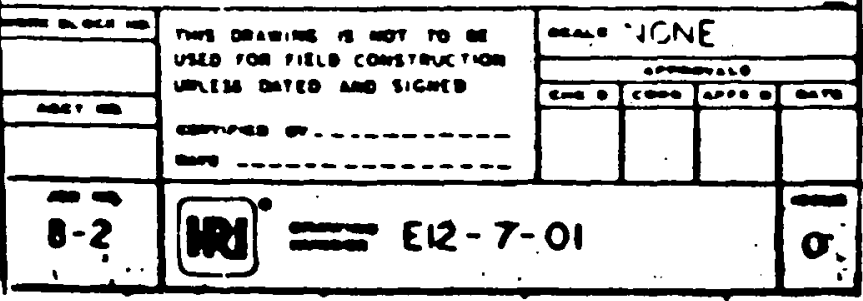

\section{EXHIBIT 3}

(41) RECYCLE ÓIL TO Q-1ก1-501 
Partial oxidation is used to gasify the deashing process ash concentrate as well as the high-ash concentrate from deep-cleaning in Area 100. Gasification takes place at elevated temperatures and pressures in the presence of steam and oxygen. The ash concentrate is fed to the gasifier siurried with water. Ash is withdrawn from the gasification vessel. The primary products of gasification are $\mathrm{H}_{2}, \mathrm{CO}, \mathrm{CO}_{2}$, and $\mathrm{H}_{2} \mathrm{O}$. Carbon monoxide in the product gas is shifted to hydrogen via the water gas reaction. Acid gases are removed using conventional technology.

Steam and oxygen requirements, as well as hydrogen yields and selectivities, are based on the extensive partial oxidation testjng of liquefaction residues done by Texaco under contract to DOE. 6 ) HRI has analyzed this data and developed performance correlations versus feedstock qualities. The partial oxidation feedstock qualities for this conceptual design are as follows:

Feedstock Composition,

$\frac{W \% \text { on Dry Coal }}{975^{\circ} \mathrm{F}^{-}}$

$975^{\circ} \mathrm{F}^{+}$

Unconverted CoOl

Ash

Total

Percent Solids

HHV, Btu/Lb (M.A.F. Basis)

\begin{tabular}{cc} 
Vacuum Bottoms & Coal \\
\cline { 1 - 2 } 0.14 & \\
2.89 & \\
2.77 & 77.00 \\
5.77 & $\frac{23.00}{100.00}$
\end{tabular}

73.8

100.00

Investment and utility estimates are based on information previously provided to HRI by Texaco as well as other published information.

Material balance and utility summaries are provided in Tables 31 and 32. 


\section{AREA 300 - PARTIAL OXIDATION}

MATERIAL BALANCE SUMMARY

FEEDS, LB/HR

Soligs Separation Bot toms.

81,000

Coal (1)

Light Gases

Oxygen

Stean (2)

TOTAL

367,110

2,183

313,135

410,940

$\longdiv { 1 , 1 7 4 , 3 6 8 }$

PRODUCTS, LB/HR

Make-up Hydrogen (3)

Ash

$\mathrm{SO}_{2}$

Other Gases

TOTAL

$$
\begin{array}{r}
62,745 \\
124,810 \\
21,900 \\
964,913 \\
\hline 1,174,368
\end{array}
$$

(1) Dry Coal Basis. Fed to gasifier as $30 \%$ water slurry.

(2) Includes water to slurry coal feed.

(3) $98 \mathrm{~V} \%$ hydrogen.

\section{AREA 300 - PARTIAL OXIDATION}

UTILITIES SUMMARY

Electric Power, Kw

12,852

Cooling Water, Gpm

Net Steam Produced

75 Psig, Lb/Hr

600,505

Raw Water; Gpm

337

Process Fuel, MMBtu/Hr

28 
The oxygen plant produces high purity (99.5\%) oxygen for use in gasification of deashing ash concentrate. Oxygen compression facilities are included. Excess nitrogen is available for export. No credit for nitrogen sales is taken in this evaluation. The technology used is conventional.

Material balance and utility summaries are provided in Tables 33 and 34. 
AREA 400 - OXYGEN

MATERIAL BALANCE SUMMARY

Products, Lb/Hr (99:5 $\vee \%$ Oxygen)

313,135

\section{AREA 400 - OXYGEN}

UTILITIES SUMARY

$\begin{array}{ll}\text { Turbine Power, Kw } & 65,937 \\ \text { Cooling Water, Gpm } & 29,299\end{array}$


Product treating contains four major areas.

1) Light ends recovery using conventional refining technology. $C_{4} s$ are separated for blending to gasoline and for sale as LPG The lighter gases are used as plant fuel.

2) Acid gases $\left(\mathrm{CO}_{2}\right.$ and $\left.\mathrm{H}_{2} \mathrm{~S}\right)$ are removed from product gases using cunvenliunal technology.

3) Collected sour water from the plant is stripped with steam. $\mathrm{H}_{2} \mathrm{~S}$ and $\mathrm{NH}_{3}$ are recovered. $\mathrm{NH}_{3}$ is recovered for by-product sales. The waste water is further treated in a phenolsolvan unit to remove dissolved phenols. No credit is taken for the phenols recovered.

4) Elemental sulfur is recovered from $\mathrm{H}_{2} \mathrm{~S}$ in a Claus-type sulfur plant.

Material balance and utility summaries are provided in Tables 35 and 36. 


\section{AREA 500 - PRODUCT TREATING}

MATERIAL BALANCE SUMMARY

Acid Gas Removal, Lb/Hr

$\mathrm{H}_{2} \mathrm{~S}$

2,784

$\mathrm{CO}_{2}$

82

Sour Water Stripping, LD/Hr

Sour Water

428,286

$\mathrm{CO}_{2}$ Renoved

1,087

$\left.\mathrm{H}_{2}\right\}$ Removed

14,824

$\mathrm{NH}_{3}$ Recovered

11,946

Stripped Sour Water

TOTAL

400,429

428,286

Sulfur Plant, Lb/Hr

Sulfur Recovered

27,390

Light Ends Plant, Lb/Hr.

Process Fuel

80,098

$\mathrm{C}_{4}$ to Blending

$\mathrm{C}_{5}+$ to Upgrading

11,186

$L P G$

9,195 .

Partial 0xidation Feed

2,199

2,183

\section{TABLE 36}

\section{AREA 500 - PRODUCT TREATING}

UTILIITIES SUMMARY

Electric Power, Kw

Cooling Water, Gpm

2,398

Net Steam Consumed

$75 \mathrm{Psig}, \mathrm{Lb} / \mathrm{Hr}$

4,830

600 Psig, Lb/Hr

i10,663

68,511

Process Fuel, MMBtu/Hr

4 


\section{AREA 600 - PRODUCT UPGRADING}

The net liquid product is hydrotreated at high severity over a fixed bed of catalyst. The hydrotreated product is fractionated to recover light naphtha $\left(C_{5}-180^{\circ} \mathrm{F}\right)$, heavy naphtha $\left(180-350^{\circ} \mathrm{F}\right)$, and middle-distillate $\left(350-650^{\circ} \mathrm{F}^{+}\right)$. Light naphtha goes to gasoline blending and the middle distillate goes to diesel fuel.

Heavy naphtha is catalytically reformed at high severity (103 RON clear). The high octane reformate is blended to gasoline. Hydrogen produced in catalytic reforming is compressed and fed to the hydrotreating reactor to reduce the net hydrogen requirements.

Process and economic data on upgrading $\mathrm{H}$-Coal and CTSL products are based on coal jiguid prodyçt upgrading work done under DOE contract by Chevron (7) and UOP(8). Chevron's hydrotreating work has shown, on a variety of coal derived liquids (H-Coal», SRC, EDS and ITSL), that high severity hydrotreating (LHSV less than 1.0 and $775^{\circ} \mathrm{F}$ ) can produce a middle distillate product with a cetane number greater than 40, and an acceptable quality feedstock for catalytic reforming over bi-metallic reforming catalysts. Chevron is currently extending their data base to include upgrading products from HRI's CTSL Process(9). Both UOP and Chevron have shown the excellent reformability of coal derived naphthas, with high yields of high octane (103 RON) $\mathrm{C}_{5}{ }^{+}$reformate, with low gas and high hydrogen yields. Product upgrading for this conceptual design is based on HRI's interpretation of this data. Following are the feedstock qualities to product upgrading.

\begin{tabular}{lr}
${ }^{\circ}$ API & 25.4 \\
Carbon & 88.05 \\
Hydrogen & 11.56 \\
Nitrogen & 0.38 \\
Sulfur & 0.01 \\
H/C Atomic Rat10 & 1.58 \\
KW & 10.80 \\
Composition, W\% & \\
\hline$C_{5-180^{\circ} \mathrm{F}}$ & 4.0 \\
$180=350^{\circ} \mathrm{F}$ & 14.9 \\
$350^{\circ} \mathrm{F}+$ & 81.1
\end{tabular}

Material balance and utility sumaries are provided in Tables 37 and 38. 


\section{AREA 600 - PRODUCT UPGRADING}

MATERIAL BALANCE SUMMARY

FEEDS, LB/HR

Coal Liquids

Net Make-up Hydrogen ${ }^{\star}$

494,715

TOTAL

10,338

505,053

PRODUCTS, LB/HR

Purge Gases

Light Naphtha plus Reformate

8,379

Diesel

139,574

TOTAL

357,100

$\overline{505,053}$

* Net hydrogen make-up. Tot al hydrogen consumption less hydrogen produced in catalyt ic refoming.

\section{AREA 600 - PRODUCT UPGRADING}

UTILITIES SUMMARY

Electric Power, Kw

Cooling Water, Gpm

14,915

4,151

Net Steam Consumed

75 Psig, Lb/Hr

38,589

Process Fuel, MMBtu/Hr 
All of the utility requirements for the liquefaction plant are generated on site, with the exception of purchased electric power. High pressure steam is generated in boilers fired by gases produced in the process. Facilities for electric power distribution are provided. Some major electric power requirements (compressors, etc.) are provided by steam turbines. All water facilities (boiler feedwater, cooling water, process water and potable water) are al so provided. Process fuel is internally derived.

Utility usages by plant section are summarized in Table 39. Steam balances are shown in Tables 40 . 


\section{UTILITIES}

\section{$\frac{\text { Power, Kw }}{\text { Electric Turbine }}$}

AREA

100-Coal Preparation

200 - Liquefaction

300 - Partial Oxidation

400 - Oxygen Plant

500 - Product Treating

600 - Product Upgrading

700 - Utilities

800 - Tankage

TOTAL

$\begin{array}{r}7,980 \\ 63,811 \\ 12,852 \\ 2,398 \\ 14,915 \\ 2,535 \\ 1,179 \\ \hline 105,670\end{array}$

Cooling Water, Gpm
Process Fue? MMBtu/Hr
Raw Water, Gpm

\begin{tabular}{rrr}
132 & 266 & \\
4,520 & 731 & 5 \\
29,847 & 28 & 337 \\
29,299 & & \\
4,830 & 4 & \\
4,151 & 282 & \\
& 160 & 3,015 \\
\hline 24 & & \\
\hline 72,803 & $\overline{1,471}$ & $\overline{3,357}$
\end{tabular}

TABLE 40

\section{STEAM BALANCE}

Net Steam Consumption, $\mathrm{Lb} / \mathrm{Hr}$

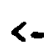

$$
600
$$

P S I G 200 75

\section{AREA}

$\overline{300}$ - Partial Oxidation

500 - Product Treating

600 - Product Upgrading

700 - Utilities*

TOTAL

Net Steam Production, $\mathrm{Lb} / \mathrm{Hr}$

AREA

$\overline{200}$ - Liquefaction

300 - Partial oxidation

700 - Utilities

TOTAL

$$
\begin{aligned}
& 84,920 \\
& 68,511
\end{aligned}
$$

$\begin{array}{llr} & \begin{array}{r}38,589 \\ 153,431\end{array} \quad \frac{10,095}{10,095} \quad \frac{461,348}{610,600}\end{array}$

$\begin{array}{ccr}60,767 & 10,095 & \\ \frac{92,664}{153,431} & & 600,505 \\ 10,095 & \frac{10,095}{610,600}\end{array}$

* Stean consumed in turbine arivers. 


\section{AREA 800 - TANKAGE}

Intermediate and final product tankage for plant products and byproducts is provided for thirty days. Also included are associated transfer pumps, railcar loading and railcar unloading facilities. 
AREA 900 - GENERAL OFFSITES

Included in the plant of fsites are electrical systems, interconnecting piping, site preparation, perimeter fencing, roads, parking areas, maintenance equipment, laboratory equipment, mobile equipment, fire protection equipment, buildings, furnishings, communication systems and railroad facilities. 
SECTION 5

CAPITAL COST ESTIMATES AND ECONOMIC EVALUATION 


\section{CAPITAL INVESTMENT BASIS}

The capital investment estimates are based on the following assumptions:

Plant size

8,400 TPSD of dry coal to liquefaction. This plant size is based on design studies done by Bechtel for the Breckinridge Project. These studies detemined the minimum economic plant size for a commercial $\mathrm{H}$-Coalo liquefaction plant. The minimum plant contains five parallel reactor trains, each processing 1,680 TPSD of dry coal. The capacity per train is set by providing the maximum size reactor (diameter) that can be shop fabricated using conventional techniques.

\section{Capital Cost Basis}

1984 dollars at a U. S. Gulf Coast location. This bas is was selected to be cons istent with prior studies on Illinois and Wyodak couls.

\section{Estimate Basis}

Cost estimates are detailed for the various functional areas of the plant. Area 200 - Liquefaction is based on the preliminary designs done by HRI. Costs for major equipment are estimated based on vendor input or recent quotations for similar equipment. (see Table 41). Commodity materials and labor are factored based on statistical techniques which HRI has developed for the H-Coalo and H-Oil Processes. For areas other than liquefaction, curve-type cost estimates are developed based on information contained in HRI's Process Planning Model. 


\section{Total Erected Cost}

The total erected cost estimated is the sum of direct material and labor, indirect costs and project contingency. Indirect cost is estimated to be $40 \%$ of the total direct cost and includes field supervision, equipment and tools, sales tax, and engineering and home office fees. Project contingency is used to allow for the cost of additional equipment that would be specified in a more detailed design of a definitive project at a specific site. The project contingency used is $25 \%$. The total erected costs for the liquefaction section and total plant are detailed in Tables 42 . The total erected cost is 2,109 MMS.

\section{ECONOMIC EVALUATION}

Product (gasoline and diesel) costs are calculated using a proprietary program developed by HRI for discounted cash flow (DCF) economic calculations. The product costs are based on an economic basis which closely corresponds to those used for major projects proposed for consideration by the U. S. Synthetic Fuels Corporation $(S F C)$. Although this econamic bas is is not completely valid with the current day situation, it was selected to be consistent with the prior studies on Illinois coal. The economic basis is presented in Table 43 and some highlights are summarized below:

- Debt/Equity Ratio - 75/25 ratio, based on maximum loan guarantees available from SFC.

- Depreciation Method - Accelerated Cost Recovery System (ACRS) based on legislation enacted by Congress in 1981. According to the guidelines of ACRS, a plant of this type can be depreciated over a five year period by the percentages shown below:

\begin{tabular}{cr} 
Year & \% of Investment Depreciated \\
\hline 0 & 20 \\
1 & 32 \\
2 & 24 \\
3 & 16 \\
4 & 8
\end{tabular}


- Investment Tax Credit - .10\% taken in the year of investment.

- Working Capital - Estimated at $6 \%$ of total erected cost and covers operator. training, equipment checkout, major changes in plant equipment, extra maintenance and inefficient use of fuel and other materials that occur during plant start up.

- Inflation - 5\% per year on all costs and revenues.

- Production Schedule - Accounts for reduced plant service factor over the initial years of piant operations. It is assumed that the plant operates at $50 \%$ of its stated capacity in the first

- year of operation, $75 \%$ in the second and $100 \%$ thereafter.

- Interest on Debt - $10 \%$

- DCF Return on Equity - $15 \%$

Based on this assumed economic basis, the equivalent capital charge factor (equivalent to that used in constant dollar economics) is 11\% of the total erected cost per year. The capital charge factor is used to calculate a first-year product selling price.

Other operating costs are calculated as follows:

- Coal - \$30/Ton Dry Coal

- Electric Power - $\$ 0.035 / \mathrm{Kwh}$

- Natural Gas - \$2.50/MMBtu

- Raw Water - \$0.50/1000 Gallons

- Catalysts and Chemicals (Per Individual Unit Requirements) Catalyst used in liquefaction is estimated to have a net cost of $\$ 2.70 / 1 \mathrm{~b}$ after resale for met.als reclamation. This is substantially higher than current costs for similar catalysts based on a current highly competitive catalyst market.

- Ash Disposal - \$2/Ton

- Labor, Supervision and Overhead - Estimated to be $3 \%$ of the total erected cost per year. 
- Maintenance - Also estimated at a percentage of the total erected cost. Percentages vary for plant areas as shown below:

\begin{tabular}{ccc} 
Area & & \multicolumn{2}{c}{ Maintenance, } \\
\hline 100 & - Coal Preparation & \% of Total Erected Cost \\
$200-$ Liquefaction & 4.0 \\
$300-$ Partial Oxidation & 4.0 \\
$400-$ Oxygen Plant & 4.0 \\
$500-$ Product Treating & 2.0 \\
$600-$ Product Upgrading & 2.0 \\
$700-$ Utilities & 2.0 \\
$800-$ Tankage & 2.0 \\
$900-$ General Offsites & 2.0 \\
\end{tabular}

By-product revenues are included for LPG (\$20/Bb1) sulfur (\$60/LT) and ammonia $(\$ 150 / T)$.

The product costs are tabulated in Table 44 . The calculated firstyear product cost is $\$ 38.35 / \mathrm{Bb}$. 


\section{:LIQUEFACTION PLANT INVESTMENT DETAILS}

SECTIONS 100-500 (REACTION)

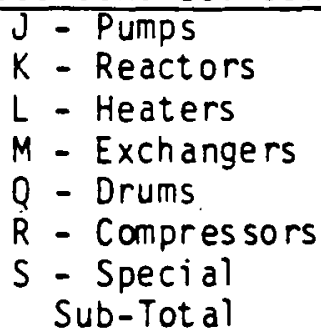

SECTION 600 (PRODUCT FRACTIONATION)

J - Pumps

$L$ - Heaters

$M$ - Exchangers

$N$ - Towers

Q - Drums

$R$ - Compressors

$S$ - Special

Sub-Tot al

TOTAL

\section{TOTAL PLANT INVESTMENT}

Direct Material, MM\$

Direct Labor, MM\$

Total Direct Cost, MM\$

Indirect Cost, MMS

Cont ingency (25\%), MMS

TOTAL PLANT INVESTMENT, MMS
MAJOR EQUIPMENT"COSTS, MS

16,725

46,760

8,233

11,629

18,608

23,224

12,390

$\frac{12,390}{137,569}$

1,052

152

4,288

$\frac{305}{5,797}$

672

57

13,461

$\frac{13,461}{14,190}$

449

2,051

2,261

934

394

467

279

6,835

164,391

316

$\frac{91}{407}$

88

124 


\section{TOTAL PLANT INVESTMENT SUMMARY}

AREA

100 - Coal Preparation

200 - Liquefaction

300 - Partial Oxidation

400 - Oxygen Plant

500 - Product Trcating

$600=$ Product Upgrading

700 - Utilities

800 - Tankage

900 - General Offsites

TOTAL (TEC)
INVESTMENT, MMS

176

619

283

130

77

151

109

81

477

2,109

* 1984 U.S. dollars at a U.S. Gulf Coast location. 


\section{ECONOMIC BASIS}

\begin{tabular}{|c|c|}
\hline $\begin{array}{l}\text { Project Life, Years } \\
\text { Tax Rate, } \% \\
\text { Debt/Equity Ratio } \\
\text { Depreciation Method } \\
\text { Depreciation, Years } \\
\text { Investment Tax Credit, } \% \\
\text { Working Capital, } \% \text { of TEC } \\
\text { Start-up Expense, } \% \text { of TEC } \\
\text { Inflation Rate, } \% / \text { Year }\end{array}$ & $\begin{array}{r}25 \\
50 \\
75 / 25 \\
\text { ACRS } \\
5 \\
10 \\
6 \\
6 \\
5\end{array}$ \\
\hline 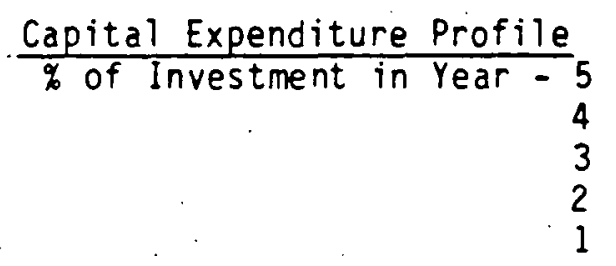 & \\
\hline
\end{tabular}

Production Schedule

\begin{tabular}{rrr}
\hline \% of Capacity in Year & -0 & 50 \\
& 1 & 75 \\
& 2 & 100 \\
& 3 , etc. & 100
\end{tabular}

Service Factor, \%

90

Interest Rate on Dett, \% 10

DCF Return on Equity, \% 15 
PRODUCT COST

OPERATING COSTS, MMS/YR

Coal e \$30/Ton

Electric Power a $\$ 0.035 / \mathrm{Kwh}$

126.8

Raw Water o \$0.50/MGal

29.3

Catalyst and Chemicals

0.8

Ash Disposal o \$2/Ton

28.8

Labor, Supervision and Overhead

1.0

Maintenance

Capital Charges(1)

63.3

63.7

TOTAL

232.0

545.7

By-Product Revenues, $M M \$ / Y_{r}$

LPG \& \$20/Bbl

Sulfur $0 \$ 60 / L T$

1.9

Ammonia 0 \$150/T

TOTAL

5.8

$\frac{7.1}{14.8}$

Product Cost (2)

MMS/Yr

530.9

$\$ / B b l$

38.35

(1) Equivalent capital charge factor is $11 \%$ of total erected cost per year.

(2)First year product cost. 
SECTION 6

OVERALL ASSESSMENT OF ECONOMICS

95 
It is important to analyze the results of this study to identify the major cost areas in coal liquefaction, their impact on product costs and opportunities for improvement in overall econanics. This section will address these topics, while specific recommendations to better utilize some of the unique advantages of the CTSL technology, to further improve economirs, will be detailed later.

\section{ANALYSIS OF PRODUCT COSTS}

Product costs are analyzed in two different ways to provide a better understanding of the major cost areas in direct coal liquefaction. The first method details the product costs according to the major cost items. Included in the breakdown of cost items are coal, utilities, catalyst and chemicals, labor, supervision and overhead, maintenance, capital charges and by-product revenues. The second method separates the product cost into the respective process areas of the plant including liquefaction, hydrogen production, projduct upyrading, product treating and of fsites.

The breakdown of product cost by cost item is shown in the top part. of Table 45 . The largest contribution is capital charges at $44 \%$ of the total product cost. The next largest contribution is the cost of coal at $24 \%$ of the total product cost. Labor, supervision and overhead, and maintenance are both roughly equivalent at $12 \%$ of the total product cost. The cost of utilities and catalyst and chemicals are also roughly equivalent at $6 \%$ and $5 \%$. By-product revenues reduce product cost by only $3 \%$.

Product costs separated into the major process areas are shown in the bottom part of Table 45. Liquefaction is the largest cost process area at $49 \%$ of the total. Hydrogen produrtinn and of fsites each contribute about $22 \%$ of the total product cost. Product upgrading arid producl treating represent relatively small cost contributions at $7 \%$ and $3 \%$, respect ively. 


\section{CATALYST COST}

In the economics presented in Table 45 , the catalyst usage amounted to three pounds per ton of dry coal fed to liquefaction, estimated using the rate of catalyst deactivation indicated in a kinetic model based on CTSL bench unit operations. Recent laboratory work, Run 227-34(1-15), successfully demonstrated the feasibility of cascading catalyst from the first stage to the secgnd reactor stage, while maintaining overall process performance. (1) Catalyst cascading was projected to reduce consumption by $20 \%$. This would reduce catalyst and chemicals cost from $\$ 2.08 / \mathrm{Bb}$ to $\$ 1.76 / \mathrm{Bb}$ l and the overall product cost from $\$ 38.35 / \mathrm{Bb}$ i to $\$ 38.03 / \mathrm{Bb}$.

It should be noted that catalyst usage reported for the light recycle. CTSL previous case was a projected number of one pound per ton, to be comparable with H-Coal. The actual usage demonstrated in the previous case was 3 Lbs/Ton. A usage of 2.19 Lbs/Ton, without cascading, would apply for the light recycle case, if the catalyst usage for the two cases were taken to be in inverse ratio of the catalyst ages for the CTSL operations upon which the process designs were based. Table 46 shows the revised product cost reflecting both catalyst cascading for the heavy recycle case, and the higher catalyst consumption for the light recycle case, without cascading.

\section{Comparison With Previous Illinois Coal Studies}

Table 47 presents economics of the heavy recycle CTSL Process using Illinois No. 6 coal, compared to light recycle CTSL and to onestage $\mathrm{H}-\mathrm{Coal} \otimes$. Presented also are hydrogen production alternatives of partial oxidation versus steam reforming for the two CTSL base cases, namely heavy and light recycle(10).

Heavy recycle CTSL is seen resulting in over $5 \%$ product cost savings compared to 1 ight recycle CTSL and almost $17 \%$ compared to one stage H-Coal ${ }^{\circ}$. The savings occur despite the higher required capital investment for heavy recycle, in part because of the higher 1 iquid product yield from coal, namely 3.28 versus 3.18 barrels per ton of total coal feed and, in part, because of the lower investment per unit of product, namely 50,280 \$/BPSD versus 54,900 \$/BPSD.

Heavy recycle appears more economical than light recycle regardless of hydrogen production method, as discussed below. 
Impact of Coal Cleaning Efficiency

Coal supplied to liquefaction is deep-cleaned using heavy media washing to reduce ash content to the required level. Based on experimental work done by BCR National Laboratory on this Illinois No. 6 coal and on a published report by the Electric Power Research Institute (EPRI)(11), an overall coal cleaning efficiency of $70 \%$ was assumed for this study. "While the reject stream is utilized in hydrogen manufacture, a $70 \%$ efficiency means that for every ton of coal liquefied 1.52 tons are furnished to coal cleaning. In addition hydrogen manufacture by partial oxidation of a coal water slurry is recognized to be a highly capital-intensive approach.

Table 48 presents the economic incentive for increasing coal cleaning efficiency. A considerable decrease is shown both for the total capital investment and the overall product cost. Thus, if efficiency is increased from $70 \%$ to $80 \%$, the product cost decreases from $\$ 38.35 / B b 1$ to $\$ 3 \hbar .69 / 8 \mathrm{bl}$. Figure 4 shows the product cost as a function of coal cleaning efficiency.

Figure 4 assumed that hydrogen shortfall from partial oxidation of the reject stream from deep-cleaning coal at higher efficiency would be supplied by steam reforming purchased natural gas. This hydrogen could be supplied by partial oxidation of additional coal, but as seen from the middle two columns of Table 48 , this is a more expensive alternate using $\$ 30 /$ Ton coal and natural gas at $\$ 2.50 /$ MMBtu. In other words, the justification for coal partial oxidation is that the coal stream is already present as a waste pruducl. It the stream ts lost by a more efficient coal cleaning operation, partial oxidation of additional coal becomes cost ineffective.

Figure 5 is a breakeven cost comparison of hydrogen production alternatives at $80 \%$ coal cleaning efficiency. Thus, if coal is available at $\$ 30 /$ Ton, steam reforming would be preferred over par$t i a l$ oxidation for any gas price below \$3.77/MMBtu. 
Impact of Purchasing. Deep-Cleaned Coal

The basic assumption made in this study was that low ash-level coal, required for liquefaction, would not be commercially available and, therefore, the deep cleaning operation would be performed on site. Credit was takenfor the high-ash rejection stream from the deep-cleaning operation, in supplying a part of the make-up hydrogen via partial oxidation.

Assuming that deep-cleaned coal is available on the open market, the economic impact of purchasing this deep-cleaned Illinois No. 6 coal was investigated in two alternatives:

1. Generating hydrogen by steam reforming purchased natural gas, or

2. Generating hydrogen by partial oxidation of deep-cleaned coal.

Table 49 shows the economics of the steam reforming alternative compared to the base case. It is seen that this alternative will lower the total plant investment. This is due to the high cost of both the partial oxidation and the oxygen plant, as well as the cost of the coal preparation plant. Consequently, product cost is lowered by using steam reforming.

One of the major unknowns in analyzing the economics of these alternatives is the cost of deep-cleaned coal. The delivered price of Illinois No. 6 coal containing $11.7 \%$ ash has been as sumed in the base case to be $\$ 30 /$ Ton. Equating this price on an equal-BTU basis would result in a deep-cleaned coal price of $\$ 31.42 /$ Ton. However, rough studies using published data on deep-cleaning economics would indicate a cost of around $\$ 35.50 /$ Ton. The comparative economics of the two alternatives were evaluated with varying coal and natural gas prices. Figure 6 shows using deep-cleaned coal in hydrogen manufacture and in liquefaction. to be an economic standoff with providing for deep-cleaning at the plant site.

Figure 7 shows that eliminating coal washing at the plant site and purchasing deep-cleaned coal and using steam reforming for hydrogen manufacture appears to offer significant cost reduction over the base case, with fuel cost at $\$ 2.50 /$ MMBtu and with any deep-cleaned coal cost below \$43/Ton. Alternatively, with deep-cleaned coal at $\$ 35 /$ Ton this option will offer an economic advantage over the base case for any fuel cost below $\$ 3.17 /$ MMBtu. 


\section{Hydrogen Production Alternatives}

In the previous study on light recycle CTSL processing of Illinois coal, steam reforming compared favorably with partial oxidation in many pricing situations. Using a coal cleaning efficiency of $70 \%$ for the heavy recycle operation, however, such is not the case, as seen in Table 47 . Figure 8 shows the effect of natural gas price on product cost. The breakeven natural gas cost is around $\$ 2.05 / \mathrm{MMBtu}$, compared to $\$ 2.77 / \mathrm{MMBtu}$ in light recycle operation. This is primarily due to the particular balance achieved between hydrogen requirement and hydrogen availability from the coal cleaning reject stream. As noted above, however, steam refoming is the less costly alternative when coal cleaning efficiency is increased.

\section{Coal Cost}

The base coal cost is $\$ 30 /$ Ton. Figure 9 shows that regardless of coal price, heavy recycle CTSL is less costly than light recycle CTSL (using either partial oxidation or steam reforming)and $\mathrm{H}$-Coal@. Since coal to the complex remains the same in heavy recycle, hydrogen production method does not enter into this analysis.

\section{Comparison With Wyoming Coal}

A provious study had compared CTSL economics using Illinuis cual and light recycle. with Wyoming codil(12). Table 49 updates the previous study to include Illinois codl hedvy recycle CTSL operation. Comparing heavy recycle Illinois coal CTSL with Wyodak coal CTSL, it is seen that using steam reforming to generate hydrogen Wyoming coal has very slightly better econamics $(\$ 39.30 / B$ bl versus $\$ 39.45 / \mathrm{Bb} 1)$. Using partial oxidation to generate hydrogen Illinois No. 6 coal, with either light op heavy recyele, is less costly than Wyodak coal. 
Figure 10 .presents the sensitivity of product cost to natural gas price for Wyodak coal and for Illinois coal with heavy recycle: The Illinois coal/natural gas price situation has already been discussed above and is repeated here only for comparison with Wyodak coal. Figure 10 shows that for any gas price 11 linois coal is preferred over Wyodak coal when hydrogen i.s generated by partial oxidation. For hydrogen via steam reforming the two coals are equivalent.

The above economic comparison of Wyodak versus lllinois coals assumed $\$ 10 /$ Ton for the former and $\$ 30 /$ Ton for the latter. Figure 11 presents a breakeven analys is for the coal price of Wyodak coal versus 11 linois coal with heavy recycle CTSL processing. Two 1 ines are shown for the two hydrogen production alternatives. For a given delivered Illinois coal price, a Wyodak coal price above the respect ive hydrogen-producing-method line would favor 11 linois coal while below the line would favor use of Wyodak coal. Of course, Figure 11 could also be used the other way, entering a given Wyodak coal price. In general, with steam reforming for hydrogen manufacture, Illinois coal is to be preferred if its cost differential over that of Wyodak coal is less thant $\$ 21-24 /$ Ton. With partial oxidation for hydrogen manufacture, this actual cost differential is $\$ 28-33 /$ Ton.

In summary, Illinois coal at $\$ 30 /$ Ton, using heavy recycle, is preferred, to Wyodak coat at $\$ 10 /$ Ton, for any of the hydrogen manufacturing methods considered. For the light recycle operation the relative economics depend on the hydrogen production method. 


\section{BREAKDOWN OF PRODUCT COST}

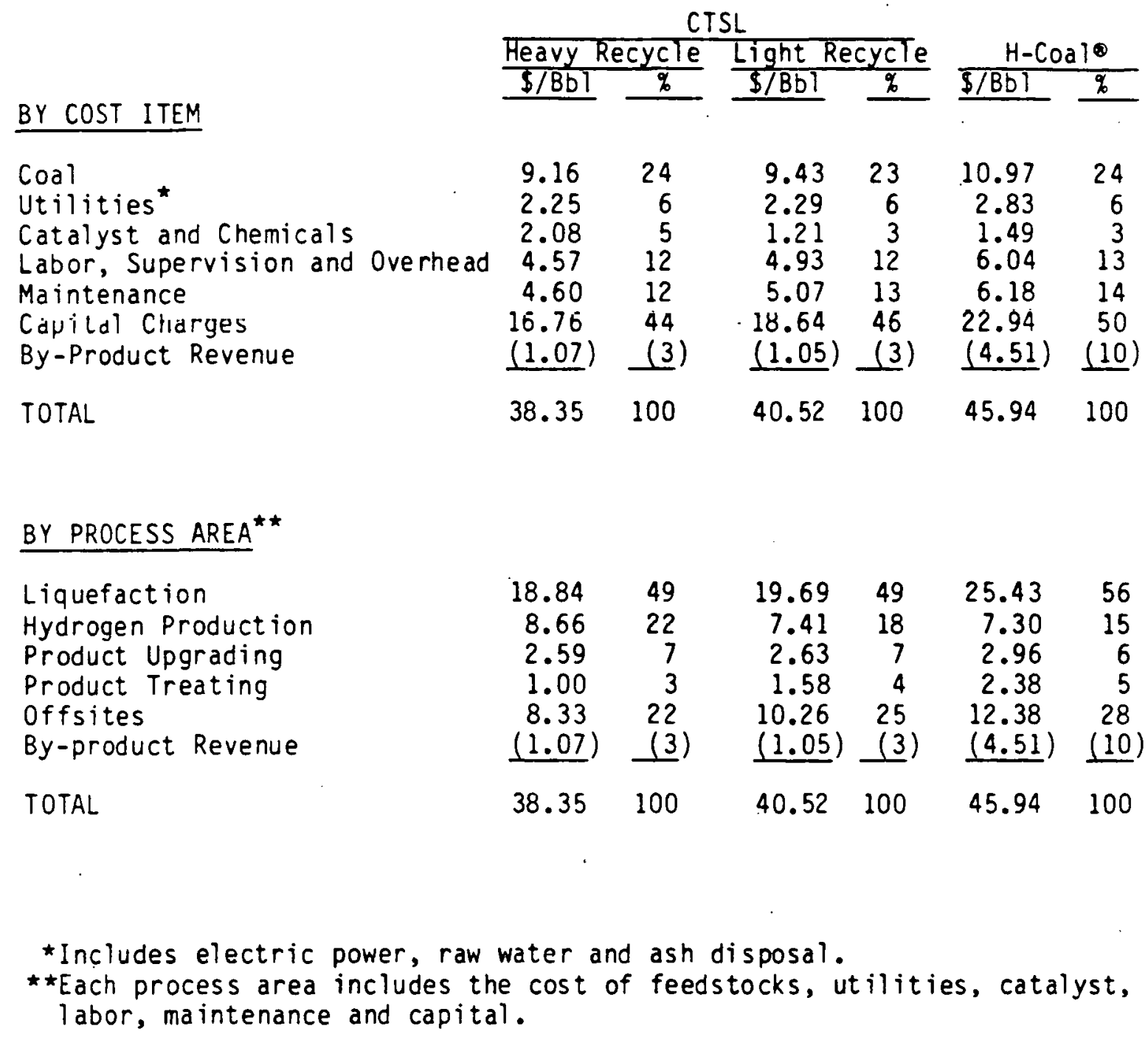


REVISED BREAKDOWN OF PRODUCT COST

BY COST ITEM

CTSL

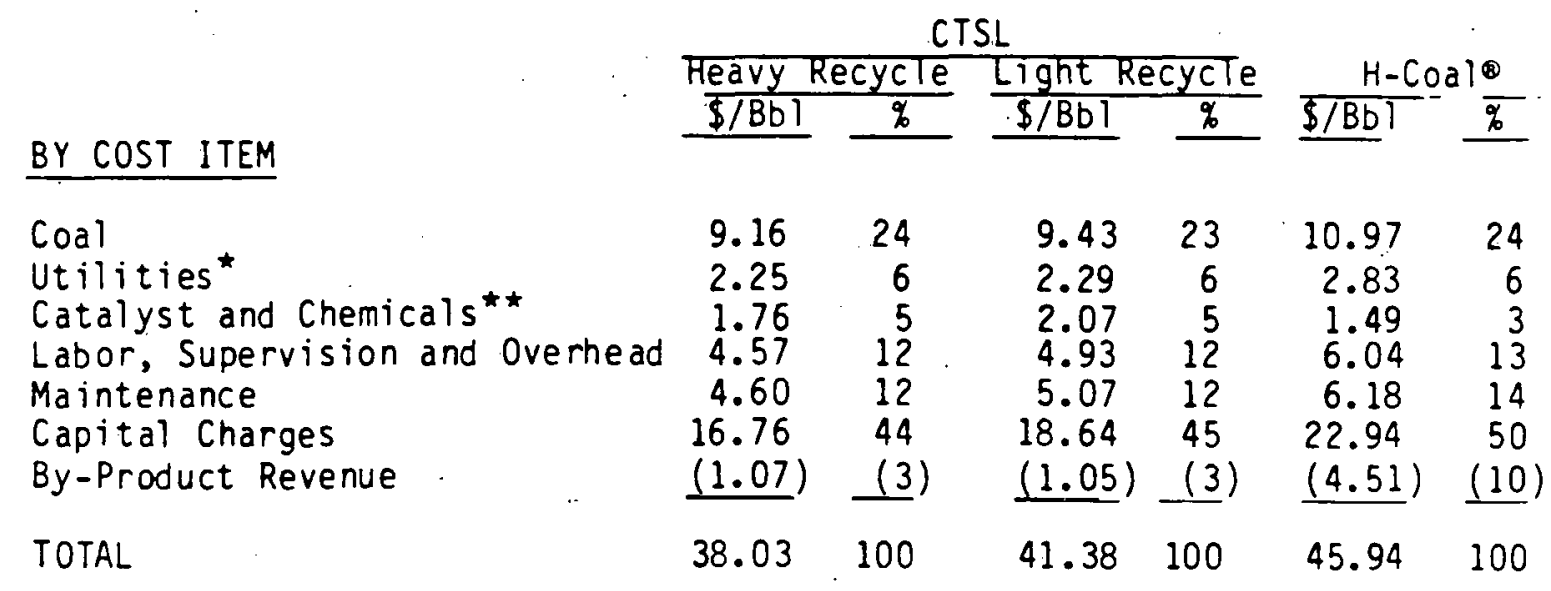

BY PROCESS AREA

$\begin{array}{lrrrrrr}\text { Liquefaction } & 18.52 & 49 & 20.55 & 50 & 25.43 & 56 \\ \text { Hydrogen Production } & 8.66 & 22 & 7.41 & 18 & 7.30 & 15 \\ \text { Product Upgrading } & 2.59 & 7 & 2.63 & 6 & 2.96 & 6 \\ \text { Product Treating } & 1.00 & 3 & 1.58 & 4 & 2.38 & 5 \\ \text { Offsites } & 8.33 & 22 & 10.26 & 25 & 12.38 & 28 \\ \text { By-product Revenue } & \underline{(1.07)} & \underline{(3)} & \underline{(1.05)} & (3) & \underline{(4.51)} & (10) \\ \text { TOTAL } & 38.03 & 100 & 41.38 & 100 & 45.94 & 100\end{array}$

*Includes electric power, raw water and ash disposal.

* Catalyst consumption in heavy recycle reflects the effect of catalyst cascading. Catalyst consumption in light recycle adjusted to reflect equivalent catalyst ages for the two CTSL cases, without cascading.

$\star \star \star$ Each process area includes the cost of feedstocks, utilities, catalyst, labor, maintenance and capital. 


\section{SUMMARY OF RESULTS OF ECOMOMIC EVALUATIONS}

PROCESS

RECYCLE

HYDROGEN MANUFACTURE(1)

\begin{tabular}{|c|c|c|c|c|}
\hline CTSL & CTSL & CTSL & CTSL & $\mathrm{H}-\mathrm{COAL}$ \\
\hline Heavy & Heavy & Light & Light & - \\
\hline POX & $S R$ & POX & SR & POX \\
\hline
\end{tabular}

COAL FEED, TPSD

To Liquefaction

To Partial Oxidation

Power Generation, etc.

TOTAL

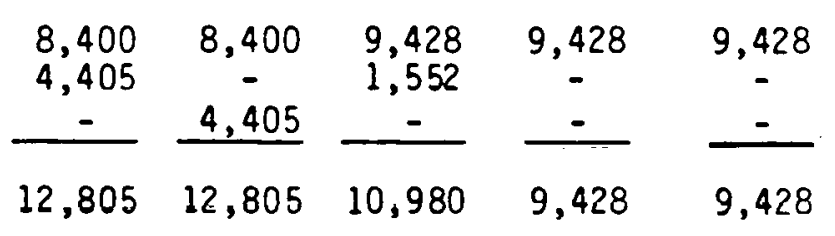

PURCHASED UTILITIES

Power, MW

Natural Gas, MMSCFD

LIQUID PRODUCTS, BPSD

Gasoline
Diesel
TOTAL
Total Plant Investment, $\$ M M(2)$
\$/BPSD

Product cost, $\$ / B b]^{(3)}$

$\begin{array}{rrrrr}13,170 & 13,170 & 10,967 & 10,967 & 9,700 \\ \frac{28,778}{41,948} & \frac{28,778}{41,948} & \frac{23,967}{34,934} & \frac{23,967}{34,934} & \frac{16,078}{25,778} \\ 2,109 & 1,880 & 1,918 & 1,765 & 1,738 \\ 50,280 & 44,870 & 54,900 & 50,520 & 67,420 \\ 38.35 & 39.45 & 40.52 & 40.23 & 45.94\end{array}$

(1) POX = Partial Oxidation, $S R=$ Steam Reforming.

(2) 1984 total erected cost at U.S. Gulf Coast location includes $25 \%$ project contingency.

(3) Based on coal at $\$ 30 /$ Ton and natural gas at $\$ 2.50 / M M B t u$. Other bases listed in Section 5 . 


\section{EFFECT OF COAL CLEANING EFFICIENCY}

ON PROJECT ECONOMICS

ASSUMED COAL CLEANING EFFICIENCY, $\%$

SUPPLEMENTAL $\mathrm{H}_{2}$ MANUFACTURE( $(1)$

$\begin{array}{llll}70 & 80 & 80 & 90\end{array}$

TOTAL COAL REQUIRED, TPSD

$\begin{array}{cccc}- & \text { SR } & \text { POX } & \text { SR } \\ 12,805 & 11,205 & 12,866 & 9,960\end{array}$

PURCHASED UTILITIES

Power, MW

Natural Gas, MMSCFD

106

92

80

77

Total Plant Investment, $\operatorname{SMM}(2)$

$2,109 \quad 1,891 \quad 2,112 \quad 1,723$

PRODUCT COST, \$/BBL (3)

Coal

Utilities

9.16

8.01

4.42

9.20

1.75

7.12

Catalyst and Chemicals

2.25

2.05

2.08

4.10

2.08

6.11

Labor, Supervision and Overhead

4.57

4.10

4.58

2.03

Maintenance

4.60

15.03

4.61

3.73

Capital Charges

16.76

16.78

3.72

By-Product Revenue

(1.07)

(1.02)

(1.07)

13.69

38.35

36.69

37.93

$\underline{(0.99)}$

35.41

(1)POX = Partial Oxidation, $S R=$ Steam Reforming.

(2) 1984 total erected cost at U.S. Gulf Coast location.

(3)Based on \$30/Ton for coal, natural gas at $\$ 2.50 /$ MMBtu. Other bases listed in Section 5 . 
COAL FEED

Recycle

Hydrogen Manufacture(1)

\section{ILLINOIS}

O Liquefaction

To Partial Oxidation

Supplemental To Fuel

Excess Coal Cleaning Waste

TOTAL
Heavy

POX

8,400

4,405

ILLINOIS

Heavy

SR

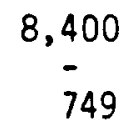

3,656

त.,8ח5
ILLINOIS

Light

POX

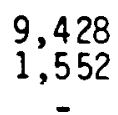

9,428

428
-

10,000

3650

1,068

10,9क्ष

$\overline{9,428}$

$14,718 \quad 10,000$

PURCHASED UTILITIES

Power, MW

Natural Gas, MMSCFD

106

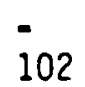

90

85

115

109

- 102

13,170

13,170
28,778

10,967

23,967

10,967

23,967

12,660

24,160

12,660

$\frac{-}{28,778}$

$\frac{-}{41,948}$

$\frac{-}{34,934}$

$\frac{-}{34,934}$

$\frac{948}{37,768}$

4,160

TOTAL

$$
41,948
$$

Total $P\}$ ant Investment,
\[ M M M(2) \]

$$
2,109
$$

1,882

1,918

1,765

2,391

1,887

Product Cost, $\$ / B b 1(3)$

38.35

40.52

40.23

41.55

39.30

(1) POX = Partial Oxidation, $S R=$ Steam Reforming.

(2) 1984 total erected cost at U.S. Gulf Coast location.

(3) Based on $\$ 30 /$ Ton for Illinois Coal, \$10/Ton for Wyodak Coal and Natural Gas at $\$ 2.50 /$ MMBtu. Other bases listed in Section 5 .

(4) Coal cleaning waste to waste disposal.

(5) Coal cleaning waste resold at equivalent fuel vlue (\$26/Ton). 


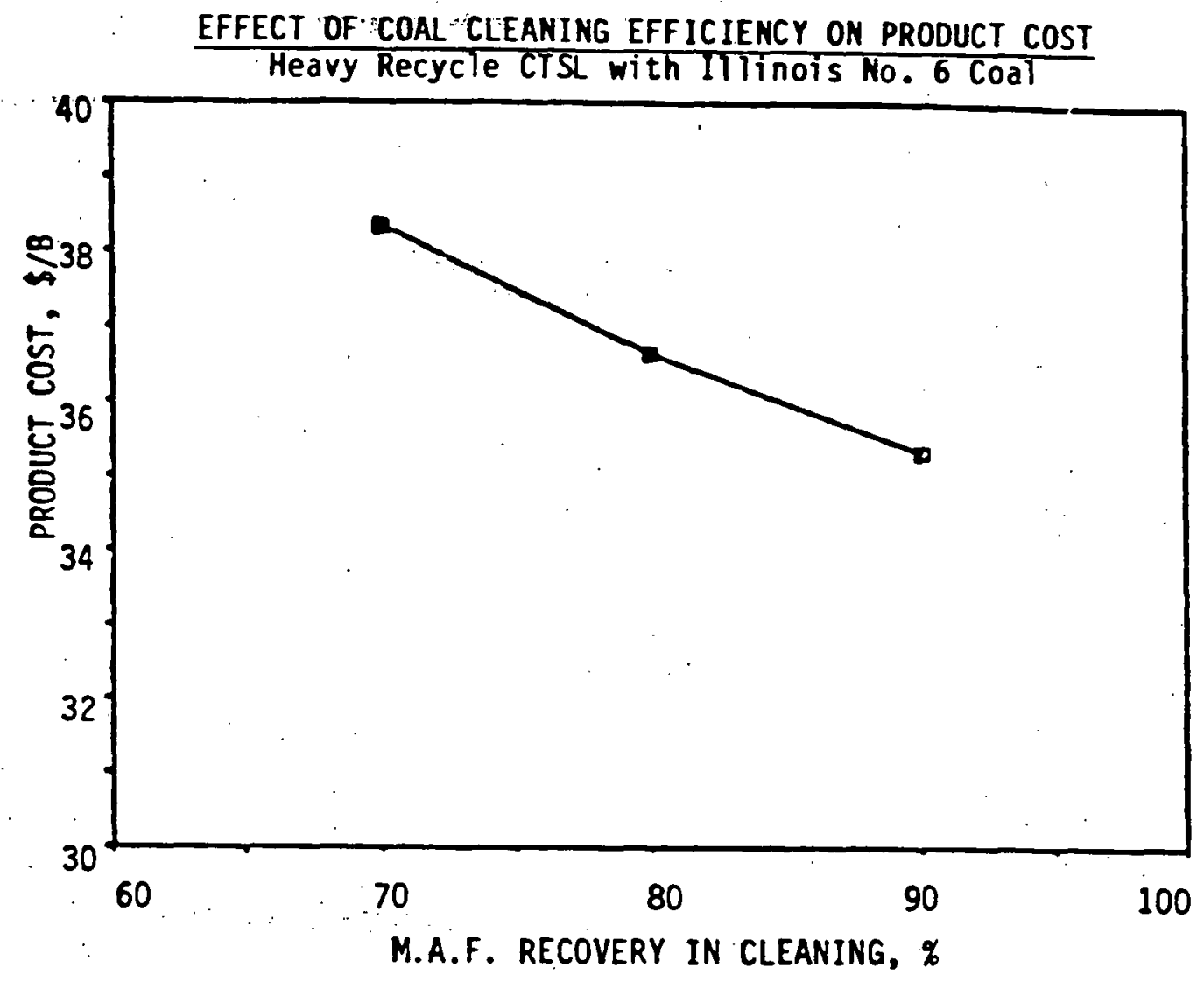

BREAKEVEN FEEDSTOCK PRICES, STEAM REFORMING VERSUS

$\underline{\text { FIGURE } \underline{5}}$

PARTIAL OXIDATION, AT 80\% COAL CLEANING EFFICIENCY

Heavy Recycle CTSL with Illinois No: 6 Coal

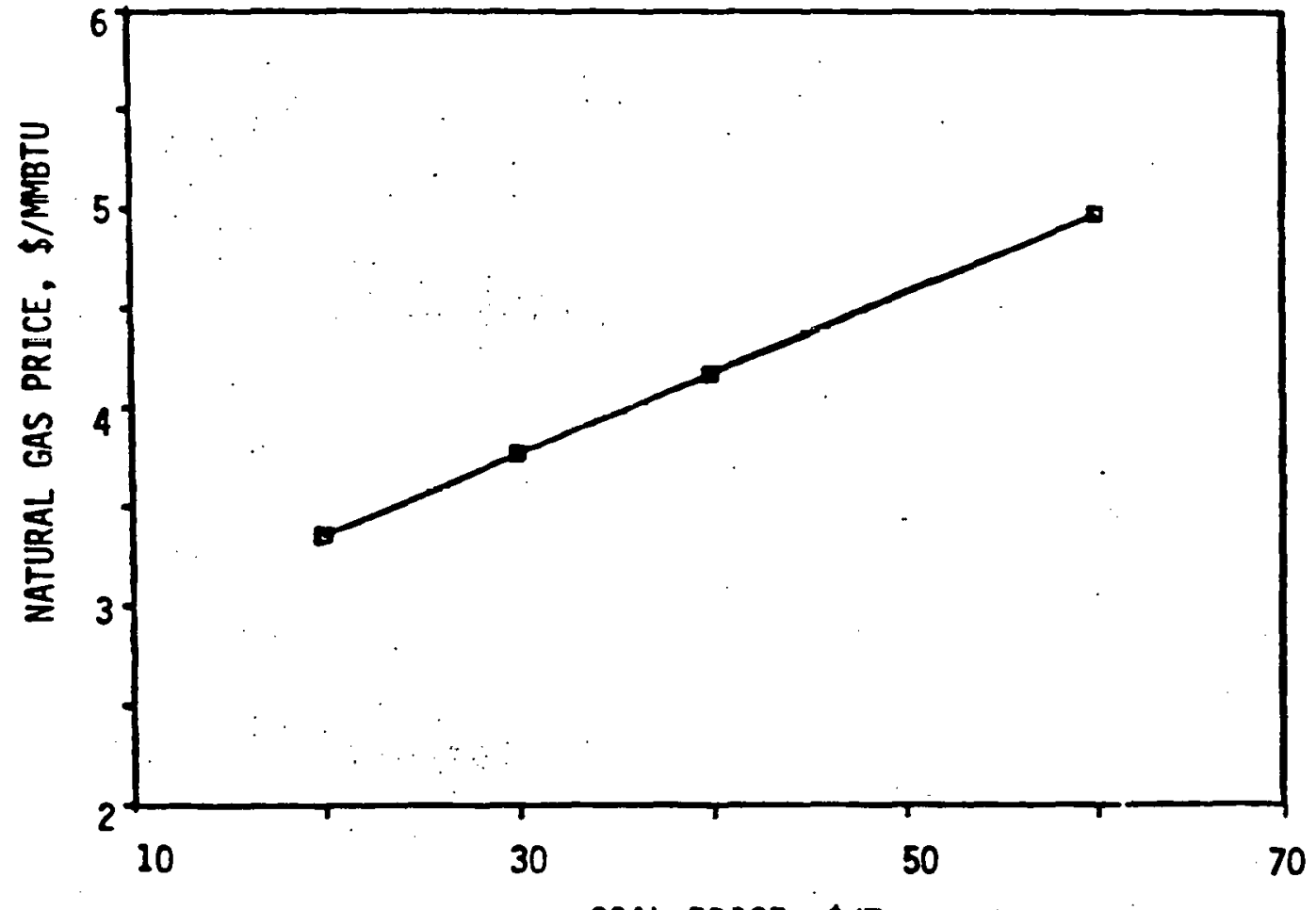

COAL PRICE, \$/T 
USING LOW-ASH COAL TO LIQUEFACTION AND POX

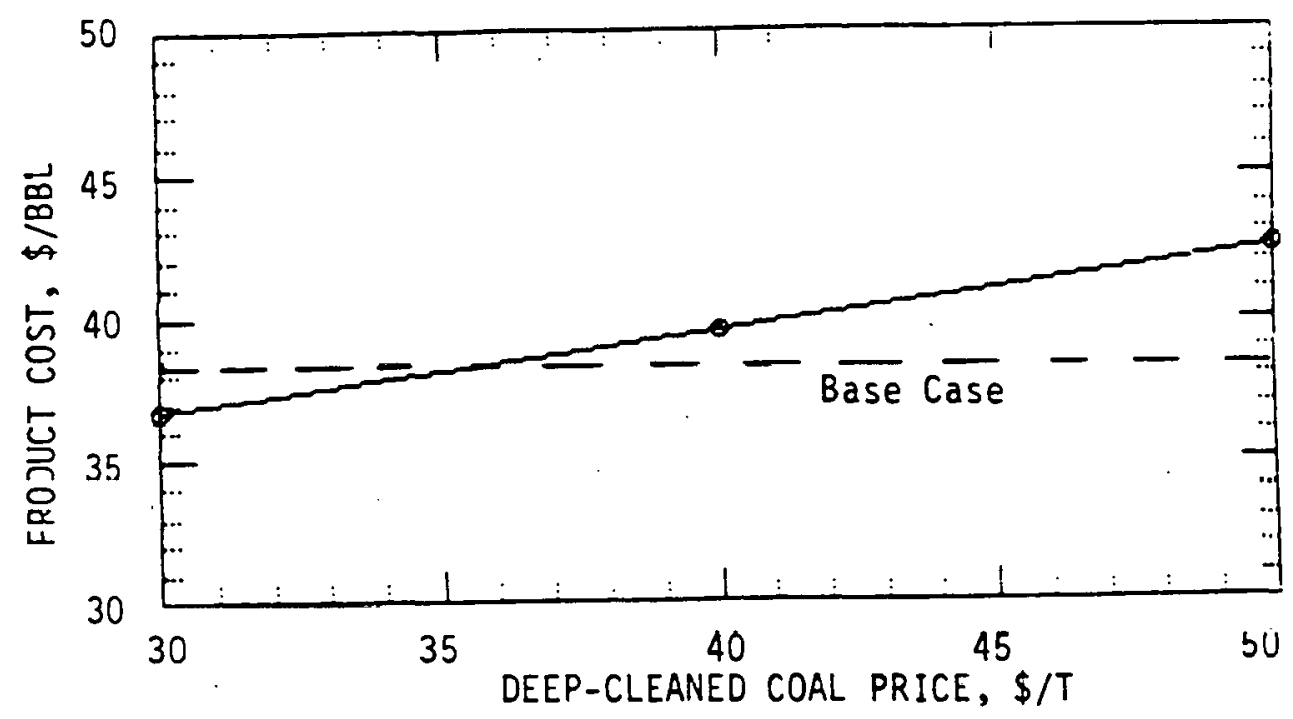

USING LON-ASH COAL TO LIQUEFACTION AND SR FOR H2 MANUFACTURE

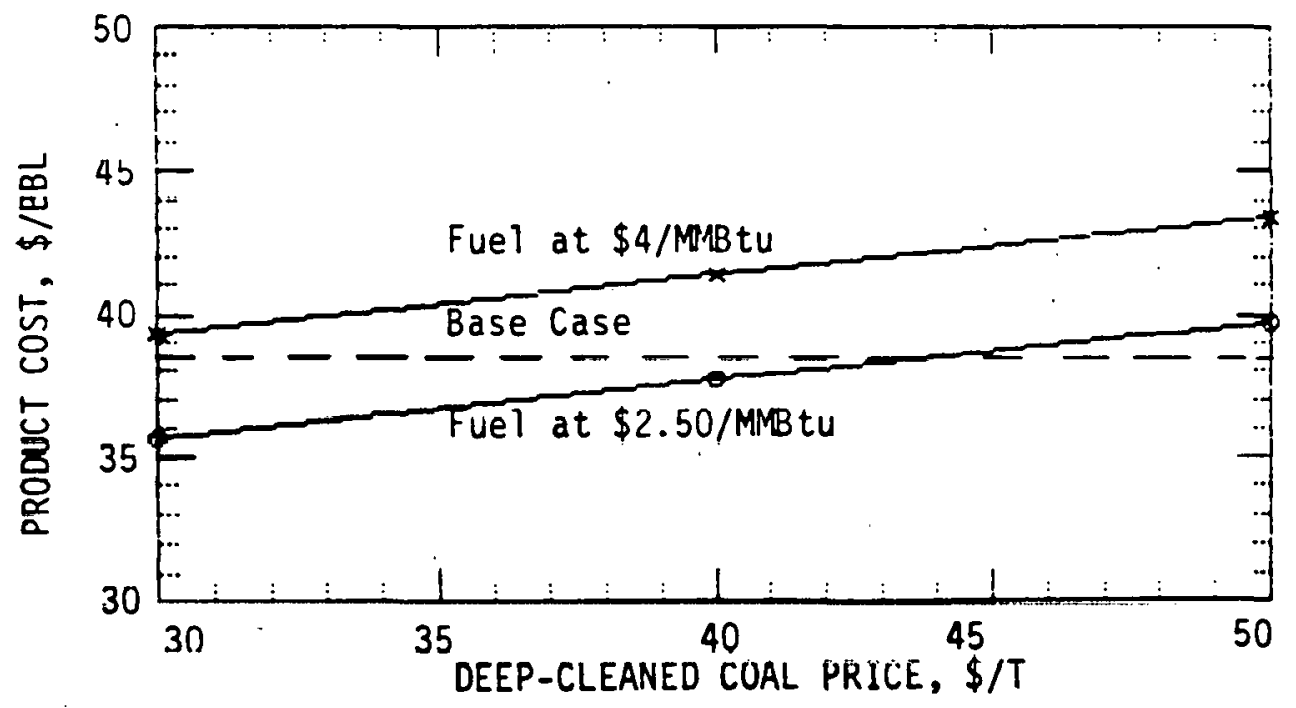


EFFECT OF NATURAL GAS PRICE ON PRODUCT COST

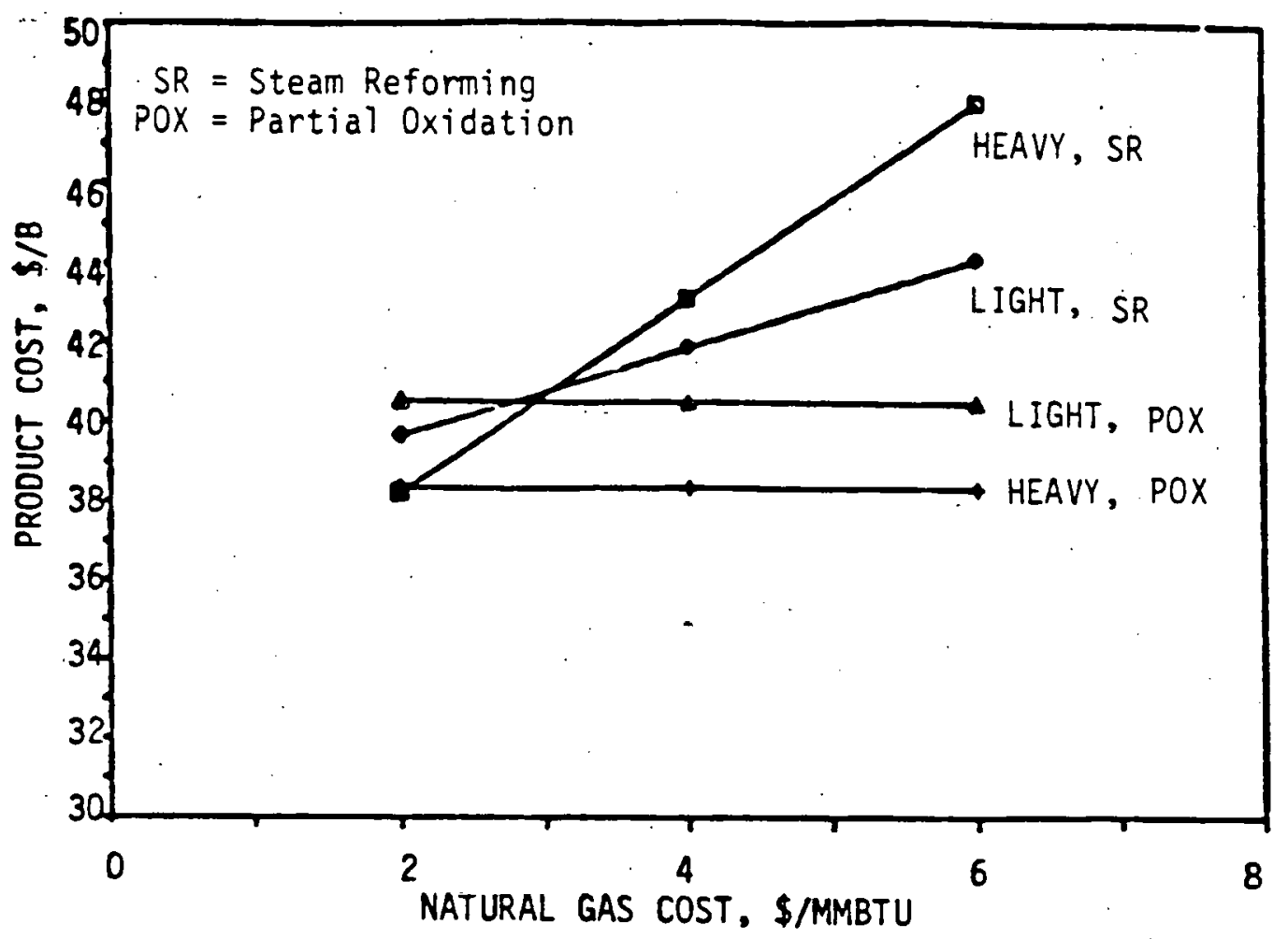

EFFECT OF COAL PRICE ON PRODUCT COST

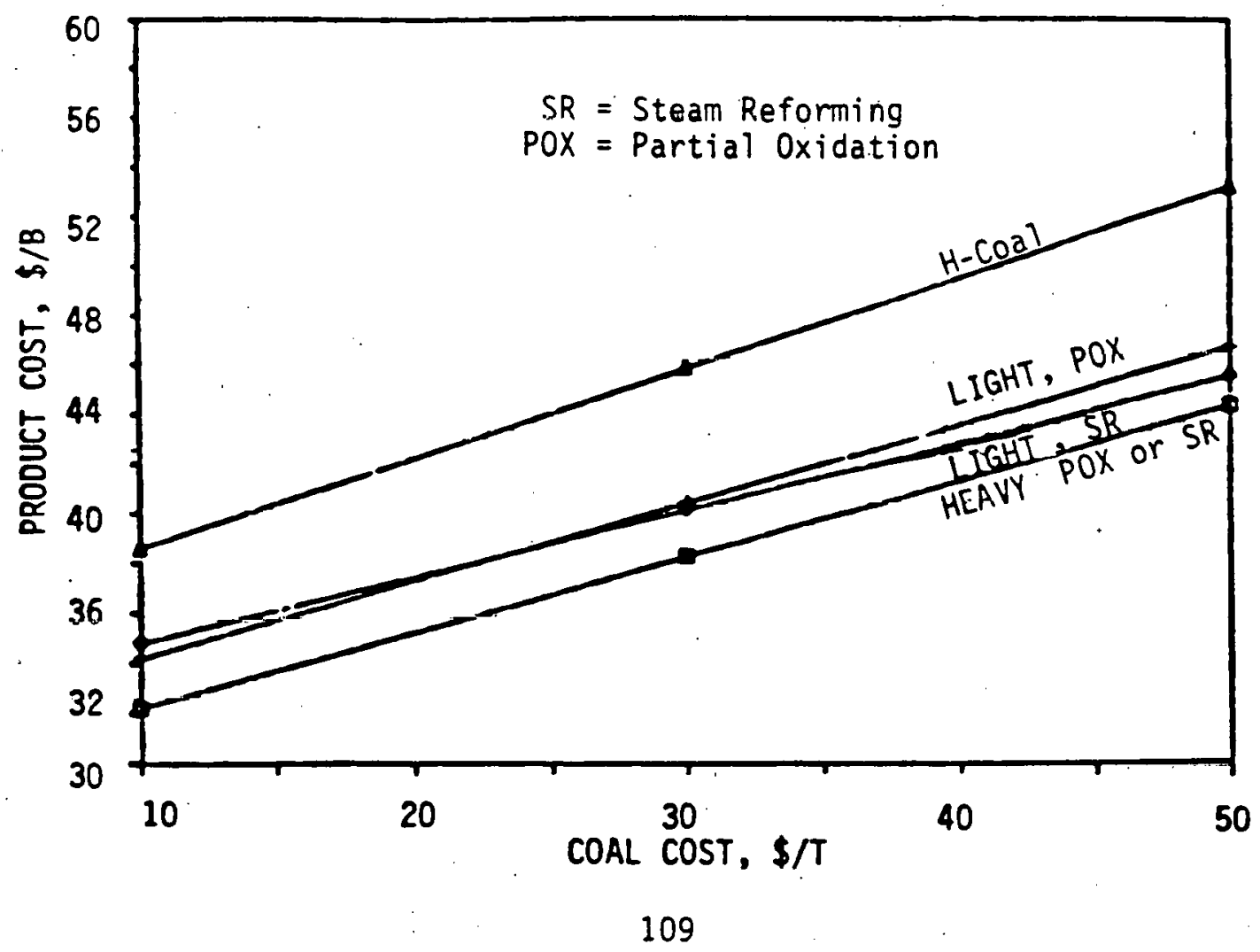


EFFECT OF MATURAL GAS PRICE ON PRODUCT COST

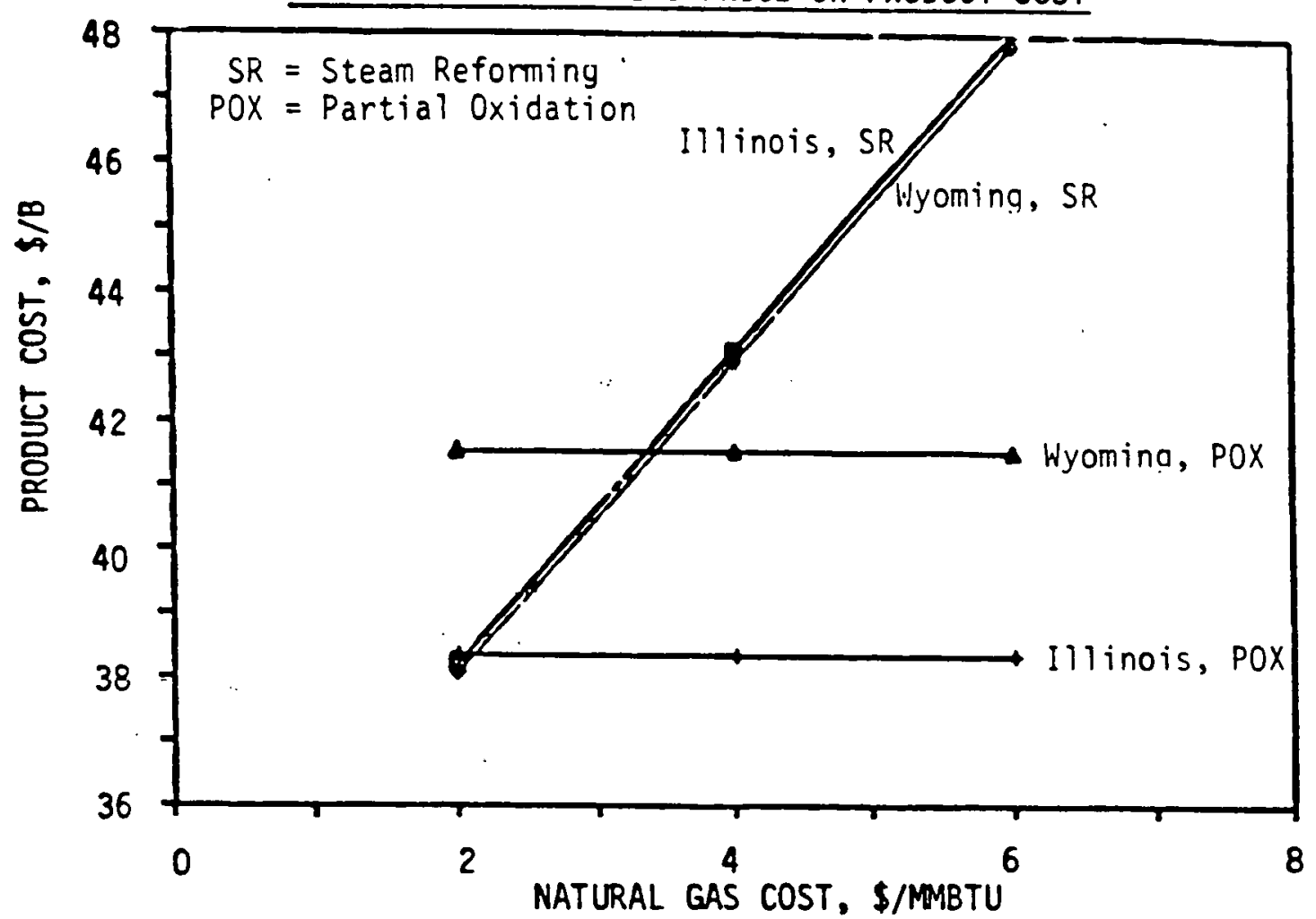

FIGURE 11

BREAKEVEN COAL COST COMPARISON OF ILLINOIS NO. 6 VERSUS HYODAK COALS

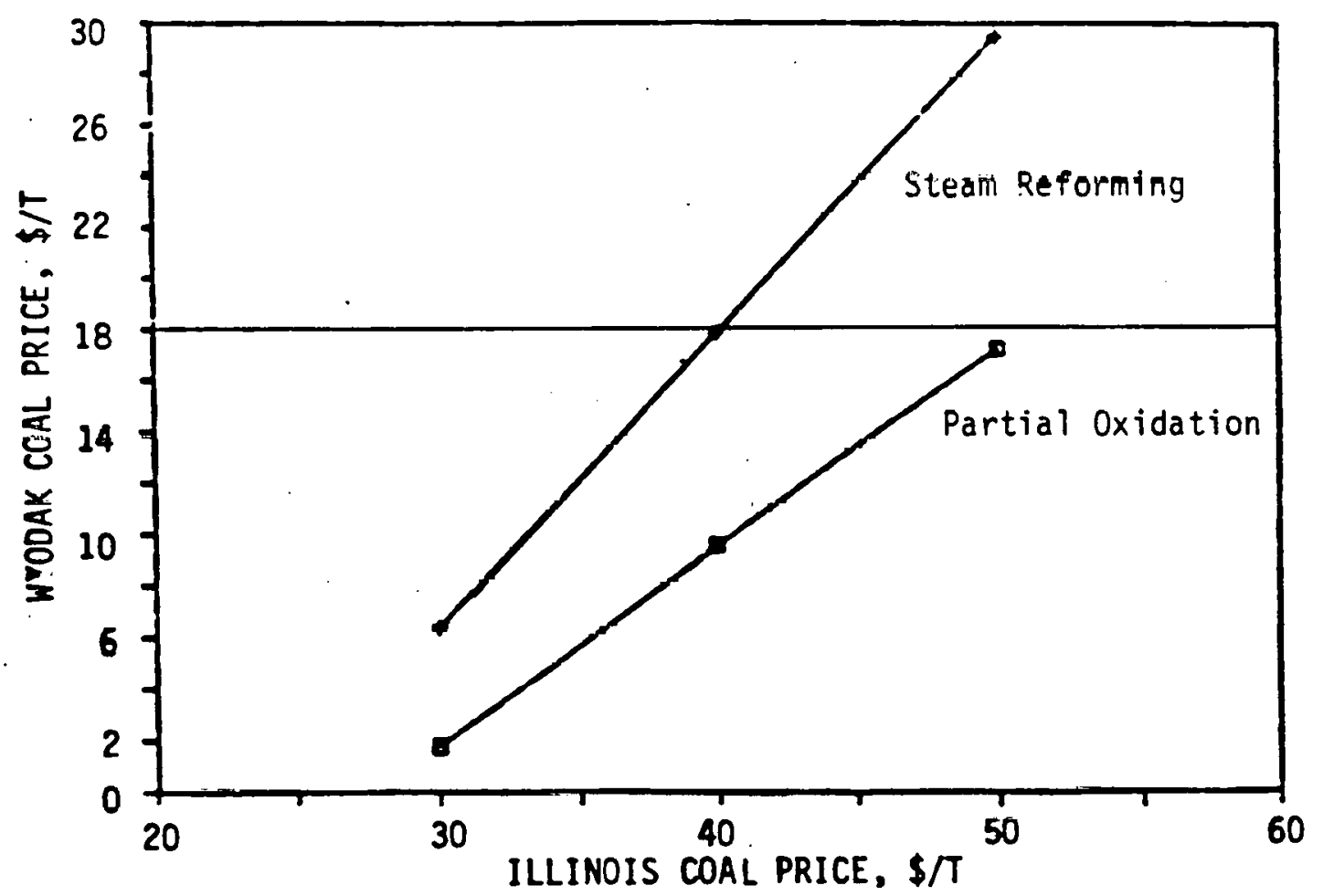

$\rightarrow$ 
HRI's Catalytic Two-Stage Liquefaction (CTSL) Process has demonstrated greatly improved process performance compared to the single-stage $\mathrm{H}$-Coal Process using both 11 linois No. 6 and Wyoming sub-bituminous coals. An earlier study comparing light recycle CTSL operation with $\mathrm{H}$-Coal ${ }^{2}$ Process showed a $12 \%$ economic advantage for CTSL and identified a number of areas for process and design improvements. These resulted in the heavy recycle CTSL Process with deep-cleaned coal, the economic results of wich are contained in this study. These results shows:

- A turther $b \%$ economic advantage over lighl recycle prucessing and an overall $17 \%$ advantage over $\mathrm{H}$-Coal 0 .

- Product cost for heavy recycle CTSL could be further reduced by $4 \%$, from $\$ 38.35 / \mathrm{Bb}$ l to $\$ 36.69 / \mathrm{Bb}$ if coal-cleaning efficiency is increased from $70 \%$ to $80 \%$.

- At increased coal cleaning efficiency, hydrogen manufacture by steam reforming natural gas is preferred over partial oxidation of supplemental coal.

- Catalyst cascading could reduce consumption by $20 \%$ and lower product cost from $\$ 38.35 / \mathrm{Bb}$ l to $\$ 38.03 / \mathrm{Bbl}$.

- The price advantage of heavy recycle CTSL processing over light recycle is independent of Illinois No. 6 coal price or natural gas price.

- Partial oxidation is preferred over steam reforming at the assumed $70 \%$ coal cleaning efficiency, unless natural gas price falls below $\$ 2.05 /$ MMBtu with Illinois No. 6 coal at $\$ 30 /$ Ton.

- Illinois coal is a more economically attractive liquefaction feedstock than Wyodak coal: its cost differential over Wyodak coal is less than $\$ 28 / T$ Tn with partial oxidation to produce hydrogen; the required coal cost differential is lowered to $\$ 21 /$ Ton, with steam reforming to produce hydrogen. 
1. Comolli, A. G., E. S. Johanson, J. B. McLean and T. 0. Smith. "Low-Severity Catalyt ic Two-Stage Liquefaction Process Illinois Coal Studies", DOE-80002-T2, January 1988. Hydrocarbon Research, Inc., Lawrenceville, New Jersey, for U.S. Department of Energy, Contract No. DE-AC22-85PC-80002.

2. Comolli, A. G., P. Ganguli, E. Harris, J. B. MacArthur, J. B. McLean and T.:O. Smith. "New Technology Concept for Two-Stage Liquefaction of Coal - Illinois Coal Program", DE-60017-TOP-1, August 1985. Hydrocarbon Research, Inc., Lawrenceville, New Jersey, for the U. S. Department of Energy, Contract No. $D E-A C 22-83 P C-60017$.

3. "The Breckinridge Project" DOE Agreement No. DE-FC05-80OR10717.

4. "H-Coal Pilot Plant Final Report" DOE Contract Number DE-AC05-76ET10143. Ashland Synthetic Fuels, Inc., Catlettsburg, Kentucky (1984)

5. Duddy, J.E. and J. B. MacArthur. "H-Coal Process Optimization Via LP Model" 9lst National Meeting of AICHE, Detroit, Michigan (1981)

6. Child, C. A. and A. M. Robin, "Gasification of Residual Materials from Coal Liquefation", DOE/ET/10137-T11, Final Report. Texaco, Ine., Muritebell10, California (August 1984 ).

7. Sullivan, R. F., D. J. O'Rear and H. A. Frumkin, "Refining and Upgrading of Synfuels from Coal and Shales by Advanced Catalyt ic Processes", DOE/ET/10532-T3, Fifth Interim Report: Processing $\mathrm{H}$-Coal Syncrude. Chevron Research Company, Richmond, California (September 1981).

8. Tan, G. and A. J. deRosset, "Upgrading of Coal Liquids", Interim Report: Hydrotreating and Reforming $\mathrm{H}$-Coal ${ }^{\circ}$ Process Derived Naphthas, FE-2566-12. UOP, Inc., DesPlaines, Illinois (March 1978). 
9. Sullivan, R.F., "Refining and Upgrading of Synfuels from Coal and Oil Shale by Advanced Catalytic Processes", Quarterly Report for the Period January - March 1986, Chevron Research Company, Richmond, California. April 1986.

10. Abrams, L.M., R. Caruso, J. E. Duddy, J. B. MacArthur and M. Srouji, "New Technology Concept for Two-Stage Liquefaction of Cual - Conceptual Commercial Plant Design and Economirc". DE-60017-TOP-2, December 1985.

11. Buder, et al, "Impact of Coal Cleaning on the Cost of New Coal-Fired Power Generation", EPRI Report No. CS-1622, Bechtel National, Ine., March 1381.

12. Abrams, L. M., R. Caruso, A. G. Comolli, J. E. Duddy, G. A. Popper and C. Wang. "Low-Severity Catalytic Two-Stage Liquefaction Process Wyoming Coal Conceptual Commercial Plant Design and Economics", DE-80002-TOP-1, September 1987, for the U.S. Department of Energy, Contract No. DE-AC22-85PC-80002.

13. Private Communication, Kerr-McGee Corporation to HRI, August 15, 1985.

14. Private Communication, Sandwell Technologies to HRI, October 31, 1985. 
ADDENDUM

CATALYST REQUIREMENTS

FOR

CTSL DEMONSTRATION OPERATION WITH ILLINOIS NO. 6 COAL

The equations for the kinetic model developed for CTSL operations with Illinois No. 6 coal have been used for estimation of the catalyst replacement requirements to obtain the residual oil yield obtained in the design basis operation using the Run 227-47, Period 21, yields. Direct application of the of correlating parameters (which were based on Run 227-30 and Run 227-32 process variable runs) indicated a minimum catalyst requirement of 2.02 Lbs/Ton dry coal $(1.52$ pounds to the first stage, and 0.50 pounds to the second stage) or 2.17 Lbs/Ton with equal amounts of catalyst to each stage. A comparison of the Run 227-47 results with those projected using the correlating parameters, suggested that catalyst deactivation in that run might have been more severe than reflected by the correlating parameters. With adjustment of the catalyst deactivation parameters of the correlation the estimated catalyst replacement increased to 2.69 Lbs/Ton dry coal 12.00 pounds and 0.69 pounds) or 2.89 Lbs/Ton with equal amounts of catalyst to each stage.

\section{MODEL PARAMETERS AND YIELD CALCULATION METHOD}

The calculations were based on the reaction rate equation for the key catalytically dependent reaction in the model, the hydrogenation of the primary low-hydrogen content dissolved residuum component to a secondary hydrogenated residual oil component. In the model, the dissolution of the coal forming the primary residual component, and the cracking of the secondary residual oil component to lighter products were found not to be dependent upon catalyst activity.

In the model, following first order CSTR kinetics based on the weight fraction of the reacting component in the the slurry phase, the key parameters for the primary residual oil component are as follows: 
Formation - $50 \mathrm{~W}$ \% of Converted coal

Reaction rate to hydrogenated secondary component follows the equation

$K=K 1 * \exp (-D 1 * A g e)+K 2 \star \exp (-D 2 \star A g e)$

$K 1=130 \mathrm{Lbs} / \mathrm{Hr} / \mathrm{Ft} \mathrm{H}^{3}$ at $750^{\circ} \mathrm{F}$

$\mathrm{K} 2=11 \mathrm{LbS} / \mathrm{Hr} / \mathrm{Ft} 3$ at $750^{\circ} \mathrm{F}$

Activation energy for both rate constant factors - $20 \mathrm{Kcal} / \mathrm{mole}$

$D 1=0.071 \star(1.04 \star \star(T-750)) D 2=0.0033 \star(1.04 \star \star(T-750))$

Age - Time of operation with coal feed, Days

This equation rationalizes the relatively high hydrogenation rates, with a relatively moderate decline in the rate constant with increasing catalyst age, in the lower temperature first stage, and the sumiewhat higher apparent loss of activily in the higher tempcraturc second stage, but with retention of a measure of reaction potential even at the higher catalyst ages. Figure 1 of this addendum summarizes the rate constants against effective catalyst age for the correlated data with a curve showing the fit of the above equations to the experimental resuits.

The rate constant for the cracking to lighter products of the secondary hydrogenated residual was $15.5 \mathrm{Lbs} / \mathrm{Hr} / \mathrm{Ft}^{3}$ at $750^{\circ} \mathrm{F}$, with an activation energy of $16.5 \mathrm{Kcal} / \mathrm{mole}$.

In using the above equations to the system with continuous replacement of the catalyst, the reaction rate constant, $K t$, was calculated by the relation

$K t=[K 1 * C a t /(C a t+D 1)]+[K 2 * C a t /(C a t+D 2)]$

where Cat is the catalyst replacement rate in the same units as thie deactivation factors, $D I$ and $\mathrm{V}_{2}$, in this case fracliur replacement of the catalyst inventory per day. The replacement rates in Lbs/Ton dry coal were converted to fractional replacement rates by taking the catalyst inventory to be the same as the demonstration run, 16.5 Lbs $/ \mathrm{Ft}^{3}$ reactor volume.

The calculation of residual oil yields used the conditions that were used during the Run 227-47, Period 21, operation, namely, the same stage temperatures, dry coal feed rate, recycle of pressure filter liquid to the first stage and as buffer flow to the second stage, and residual ofl content of the pressure filter liquid. The calculation 
required setting the slurry phase flow from each stage, which was done by taking the vapor phase flow to be the same as obtained from the second stage hot separator during the demonstration operation.

\section{MATCHING DEMONSTRATION RUN RESULTS WITH CORRELATION PROJECTIONS}

The target of the calculations was to match the experimental residual oil yield for the demonstration operation, $2.54 \mathrm{~W} \%$ of dry coal. Initially, the correlation and calculation method were tested against the results during Run 227-47, Period 21. For a case that assumed a degree of catalyst deactivation that. would have occurred had the entire run been at the temperatures holding at. that stage of the run, the residual oil yield was calculated as $6.78 \mathrm{~W} \%$ of dry coal, corresponding to a greater degree of deactivation than indicated experimentally. Projections using the model parameters indicated that the $2.54 \mathrm{~W} \%$ yield would was to be expected at 18 days of operation with constant stage temperatures maintained as those holding in the twenty-first day.

Such a deviation is to be expected since in Run 227-47 the temperatures of each of the stages had been increased by $25-30^{\circ} \mathrm{F}$ during the course of the operations so as to sustain the bottom extinction objective of the demonstration operation. Consequently, following the model, catalyst deactivation should have been somewhat less than that projected assuming that final temperature had been maintained from the beginning of the coal operations. Using the relations given above of the deactivation factors, D1 and D2 above, and temperature, it was estimated that degree of catalyst deactivation to be expected at 21 days of the demonstration operation with progressively increasing temperatures, should have been the same as after 13.5 days of operations in which the final temperature had been maintained from the beginning of coal operations.

The discrepancy between the nominal 18 days of deactivation, corresponding to the experimental residual oil yield, and the expected 13.5 equivalent days of deactivation based on the pattern of temperatures earlier in the run, corresponds to an experimental catalyst deactivation somewhat more severe than indicated by the parameters of the model, by a factor of 1.33 . 


\section{PROJECTIONS WITH CONTINUOUS CATALYST REPLACEMENT}

Calculations using the unmodified parameters of the correlation gave the following first and second stage catalyst requirements to obtain the target of $2.54 \mathrm{~W} \%$ yield of residual oil:

Catalyst Addition, Lb/Ton

\begin{tabular}{lrr}
\hline \multicolumn{2}{c}{ Stages } & \\
First & $\frac{\text { Second }}{1.080}$ & Total \\
\cline { 2 - 3 } 1.130 & 1.080 & 2.160 \\
1.275 & 0.750 & 2.130 \\
1.518 & 0.500 & 2.025 \\
1.619 & 0.400 & 2.018 \\
& &
\end{tabular}

Hydrogenation Rate Constants

\begin{tabular}{cc}
\multicolumn{2}{c}{ Stages } \\
\hline First & Second \\
\cline { 1 - 1 } 24.96 & 9.31 \\
25.66 & 8.73 \\
27.82 & 7.05 \\
31.22 & 4.65 \\
32.56 & 3.78
\end{tabular}

These calculations show a flat minimum in total catalyst requirement at 2.02 Lbs/Ton dry coal, with about one-fourth of the catalyst going to the second stage. With equal amounts of catalyst added to the two stages total catalyst requirement increases by about $7 \%$.

Calculations with the deactivation factors increased by $33 \%$ over the original values in the kinetic model correlation gave the following results:

Catalyst Addition, Lb/Ton

\begin{tabular}{lrl}
\hline \multicolumn{2}{c}{ Stages } & \\
\hline First & $\frac{\text { Second }}{1.444}$ & Total \\
& 1.444 & 2.888 \\
1.500 & 1.347 & 2.847 \\
2.000 & 0.690 & 2.690 \\
2.250 & 0.451 & 2.701 \\
2.500 & 0.250 & 2.750
\end{tabular}

Hydrogenation Rate Constants

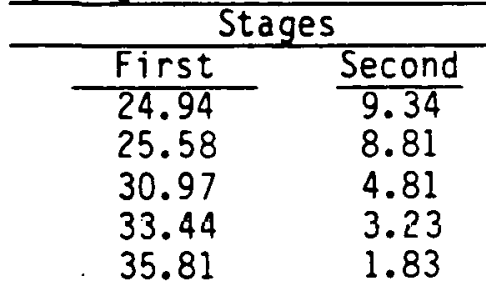

Again, there is a flat minimum in the total requirement, here at aboul 2.69 lbs/Ton, with about one-fourth of the catalyst going to the second stage. With equal amounts of catalyst added to the two stages the total catalyst requirement increases by about $7 \%$. 


\section{ADJUSTED HYDROGENATION RATE CONSTANT \\ VERSUS \\ EQUIVALENT DAYS OF OPERATION}

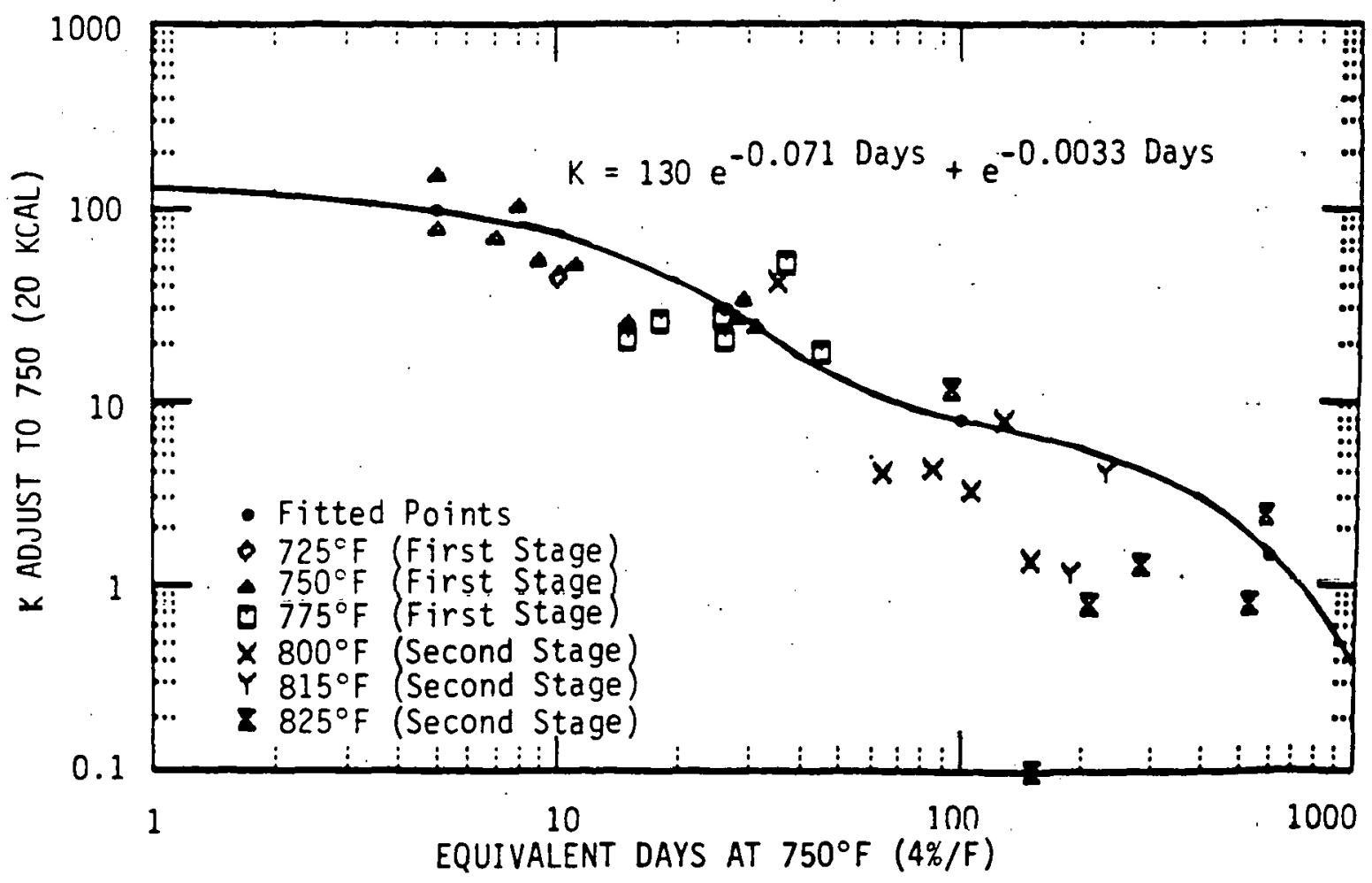


